\title{
Electrochemical Corrosion of
} Iron-Magnesium-Alumina Spinel (FMAS) in Molten Potassium Salts and Coal Slag

D. D. Marchant

C. W. Griffin

J. L. Bates

January 1981

Prepared for the U.S. Department of Energy under Contract DE-AC06-76RLO 1830

Pacific Northwest Laboratory Operated for the U.S. Department of Energy by Battelle Memorial Institute 
This report was prepared as an account of work sponsored by the United States Covernment. Vetther the United States nor the Department of Energy. nor any of their emplovees, nor any of their contractors, subcontractors. or their employees, makes any warranty, express or implied, or assumes any legal liability or responsibility for the accuracy. completeness or usefuiness of any information. apparatus. product or process disclosed. or represents that its use would not infringe privately owned rights.

The views. opinions and conclusions contained in this report are those of the contractor and do not necessarily represent those or the United States Government or the Lnited States Department of Energy.

PACIFIC NORTHWEST LABORATORY

operated by

BATTELLE

for the

UNITED STATES DEPARTMENT OF ENERGY

Under Contract DE-AC06-76RLO 1830

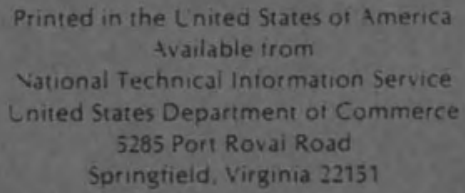

Price: Printed Copy 5. $\therefore$ Microtiche 53.00

$\begin{array}{cc} & \text { NTIS } \\ \text { •Pages } & \text { Selling Price } \\ 001-025 & \$ 4.00 \\ 026-050 & \$ 4.50 \\ 051-075 & \$ 5.25 \\ 076-100 & 56.00 \\ 101-125 & 56.30 \\ 126-150 & 57.25 \\ 151-175 & 58.00 \\ 176-200 & 59.00 \\ 201-225 & 59.25 \\ 226-250 & 59.50 \\ 251-275 & 510.75 \\ 276-300 & \$ 11.00\end{array}$


PNL -3627

UC $-90 \mathrm{~g}$

\section{2}

ELECTROCHEMICAL CORROSION OF IRONMAGNESIUM-ALUMINA SPINEL (FMAS) IN MOLTEN POTASSIUM SALTS AND COAL SLAG

D. D. Marchant

C. W. Griffin

J. L. Bates

January 1981

Prepared for the U.S. Department of Energy under Contract DE-ACO6-76RLO 1830

Pacific Northwest Laboratory

Richland, Washington 99352 


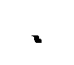

$+$ 


\section{SUMMARY}

Iron- $^{(\mathrm{a})}$, magnesium-alumina spinel (FMAS) $\left(0.25 \mathrm{Fe}_{3} \mathrm{O}_{4} \cdot 0.75 \mathrm{MgAl}_{2} \mathrm{O}_{4}\right)$ has been considered for use as an electrode in magnetohydrodynamic (MHD) generator channels. Predominantly an electronic conductor, FMAS has adequate electrical conductivity $(>1 \mathrm{~S} / \mathrm{m})$ above 520K. In addition, FMAS can be easily fabricated into a form and sintered in air to $>90 \%$ theoretical density and has a melting point of $2124 \pm 20 \mathrm{~K}$.

Laboratory tests to measure both the electrochemical and chemical corrosion of FMAS in molten $\mathrm{K}_{2} \mathrm{CO}_{3}, \mathrm{~K}_{2} \mathrm{SO}_{4}$ and coal slags were developed at the Pacific Northwest Laboratory to evaluate the relative corrosion of FMAS. Under isothermal conditions, a direct electric current was passed between an anode and a cathode through a molten electrolyte. The molten coal slags were synthetic high-calcium, low-iron Montana Rosebud and low-calcium, high-iron Illinois No. 6. Evaluations of electrochemical corrosion were made as functions of current density, temperature, and slag composition. These results were compared to those of FMAS tested without electric current. The corrosion rates and reaction products were investigated by optical microscopy and scanning electron microscopy.

In molten $\mathrm{K}_{2} \mathrm{CO}_{3}$ and $\mathrm{K}_{2} \mathrm{SO}_{4}$, the electrochemical corrosion rates were at least five times greater than the chemical corrosion rates. The electrochemical corrosion was due to salt penetration along the grain boundaries and ultimate grain separation. Also, the surfaces of the samples were uniformly corroded, i.e., the grains themselves dissolved. Grain boundary attack increased at the cathode and decreased at the anode compared to samples without an electric field. At the anode, grain boundary attack was greater in $\mathrm{K}_{2} \mathrm{CO}_{3}$ than $\mathrm{K}_{2} \mathrm{SO}_{4}$. Iron was leached from the cathode and reduced to metallic iron or complex iron oxide. At the anode, gas bubbles were generated due to the oxidation of sulfate or carbonate ions.

In molten coal slag, the electrochemical corrosion rates at both the anode and cathode were greater than the chemical corrosion rates. The corrosion

(a) Both ferrous and ierrite ions. 
rate at the cathode was greater than at the anode. This electrochemical corrosion was decreased by increasing the iron content of the slag. For example, the corrosion in Rosebud coal slag was twice that of the Illinois No. $6 \mathrm{slag}$. The electrochemical corrosion was increased with decreasing potassium content and increasing electrical current density and temperature. Slag penetrated the grain boundaries of the FMAS, reacted with the impurity phases and weakened the bonds between grains. The extent of the penetration was greatest in this order: cathode, control, and anode.

Phase changes occurred at the cathode due to 1 ) chemically reducing conditions and 2 ) reactions with slag components. The species $\mathrm{Ca}, \mathrm{K}$ and $\mathrm{Na}$ diffused through the slag and were concentrated in the slag near the cathode. Exsolution of iron occurred in the FMAS and was more pronounced in the lowiron slags. Also, iron was leached from the FMAS in the low-iron slag, forming iron metal or iron oxides in the slag. The metallic iron or iron oxides were not found in the high-iron slag.

Phase changes did not occur at the anode. Chemically oxidizing conditions existed at the anode due to the formation of gas $\left(\mathrm{O}_{2}\right)$ bubbles. The erosion caused by the formation and migration of these bubbles added to the corrosion of the anode. The species $\mathrm{Ca}, \mathrm{K}$ and $\mathrm{Na}$ migrated away from the anode, resulting in a lower concentration. The current transfer between the anode and slag was nonuniform due to the generation and migration of gas bubbles and due to the depletion of the species. The nonuniformity was greatest in the Montana Rosebud slag.

Overa11, FMAS has too-high an electrochemical corrosion rate to be considered as MHD electrodes in Montana Rosebud coal slag or in systems where only molten potassium salts are present. However, FMAS may be considered for use in high-iron coal slags although the corrosion rates are still quite high even in these slags. 


\section{CONTENTS}

SUMMARY

i i i

INTRODUCTION

EXPERIMENTAL PROCEDURES

FMAS FABRICATION $\quad$ • . . . . . . . . . . . .

ELECTROLYTE PREPARATION

ELECTROCHEMICAL TESTING TECHNIQUES •

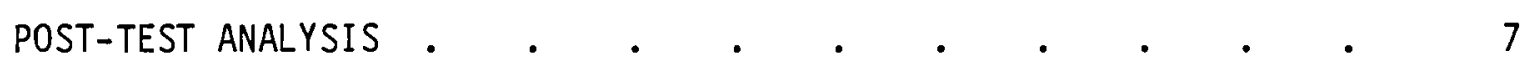

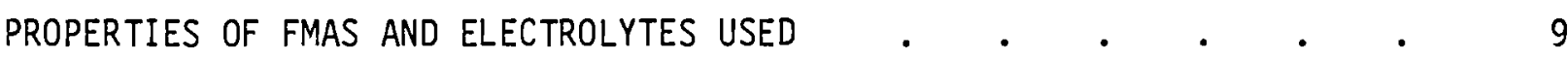

FMAS $\left(0.25 \mathrm{Fe}_{3} \mathrm{O}_{4} \cdot 0.75 \mathrm{MgAl}_{2} \mathrm{O}_{4}\right) \quad$. $\quad . \quad . \quad . \quad . \quad .99$

ELECTROLYTES •

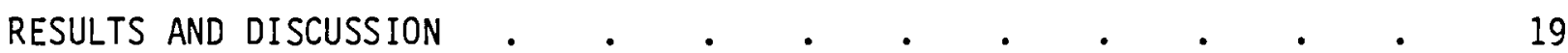

ELECTROCHEMICAL TESTING IN POTASSIUM SALTS $\quad . \quad \cdots \quad \cdot \quad \cdot \quad \cdot \quad 19$

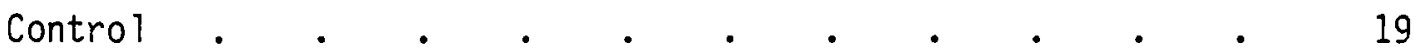

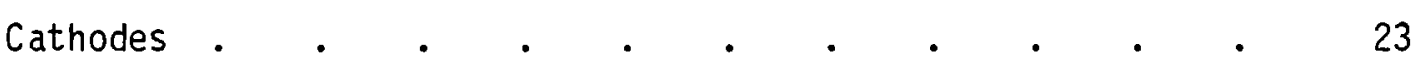

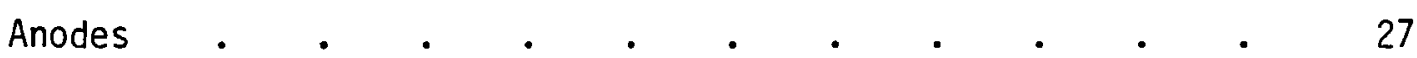

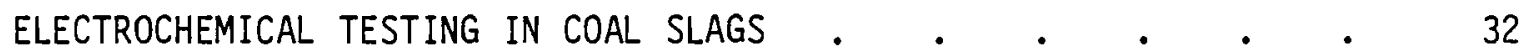

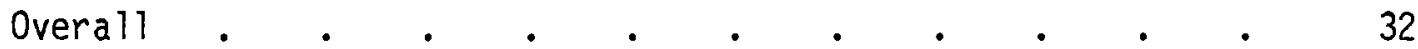

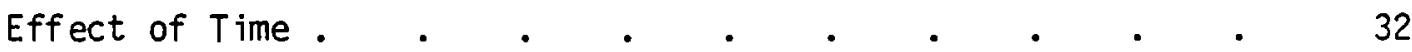

Effect of Current Density . . . . . . . . 33

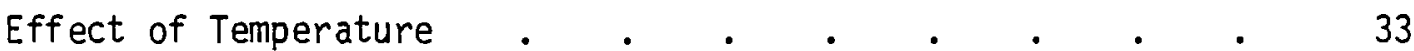

Effect of Slag/Iron Content . . . . . . . . 33

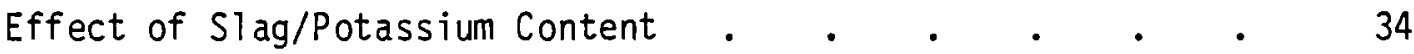

Overail Reactions . . . . . . . . . . . . 36

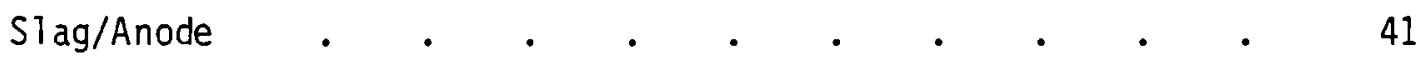




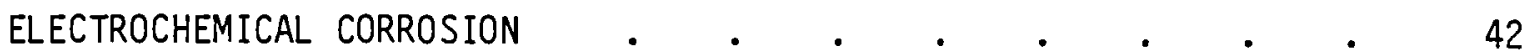

Electrochemical Corrosion in MR-1 at 1723K . . . . 42

Control . . . . . . . . . . . . . . 43

Cathode/Slag . $\quad . \quad$. . . . . . . . . 43

Anode/Slag $\quad . \quad$. $\quad . \quad$. $\quad . \quad$. 48

Electrochemical Corrosion in I11-6-1 at 1723K . . . 48

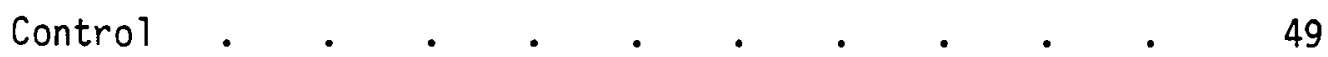

Cathode/Slag . $\quad$. $\quad$. 50 . 50

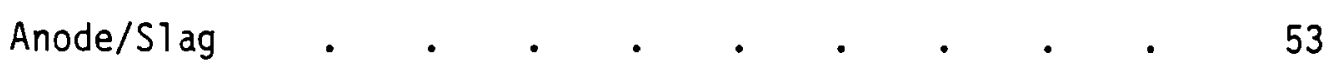

COMPARISON OF CORROSION BETWEEN MR-1 AND I11-6-1 • • • • • 54

ELECTROCHEMICAL CORROSION IN MR-1 + $\mathrm{Fe}_{2} \mathrm{O}_{3}(\mathrm{MR}-1-\mathrm{Fe})$

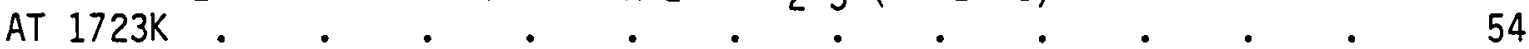

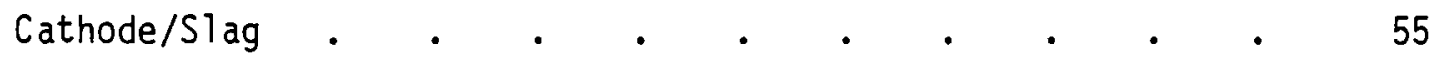

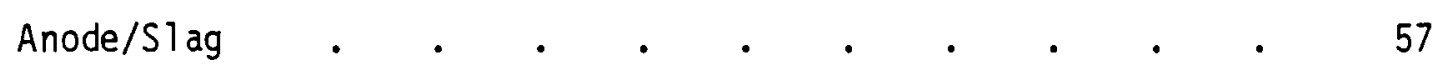

COMPARISON OF TESTS IN MR SLAG WITH AND WITHOUT ADDITIONAL

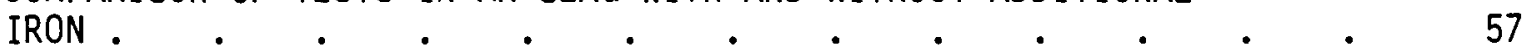

COMPARISON OF TESTS BETWEEN MR-1-Fe AND I11-6-1 . . . • • 58

ELECTROCHEMICAL CORROSION IN MR-1 AT 1573K

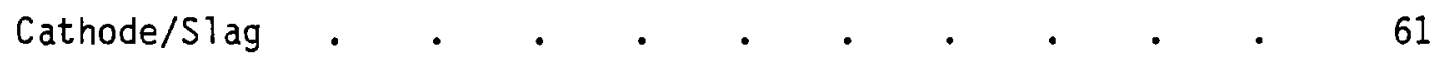

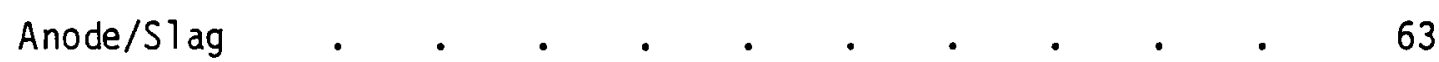

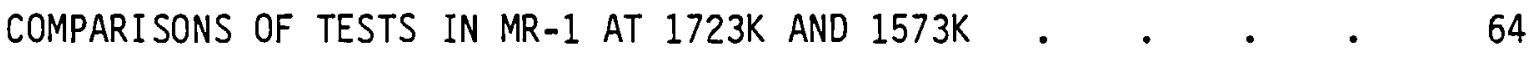

ELECTROCHEMICAL CORROSION IN MR AT 1476K

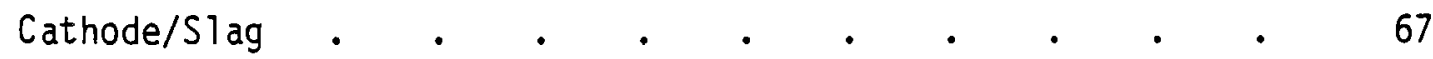

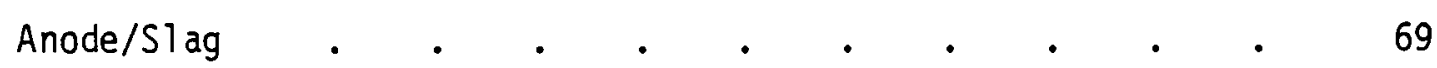

COMPARISON BETWEEN TESTS IN MR AT 1476K AND MR-1 SLAGS AT 1573K • 69

CHEMICAL CORROSION IN MR SLAG AT 1723K 


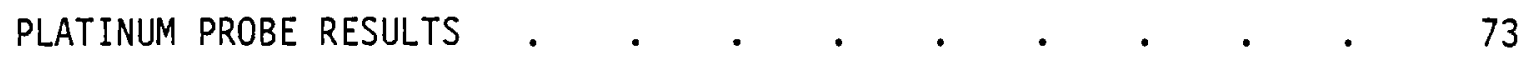

CONCLUSIONS/RECOMMENDATIONS $\quad . \quad$ •

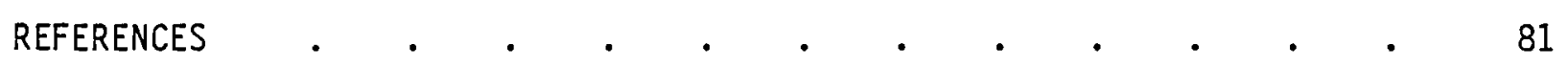

APPENDIX - QUANTITATIVE ANALYSIS RESULTS FROM THE SEM-EDX • • • • A.1

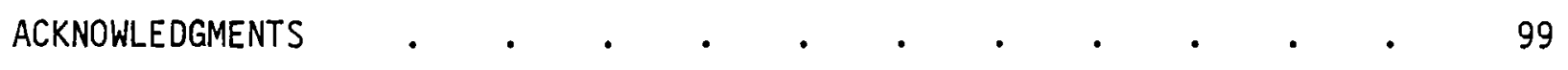


FIGURES

1 Electrochemical Test Configuration ..$\quad$. $\quad$. $\quad$. 5

2 Microstructure of FMAS (Electrode No. 99) . . . . . . . 12

3 Thermal Diffusivity of Sintered FMAS (Electrode No. 130) . . 13

4 Electrical Conductivity of Sintered FMAS $\quad . \quad$. $\quad . \quad$. $\quad$. 14

5 Thermal Expansion of Sintered FMAS (Electrode No. 130) . . . 15

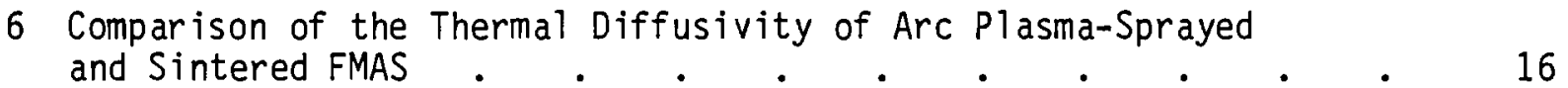

7 Electrical Conductivity of Coal Slag, Potassium Salts and FMAS in Air $. \quad . \quad . \quad . \quad . \quad . \quad . \quad . \quad . \quad . \quad . \quad . \quad 18$

8 SEM Micrograph of FMAS Control After Corrosion Test in $\mathrm{K}_{2} \mathrm{CO}_{3}$ at $1273 \mathrm{~K}$ (Experiment 314)

9 SEM Micrograph of FMAS Control After Corrosion Test in

10 Optical Macrograph of FMAS Cathode After an Electrochemical

11 Optical Micrograph of the Cathode After an Electrochemical Test in $\mathrm{K}_{2} \mathrm{SO}_{4}$ at $1423 \mathrm{~K}$ (Experiment 28)

12 Anode After and Electrochemical Test in $\mathrm{K}_{2} \mathrm{SO}_{4}$ at $1423 \mathrm{~K}$. . 28

13 Optical Micrograph of Anode After an Electrochemical Test

14 Percent Corrosion in MR-1 slag as a Function of Time, $1 \mathrm{~A} / \mathrm{cm}^{2}, 1723 \mathrm{~K} . \quad . \quad . \quad . \quad . \quad . \quad . \quad . \quad 32$

15 Corrosion Rate in MR-1 Slag as a Function of Current

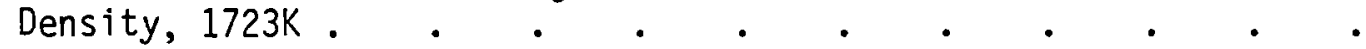

16 Corrosion Rate in MR-1 as a Function of Temperature,

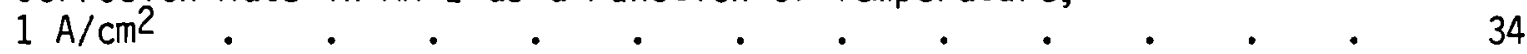

17 Corrosion Rate in Slag as a Function of Slag $\mathrm{Fe}_{2} \mathrm{O}_{3}$ Content, $1 \mathrm{~A} / \mathrm{cm}^{2}, 1723 \mathrm{~K} \quad . \quad . \quad . \quad . \quad . \quad . \quad . \quad . \quad 35$

18 Corrosion Rate in Slag as a Function of Slag Potassium Content, $1 \mathrm{~A} / \mathrm{cm}^{2}, 1723 \mathrm{~K}$ 
19 Anode, Cathode, and Control (no current) After a Test in MR-1 at $1723^{\circ} \mathrm{C} . . . . . . . . .$.

20 Macrograph and Micrograph of Control Tested in MR-1 Slag, 1723K, $24 \mathrm{~h}$ (Experiment 303) . . . . . . .

21 Scanning Electron Micrographs of Anode and Cathode in MR-1, 1723K (Experiment 21)

22 Control Tested in I11-6-1 Slag for $24 \mathrm{~h}$ at $1723 \mathrm{~K}$ (Experiment 308)

23 Scanning Electron Micrographs of Anode and Cathode in I11-6-1 at $1723 \mathrm{~K}$ (Experiment 33) . • . • . . . .

24 Scanning Electron Micrograph of Anode and Cathode in MR-1-Fe at $1723 \mathrm{~K}$ (Experiment 39).

25 Scanning Electron Micrograph of Anode and Cathode in MR-1 at 1573K (Experiment 38) . .

26 Scanning Electron Micrograph of Anode and Cathode in MR-1 at 1476K (Experiment 44)

27 Scanning Electron Micrograph of Control in MR at 1723K (Experiment 318) 
$\underline{\text { TABLES }}$

1 Nominal Compositions of Synthetic Coal Slag . . . . . . 4

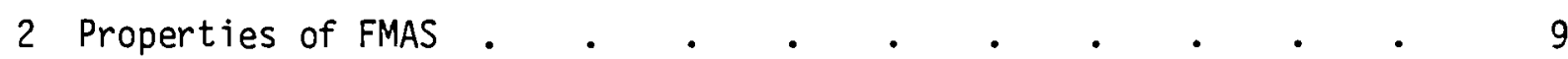

3 Spectrochemical Analyses of FMAS . . . . . . . . . . 11

4 Electrochemical Test Summary . . . . . . . . . 20

5 Mechanisms of Charge Transfer Between Potassium Carbonate

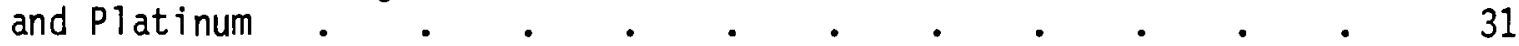

6 Observations and Explanations of Features Found in the Cathode and Anode During Electrochemical Testing in Coal Slags . . . 37

7 Comparison Summary Between Tests in MR-1 and MR-1-Fe . . . 59

8 Comparison Summary Between Tests in MR-1-Fe and I11-6-1 . . 60

9 Comparison Summary Between Tests in MR-1 at 1723K and 1573K . . 66

10 Comparision Summary of Tests in MR at 1476 K and MR-1

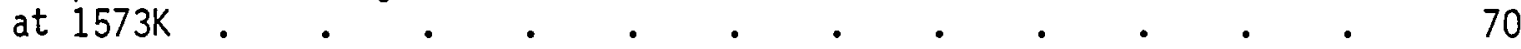

11 Summary of Platinum Electric Potential Probe Data . . . . 74

A.1 Atomic Composition of Features in Figure 8 (Experiment 314 Control in $\mathrm{K}_{2} \mathrm{CO}_{3}$ at 1273K) in Atom\% of Elemental Species Detected . . . . . • • • • . . A.2

A.2 Atomic Composition of Features in Figure 9 (Experiment 315 Control in $\mathrm{K}_{2} \mathrm{SO}_{4}$ at 1373K) in Atom\% of Elemental Species Detected

A.3 Atomic Compositions of Features in Figure 12 (Anode Tested in $\mathrm{K}_{2} \mathrm{SO}_{4}$ at 1423K, Experiment 28) in Atom\% of Elemental Species Detected

A.4 Atomic Compositions of Features in Figure 20 (Experiment 303 Control in MR-1 Slag at 1723K) in Atom \% of Element Species Detected

A.5 Atomic Composition of Features in Figure 21 (Experiment 21 in MR-1 at 1723K) in Atom\% of Elemental Species Detected. . A. . A

A.6 Atomic Composition of Features in Figure 22 (Experiment 308 Control in $111-6-1$ Slag at 1723K) in Atom\% of Elemental Species Detected 
A.7 Atomic Composition of Features in Figure 23 (Experiment 33 in I11-6-1 at 1723K) in Atom\% of Elemental Species Detected . . A.7

A. 8 Atomic Concentrations of Features in Figure 24 (Experiment 39 in MR-1-Fe at 1723K) in Atom\% of Elemental Species Detected.

A.9 Atomic Composition of Features in Figure 25 (Experiment 38 in MR-1 at 1573K) in Atom\% of Elemental Species Detected . . . A.11

A.10 Atomic Concentration of Features in Figure 26 (Experiment 44 in MR at 1476K) in Atom\% of Elemental Species Detected.

A.11 Atomic Composition of Features in Figure 27 (Experiment 318 Control in MR S1ag at 1723K) in Atom\% of Elemental Species Detected. 


\section{INTRODUCTION}

The search for electrode materials that withstand the severe operating conditions of magnetohydrodynamic (MHD) generator channels is one of the major challenges remaining in the development of commercial MHD power generation. In a coal-fired, open-cycle MHD generator the electrodes are exposed to hightemperature (up to $3000 \mathrm{~K}$ ) potassium-seeded plasma moving at near-sonic velocity. The plasma contains between $0.5 \mathrm{wt} \%$ and $2.5 \mathrm{wt} \%$ inorganic coal slag and up to $1 \mathrm{wt} \%$ potassium seed. Depending on the temperature, the slag and seed-in gaseous, liquid or solid states--may damage electrodes.

Upon application of the magnetic field used in the MHD process, direct electrical currents are conducted through the current leadouts, electrodes, slag/seed and combustion plasma. In addition, electric potentials are set up along the length of the channel. These electric currents and potentials subject the electrode materials to severe electrochemical interactions. Many of these interactions cause increased corrosion, resulting in corrosion rates that are orders of magnitude more severe than is the case in the absence of the electric fields and currents.

Since the cost and the time needed to study the electrochemical effects in actual or simulated MHD generators can be prohibitive, laboratory tests have been developed at the Pacific Northwest Laboratory (PNL). These tests are valuable in screening materials, accelerating electrochemical effects, and providing a better understanding of the electrochemical processes. These tests do not simulate plasma flow, plasma current transport nor thermal gradient effects. They simulate only isothermal current transport between the electrodes and the molten electrolytes.

The purpose of this study is to evaluate electrochemical behavior of 0.25 $\mathrm{Fe}_{3} \mathrm{O}_{4} \cdot 0.75 \mathrm{MgAl}_{2} \mathrm{O}_{3}$ (FMAS) using electrochemical tests--tests designed to study interactions as functions of electrolyte composition (coal slag and alkali seed), temperature, and electrical current density. FMAS has been seriously considered as a potential MHD electrode because of its favorable electrical properties and potential compatibility with coal slags. Promising 
FMAS characteristics include 1) electrical conductivity greater than $10 \mathrm{~S} / \mathrm{m}$ at temperatures above $800 \mathrm{~K}, 2)$ dominantly electronic electrical conductivity (Westinghouse 1978), 3) crystallographic stability in oxidizing atmospheres, and 4) ease of fabrication (Bates 1976). Many FMAS properties have been thoroughly studied; however, its electrochemical corrosion has not been investigated in detail.

This report reviews some of the physical and thermal properties of FMAS. It also describes how FMAS reacts when electrochemically tested in electrolytes of $\mathrm{K}_{2} \mathrm{CO}_{3}, \mathrm{~K}_{2} \mathrm{SO}_{4}$, and synthetic coal slags representing Montana Rosebud and Illinois No. 6 coal slags with and without additional potassium. The test results show that although FMAS offers ease of fabrication and favorable physical and thermal properties, its extensive interaction with potassium salts and Montana Rosebud slag casts doubt upon the potential usefulness of FMAS electrodes. The lower corrosion rates experienced by FMAS in Illinois No. 6 slag do, however, still allow consideration of FMAS electrode use in this slag. 


\section{EXPERIMENTAL PROCEDURES}

The experimental process for these tests first involved the fabrication of the FMAS test specimens and the preparation of electrolytes. The electrodes were then suspended in a molten electrolyte using several testing variations, after which an extensive analysis was performed on each specimen.

\section{FMAS FABRICATION}

The powder was obtained from a commercial powder fabrication company (a) and had a surface area (BET) of $2.6 \mathrm{~m}^{2} / \mathrm{g}$. The electrode test pieces were fabricated by cold-pressing and sintering. The starting powder, $-200+325$ mesh (Tyler screens), was mixed with 2 wt\% sterotex and ball-milled. Prior to each of the powder pressings, the powder was exposed to water-saturated air (298K) for several hours. The powder was preslugged at $51.48 \mathrm{MPa}$ (7450 1b/ in. ${ }^{2}$ ), screened to -40 mesh (Tyler screens), then pressed at $82.4 \mathrm{MPa}$ $\left(11,950 \mathrm{lb} / \mathrm{in}^{2}\right)$ to $\sim 60 \%$ of theoretical density. The compact was sintered in air at $1873 \mathrm{~K}$ ( 20.88 of the melting point) for $4 \mathrm{~h}$, with approximate heating and cooling rates of $200 \mathrm{~K} / \mathrm{h}$ and $400 \mathrm{~K} / \mathrm{h}$, respectively.

\section{ELECTROLYTE PREPARATION}

Reagent grade potassium carbonate and potassium sulfate were used as electrolytes. The potassium carbonate and sulfate was melted directly without pretreatment in either $\alpha$-alumina (all the alumina crucibles were $A D 998^{\circledR}$ ) or platinum crucibles.

The slags were prepared by mixing the oxide of the slag constituents (carbonates or sulfates of $\mathrm{Ca}, \mathrm{K}$, and $\mathrm{Na}$ ) and ball-milling for $3 \mathrm{~h}$. The mixture, contained in either alumina or platinum boats, was calcined in air at $1275 \mathrm{~K}$ for 15 min to minimize outgassing in the test crucibles during the homogeneous glass-forming anneals. The calcined product, partially sintered, was

(a) Trans-Tech Inc., Gaithersburg, Maryl and.

(B) Coors Porcelain Co., Golden, Colorado 
ground to -4 mesh (Tyler screens) and stored until needed for the individual tests. Before each test, the required amount of slag was vitrified and homogenized at temperatures between $1675 \mathrm{~K}$ and $1823 \mathrm{~K}$ for $16 \mathrm{~h}$. The compositions of the slags are given in Table 1.

Two of the compositions represent Montana Rosebud and Illinois No. 6 slag; the other two represent those two slags containing additional potassium to simulate the chemical properties of the slag found in an MHD generator. All four compositions were used.

\section{ELECTROCHEMICAL TESTING TECHNIQUES}

The electrochemical tests consist of submerging the anode, cathode, and control in the molten electrolyte, as shown in Figure 1. Constant current was maintained between the electrodes using a dc current-limiting power supply. This power supply maintains constant current by adjusting the electric potential. The response time of the power supply to changes in current are on the order of milliseconds. The electric current and potential were continuously monitored and recorded during the tests.

The test procedure consisted of suspending the samples above the molten slag or seed, then slowly lowering them into the electrolyte at the test

TABLE 1. Nominal Compositions of Synthetic Coal Slag

\begin{tabular}{|c|c|c|c|c|}
\hline Oxide & $\begin{array}{l}\text { Mont ana Rosebud } \\
\text { (MR), mol\% } \\
\end{array}$ & $\begin{array}{c}\text { Mont ana Rosebud } \\
+ \text { Potassium } \\
(\text { MR-1), mol\% } \\
\end{array}$ & $\begin{array}{l}\text { Illinois No. } 6 \\
(\text { I } 17-6) \text {, mol\% }\end{array}$ & $\begin{array}{l}\text { Illinois No. } 6 \\
+ \text { Potassium } \\
(111-6-1) \text {, mol\% }\end{array}$ \\
\hline $\mathrm{SiO}_{2}$ & 54.7 & 49.4 & 57.2 & 52.5 \\
\hline $\mathrm{Al}_{2} \mathrm{O}_{3}$ & 14.3 & 13.0 & 15.7 & 14.4 \\
\hline $\mathrm{CaO}$ & 17.9 & 16.2 & 7.9 & 7.2 \\
\hline $\mathrm{Fe}_{2} \mathrm{O}_{3}$ & 3.4 & 3.1 & 11.5 & 10.6 \\
\hline $\mathrm{MgO}$ & 7.9 & 7.1 & 3.5 & 3.1 \\
\hline $\mathrm{TiO}_{2}$ & 0.7 & 0.6 & 0.9 & 0.9 \\
\hline $\mathrm{K}_{2} \mathrm{O}^{\mathrm{C}}$ & 0.5 & 10.0 & 1.9 & 10.0 \\
\hline $\mathrm{Na}_{2} \mathrm{O}$ & 0.4 & 0.4 & 0.8 & 0.8 \\
\hline $\mathrm{P}_{2} \mathrm{O}_{5}$ & 0.2 & 0.2 & 0.6 & 0.5 \\
\hline
\end{tabular}




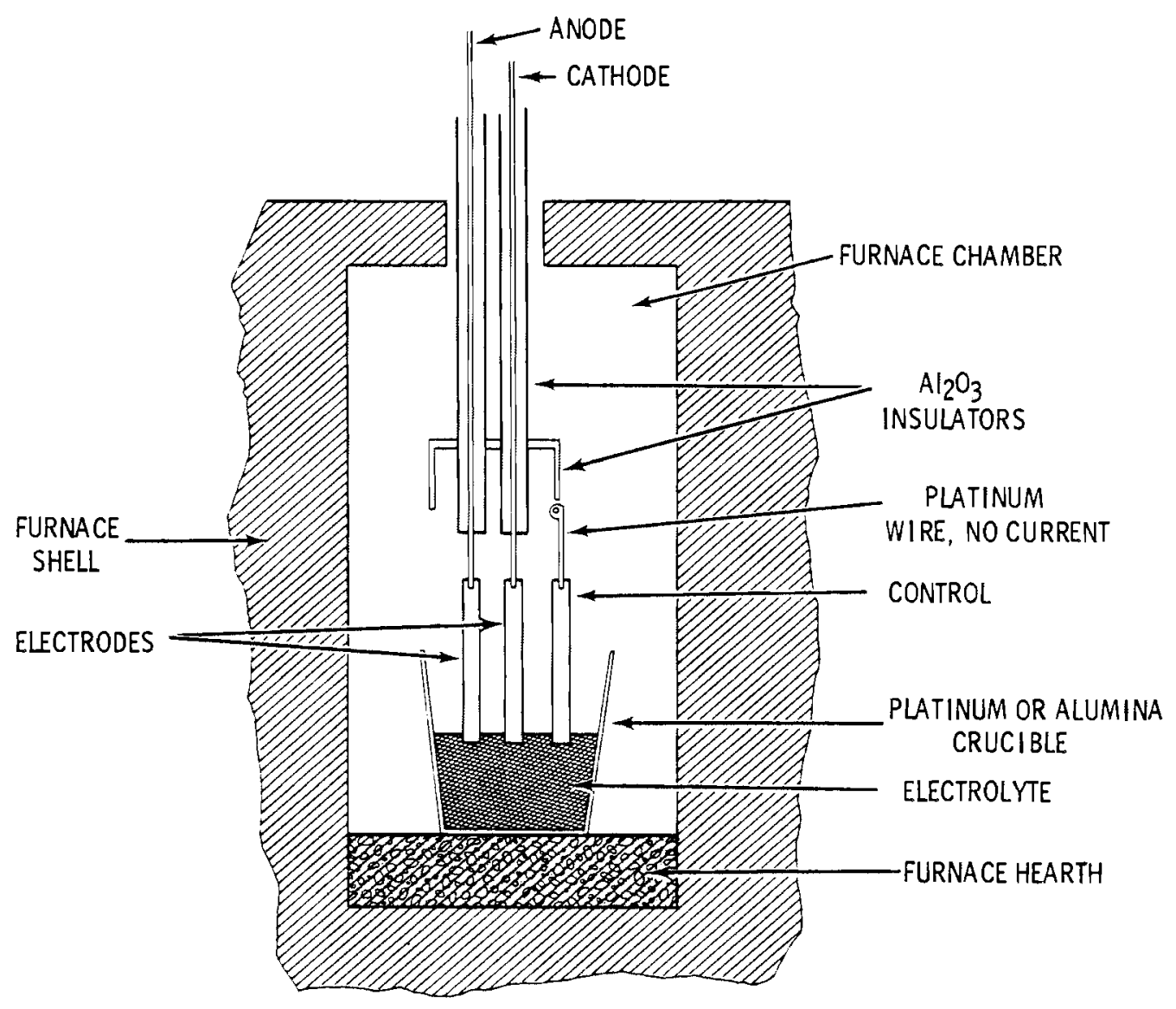

FIGURE 1. Electrochemical Test Configuration

temperature. A sudden decrease in electrical resistance between the electrodes indicated that contact was made with the electrolyte. The electrodes were then lowered into the melt (generally $3 \mathrm{~mm}$ ).

The samples for electrochemical testing were cut into rectangular parallelepipeds $(0.2 \times 0.3 \times 1.5 \mathrm{~cm})$ from the sintered FMAS. One end of the sample was notched and painted with a platinum paste to provide a good mechanical and electrical contact with the Pt wire. Platinum wire leadouts connected the electrodes to the dc power supply.

Electrodes tested in pure potassium-salt melts were withdrawn from the electrolyte and then cooled to room temperature at a rate of $200 \mathrm{~K} / \mathrm{h}$. Electrodes tested in slag were quenched in the slag from the test temperature down to $1175 \mathrm{~K}$ in $15 \mathrm{~min}$, then cooled to room temperature at $150 \mathrm{~K} / \mathrm{h}$. The purpose of 
the quench was to retain the electrodes/slag interface for examination. Care was taken to ensure the same thermal-quench conditions for each test.

Two modifications were made to the configuration during the testing program: 1) the control was not included in some tests, and 2) several tests were conducted with the sample partially surrounded by an alumina tube. The alumina tube directed the current flow to the end of the sample by preventing potential short-circuiting of the current through the electrolyte in contact with the sides of the electrode. The control was not included in the tests because 1) the anodes and cathodes degraded much more rapidly than the control, 2) the control degradation was independent of most test parameters, and 3 ) the electric field altered the slag composition even in the area of the control. Individual tests were conducted on the control sample in electrolyte without any electrical fields.

In all electrochemical test geometries, a fraction of the electrical current will conduct through all areas of the electrode exposed to the electrolyte, including the sides. This current "leakage" makes it difficult to determine precisely the current density through the exposed surfaces. Surrounding the electrodes with an insulating alumina tube directs most of the current through the end of the electrode sample. Consequently, the quoted current density is that calculated using the rectangular cross section ( $0.2 \times$ $0.3 \mathrm{~cm}$ ) of the end of the electrode sample. The test was terminated when either 1) a predetermined time period had elapsed, 2) an open circuit occurred between the electrodes, or 3 ) the potential required to maintain a constant current exceeded the limit of the power supply.

Several tests included a platinum electric-potential probe located geometrically at a location equivalent to one point of an equilateral triangle with respect to the anode, cathode and platinum probe. The potential changes between the anode probe and cathode probe show polarization, bubble formation and current-transfer instabilities. 
POST-TEST ANALYSIS

The electrodes were examined ceramographically to identify microstructural changes and to determine the extent of corrosion. The electrode surfaces were polished parallel to an original side. This polished surface geometry is compared to the original geometry to determine the amount of material lost, which included that portion of the electrode that had completely disappeared during the test or that had physically separated from the main body of the electrode. The corrosion rate is defined as either the amount of material lost per number of coulombs passed between the electrodes (mol/coul. using the FMAS atomic weight of $164.6 \mathrm{~g} / \mathrm{mol}$ ) or as the weight loss per unit area of the electrode immersed in slag per hour $\left(\mathrm{g} / \mathrm{cm}^{2}-\mathrm{h}\right)$.

Optical microscopy and scanning electron microscopy with energy-dispersive $x$-ray analysis (SEM-EDX) were used to identify the phases present in the cathode, anode, and slag. The SEM-EDX is equipped with quantitative analysis, and these capabilities are standardized using oxide minerals. Details related to the accuracy of SEM-EDX are given in the Appendix. The quantitative analysis is based on the absolute number of moles recorded in the analysis, since a11 the analyses are conducted at the same electron-current densities and times and since all the spectra are independent of spectra from other atoms. The quantitative analysis is expressed as atom\% based on the atomic species identified and quantified (SEM-EDX is sensitive to elements with atomic numbers above 10). In the compositional analysis, the oxidation state of the atomic species cannot be determined using both optical microscopy and SEM-EDX; metallic and oxide phases may be distinguished, but the extent to which the oxide phase has oxidized cannot be determined in most cases. 
The structural, chemical, thermal and electrical properties of FMAS and of the electrolytes used in these studies are discussed here. An understanding of these characteristics is useful in analyzing the results.

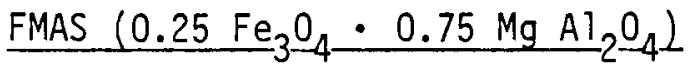

The crystal structure of FMAS is spinel in which $\mathrm{Fe}^{+2}$ and $\mathrm{Fe}^{+3}$ ions randomly replace $\mathrm{Mg}^{+2}$ and $\mathrm{Al}^{+3}$ ions. No substructure showing the ordering of the iron has been observed. The FMAS properties listed in Table 2 are nominal, based on measurements of several samples. In vaporization studies

\section{TABLE 2. Properties of FMAS}

\begin{tabular}{|c|c|}
\hline Parameters and Units & Values and Distinctions \\
\hline Formula Weight, g/mol & 164.6 \\
\hline Lattice Parameters, $10^{-10} \mathrm{~m}$ & 8.160 (powder) \\
\hline & 8.185 ( sintered compact) \\
\hline Theoretical Density, $\mathrm{g} / \mathrm{cm}^{3}$ & 4.03 \\
\hline Density Range, $\mathrm{g} / \mathrm{cm}^{3}$ & 3.60 to 3.65 \\
\hline Theoretical Density, $\%$ range & 89 to 91 \\
\hline Total Porosity, $\%$ & 7.5 \\
\hline Open Porosity, $\%$ & 0.14 \\
\hline Average Grain Size, mm & 20.5 \\
\hline $\begin{array}{l}\text { Average Thermal Expansion, } \\
\left(K^{-1} 10^{-6}\right)\end{array}$ & 9.6 (a 373 to $1673 K)$ \\
\hline Melting Point, $k$ & $2124 \pm 20$ \\
\hline Composition, (a) $\%$ & $11.7(\mathrm{Fe})$ \\
\hline & $11.1(\mathrm{Mg})$ \\
\hline & $29.7(\mathrm{Al})$ \\
\hline & $47.5(0)$ \\
\hline
\end{tabular}

(a) Atomic absorption with oxygen as difference. 
over a temperature range from 1613 to 2083K, the order of species with decreasing vapor pressures are $\mathrm{Fe}(\mathrm{g}), \mathrm{O}_{2}(\mathrm{~g}), \mathrm{Mg}(\mathrm{g})$ and $\mathrm{FeO}(\mathrm{g})$ (Plante 1978). At $2000 \mathrm{~K}$ the iron pressure is close to $1 \mathrm{~Pa}$. This vapor pressure is probably too high for long-duration testing. Therefore, FMAS should have a upper limit of operation in an MHD channel of 1900K.

The purity of both the powder and the sintered compacts are listed in Table 3. The major impurities are silicon, calcium, and manganese.

The microstructure of sintered compacts consists of large, equiaxel grains ( $0.5 \mathrm{~mm}$ in dia) with small ( $(0.002-\mathrm{mm})$ pores uniformily distributed along the grain boundaries and at the grain-boundary intersections, as shown in Figure 2. A second phase is located along some of the grain boundaries and grain-boundary intersections. This oxide phase principally contains calcium, silicon, barium, iron and aluminum.

The thermal-diffusivity data shown in Figure 3 reveal reproducible changes (i.e., they occur on both heatup and cooldown) in the smooth curves at temperatures between $1200 \mathrm{~K}$ and $1400 \mathrm{~K}$. Similar changes are found in the electrical conductivity and thermal expansion (Figures 4 and 5 ), respectively. The conductivity followed the essentially smooth curve as long as measurements were made on samples with little pretesting heat treatment. The electrical conductivity mesurements usually required about a 20-min hold at each measuring temperature, so the total time at temperatures above 1000K was only about $2 \mathrm{~h}$. When the sample was preannealed in air at $875 \mathrm{~K}$ for $60 \mathrm{~h}$, the conductivity changed and followed a hysteresis. Thermal diffusivity measurements are made in reducing atmospheres (tank-purity argon). The thermal expansion and electrical conductivity measurements were made in oxidizing atmospheres (i.e., air). The changes are found upon both heating and cooling, indicating a chemical change other than physical changes such as changes in porosity morphology and microcracking. The effect of the chemical change is much more pronounced in the electrical conductivity than with either thermal expansion or diffusivity, as is shown in the figure. The thermal-expansion cooldown curve did not show the inflections found during heatup, but since the sample exhibited a 
TABLE 3. Spectrochemical Analyses of FMAS(a)

\begin{tabular}{|c|c|c|c|c|}
\hline Element & $\begin{array}{l}\text { Starting } \\
\text { Powder }\end{array}$ & $\begin{array}{l}\text { Starting } \\
\text { Powder }\end{array}$ & Electrode & Electrode \\
\hline $\mathrm{Ce}$ & 0.39 & 0.15 & 0.83 & 0.58 \\
\hline La & 0.47 & 1.7 & 18 & 47 \\
\hline $\mathrm{Ba}$ & 54 & 14 & 54 & 14 \\
\hline $\mathrm{Zr}$ & 30 & 30 & 13 & 30 \\
\hline Y & 23 & 11 & 23 & 23 \\
\hline$S r$ & 7.3 & 3.7 & 3.7 & 16 \\
\hline $\mathrm{Ga}$ & 15 & 13 & 13 & 8.7 \\
\hline $\mathrm{Zr}$ & 17 & 24 & 19 & 56 \\
\hline $\mathrm{Cu}$ & 28 & 84 & 28 & 56 \\
\hline $\mathrm{Ni}$ & 55 & 280 & 55 & 550 \\
\hline $\mathrm{Fe}$ & --- & --- & --- & --- \\
\hline$M n$ & 2000 & 210 & 62 & 310 \\
\hline $\mathrm{Cr}$ & 12 & 730 & 35 & 730 \\
\hline $\mathrm{Ti}$ & 5.5 & 12 & 7.3 & 7.3 \\
\hline $\mathrm{Ca}$ & 150 & 170 & 150 & 220 \\
\hline$k$ & 6 & 6 & 3.4 & 3.4 \\
\hline $\mathrm{Cl}$ & 5.1 & 12 & 5.1 & 2.4 \\
\hline$S$ & 24 & 10 & 8 & 8 \\
\hline$P$ & 40 & 71 & 20 & 40 \\
\hline $\mathrm{Si}$ & 490 & 980 & 980 & 2100 \\
\hline$A 1$ & -- & -.. & --- & --- \\
\hline $\mathrm{Mg}$ & -- & $\cdots$ & -- & -- \\
\hline $\mathrm{Na}$ & 18 & 14 & 18 & 37 \\
\hline $\mathrm{F}$ & 54 & 2.5 & 13 & 450 \\
\hline$B$ & 1.2 & 2.3 & 3.9 & 41 \\
\hline Li & 16 & 22 & 65 & 0.18 \\
\hline v & 1.1 & 8.5 & 4.3 & 5.7 \\
\hline Co & 7 & 14 & 2.3 & 25 \\
\hline Mo & --- & --- & --- & 3.6 \\
\hline
\end{tabular}

(a) Determined by spark-source enmissions spectroscopy 


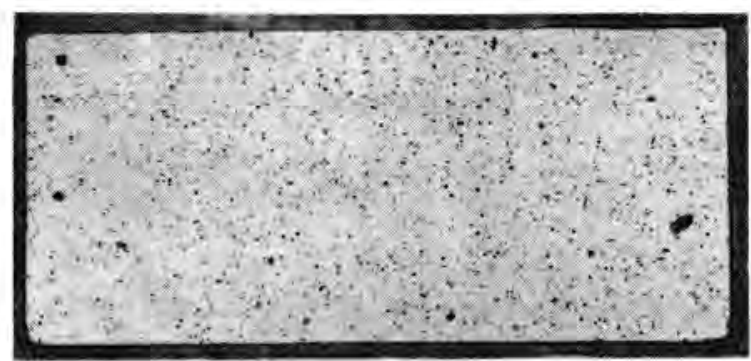

$3 \mathrm{~mm}$
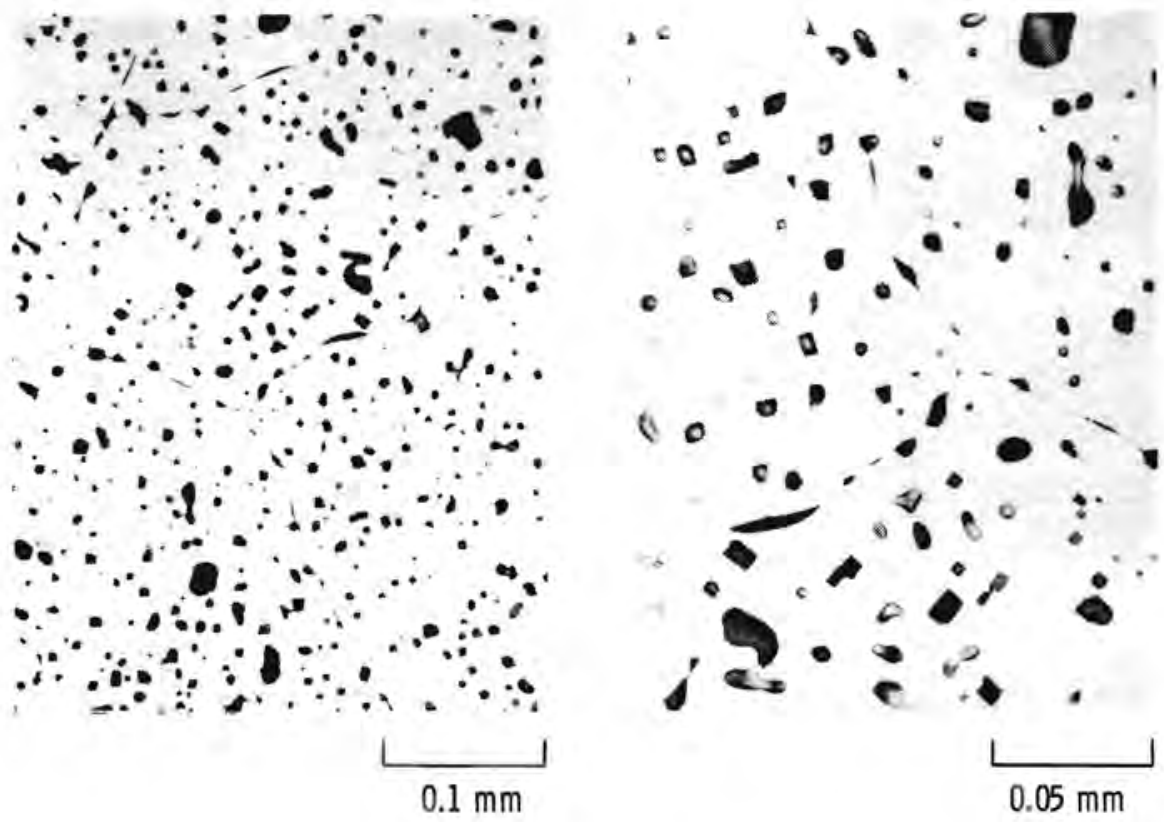

FIGURE 2. Microstructure of FMAS (Electrode No. 99)

permanent displacement, microcracking occurred. The microcracking effects dominated the effect of the phase changes and cannot be seen in the figure.

The electrical conductivity of the FMAS measured at PNL and at NBS (Hosler, Armstrong and Frederikse 1976) is shown in Figure 4. The electrical conductivity of FMAS is not affected by changes in oxygen potential (i.e., partial pressure) over a range from $0.02 \mathrm{MPa}$ to $0.61 \mathrm{~Pa}$ for a temperature range from 560 to $1700 \mathrm{~K}$ (Hosler, Armstrong and Frederikse 1976). The property hystereses at temperatures between $1200 \mathrm{~K}$ and $1400 \mathrm{~K}$ probably resulted from the 


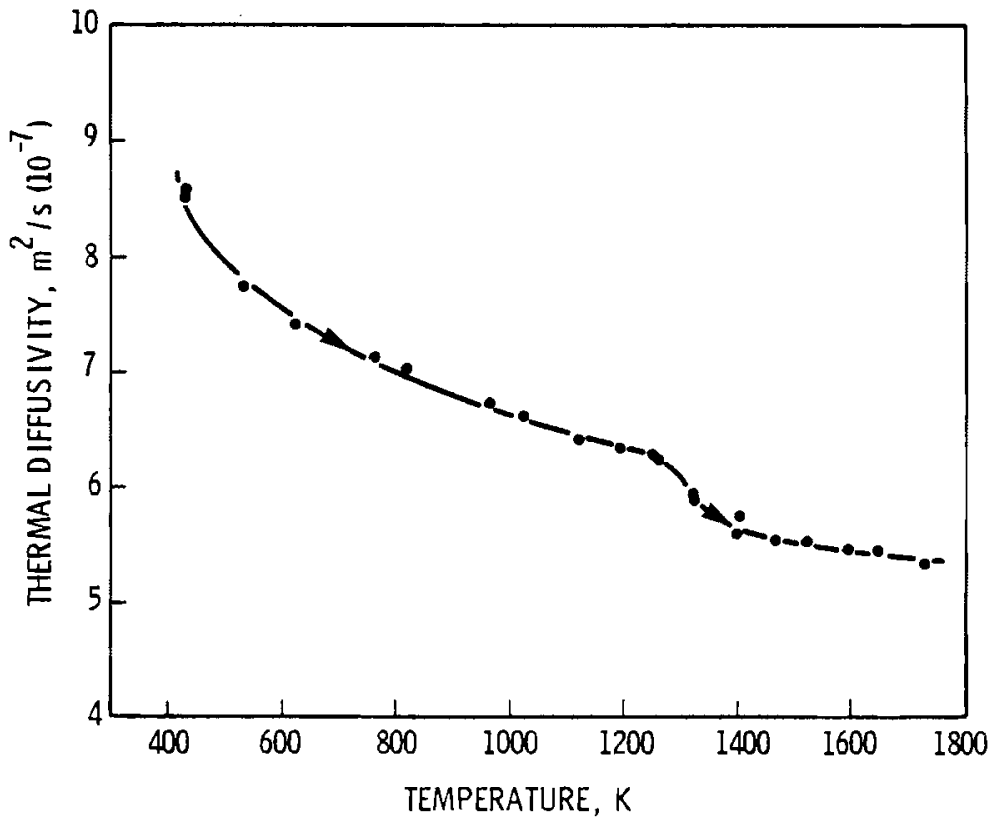

FIGURE 3. Thermal Diffusivity of Sintered FMAS (Electrode No. 130)

partial thermal decomposition of the spinel--specifically, the exsolution of iron. Examination of FMAS samples after thermal diffusivity measurements shows the original single-phase spinel to have partially altered, forming a high-aluminum phase depleted of iron and a high-iron phase rich in magnesium. Phase equilibrium data (Levin, Robbins and McMurdie 1964) show a two-phase equilibrium at temperatures of $1523 \mathrm{~K}, 1673 \mathrm{~K}$ and $1873 \mathrm{~K}$. The two equilibrium phases are $\mathrm{MgAl}_{2} \mathrm{O}_{3}$ and $\mathrm{MgFe}_{2} \mathrm{O}_{4}$ (each containing small amounts of iron and aluminum, respectively). Decomposition is more extensive in the samples exposed to a reducing atmosphere like those in the thermal diffusivity apparatus (tank argon) than in the samples exposed to oxidizing atmospheres. The valence change of the iron in the reducing atmosphere may reduce its solubility in the spinel structure. The extent of dissolution was increased when a high-dc electric current was passed through the sample in electrochemical tests. Exsolution of iron and formation of low- and high-iron-containing phases have been observed in FMAS electrodes after MHD generator testing (Westinghouse 1978).

A sample of arc plasma-sprayed FMAS (APF Materials, Indianapolis, Indiana) was obtained for comparison with the sintered material. Plasma-spraying 


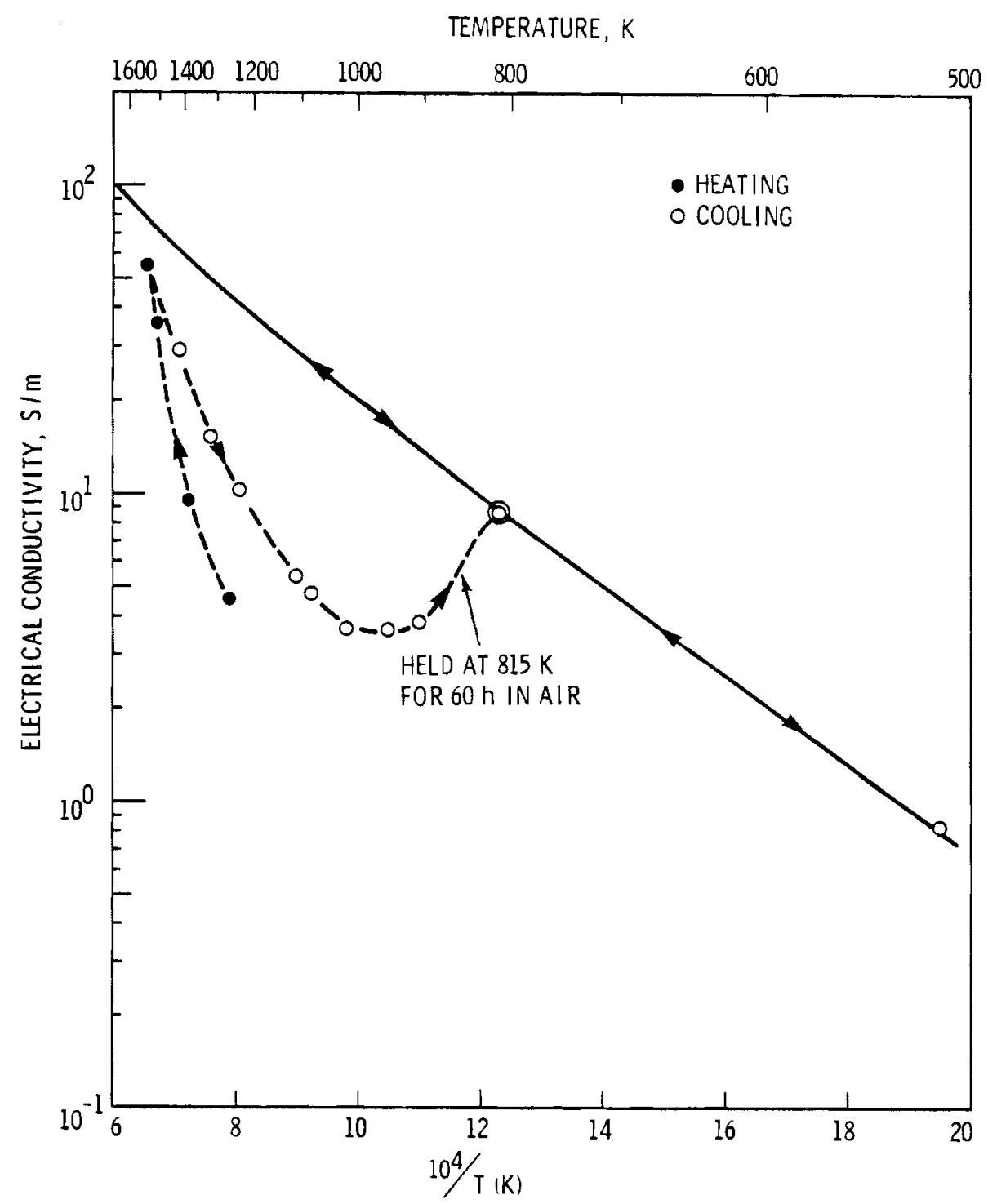

FIGURE 4. Electrical Conductivity of Sintered FMAS

offers the fabrication advantage of in-situ application of ceramics to the MHD channel. The arc plasma-sprayed material was not as well bonded and had thermal properties that varied with changes in heat treatment. The thermal diffusivity is shown in Figure 6 . After two thermal cycles the properties were similar to that of a compact sintered to $97 \%$ theoretical density, indicating that the initially porous compact had densified. Ceramographic examination showed densification, but the microstructure was not equiaxed; instead, it 


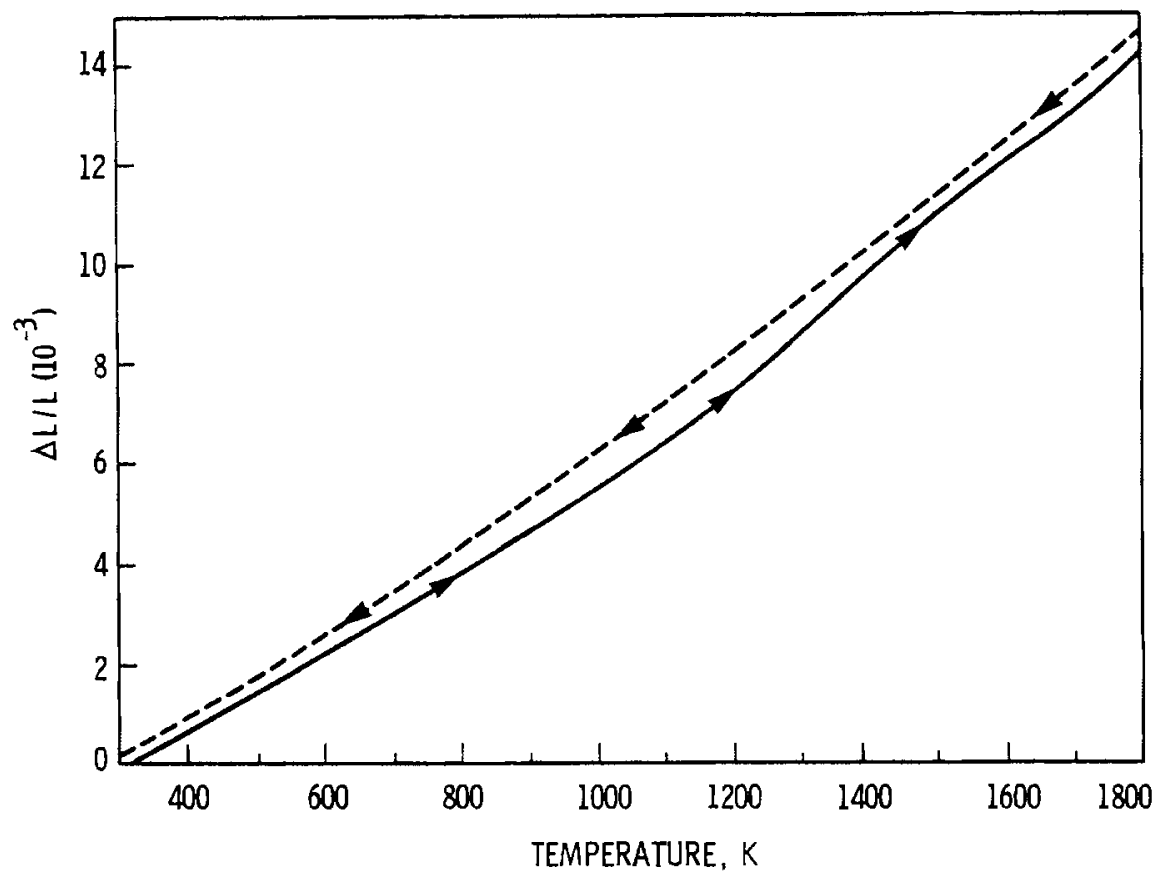

FIGURE 5. Thermal Expansion of Sintered FMAS (Electrode No. 130)

showed a layered texture ( $p$ lasma-spraying is a layered fabrication process) with the non-normal grain growth resulting in a wide distribution of grain sizes.

The effects of density on thermal diffusivity can also be observed in Figure 6 by comparing the data for sintered compacts of $87 \%$ and $97 \%$ theoretical density. The sintered compacts had equiaxed grains with the decrease in density due to the size of the porosity along the grain boundaries and triple points (grain boundary intersections as seen on a polished surface). At the higher temperatures the effects of porosity is lessened, both because of the increase in density and because of the increased radiative heat transport. Consequently, the conductivity of the samples is nearly equal at temperatures above $1700 \mathrm{~K}$.

\section{ELECTROLYTES}

Potassium sulfate $\left(\mathrm{K}_{2} \mathrm{SO}_{4}\right)$ has a melting point of $1342 \mathrm{~K}$; potassium carbonate $\left(\mathrm{K}_{2} \mathrm{CO}_{3}\right)$ has a melting point of $1174 \mathrm{~K}$. The $\mathrm{K}_{2} \mathrm{CO}_{3}$ liquid is fluid above the 


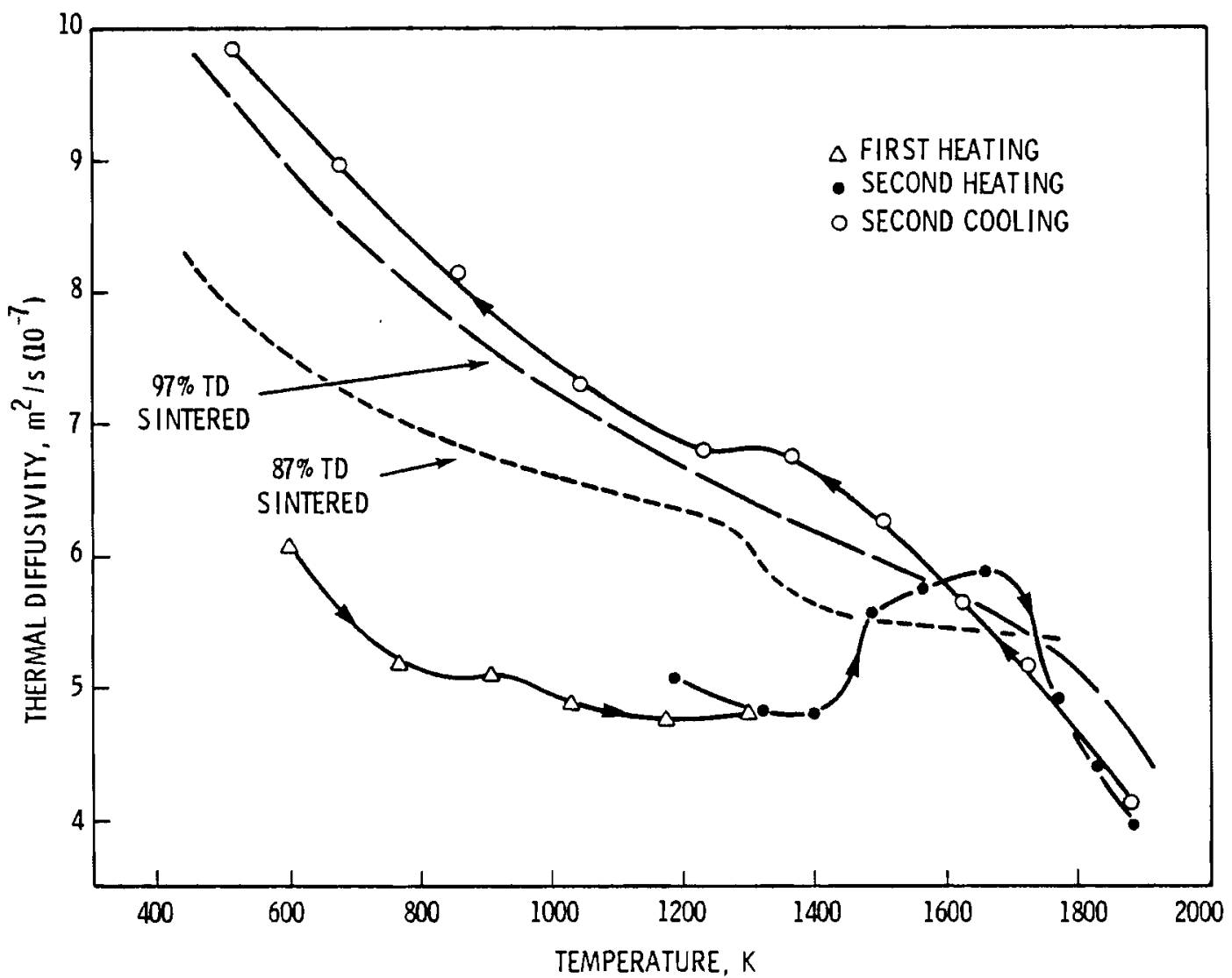

FIGURE 6. Comparison of the Thermal Diffusivity of Arc Plasma-Sprayed and Sintered FMAS

melting point, with viscosities ranging from $3.03 \times 10^{-3} \mathrm{~N} \cdot \mathrm{s} / \mathrm{m}^{2}$ at $1190 \mathrm{~K}$ to $1.66 \times 10^{-3} \mathrm{~N} \cdot \mathrm{s} / \mathrm{m}^{2}$ at $1250 \mathrm{~K}$ (Janz et al. 1968). The molten $\mathrm{K}_{2} \mathrm{SO}_{4}$ appears to be as fluid as $\mathrm{K}_{2} \mathrm{CO}_{3}$.

The coal slags do not have distinct melting temperatures. Being a silicate, the slag melts (vitrifies) over a range of temperatures with a pseudo equilibrium existing at each temperature between the vitrified (glassy) and devitrified (solid) phases. Below 1200K the slags are mostly devitrified and above $1600 \mathrm{~K}$ the slags are vitrified. The slags are viscous, with viscosities of between 4 and $100 \mathrm{~N} \cdot \mathrm{s} / \mathrm{m}^{2}$ at 1873K (Capps and Kauffman 1978).

Potassium carbonate forms hydration compounds when exposed to moisture at near-ambient temperatures. The hydration reactions are 


$$
\begin{aligned}
& \mathrm{K}_{2} \mathrm{CO}_{3}+3 \mathrm{H}_{2} \mathrm{O} \rightarrow \mathrm{K}_{2} \mathrm{CO}_{3}+3 \mathrm{H}_{2} \mathrm{O}_{\mathrm{s}} \\
& \mathrm{K}_{2} \mathrm{CO}_{3}+\mathrm{CO}_{2}+\mathrm{H}_{2} \mathrm{O} \rightarrow 2 \mathrm{KHCO}_{3}
\end{aligned}
$$

The percent increases in volumes of the solid phases due to these reactions are 42.3 and 62.3, respectively (Romanov et al. 1973). The dehydration of these hydrates will occur at temperatures above 411K (Romanov et al. 1973).

The electrical conductivities of the slags are lower than those of FMAS, as shown in Figure 7. Although not determined quantitatively, all of the slags exhibit significant ionic conductivity (Frederikse and Hosler 1973; Bates 1975; Simnad, Derge and George 1954), which probably decreases as the iron content increases.

The electrical conductivity of molten potassium sulfate and carbonate is shown in Figure 7 (Janz et al. 1968). These potassium salts have a higher electrical conductivity than does the FMAS. The potassium salts conduct almost totally by ions (Latiner 1952, Delimarskii and Markov 1961). 


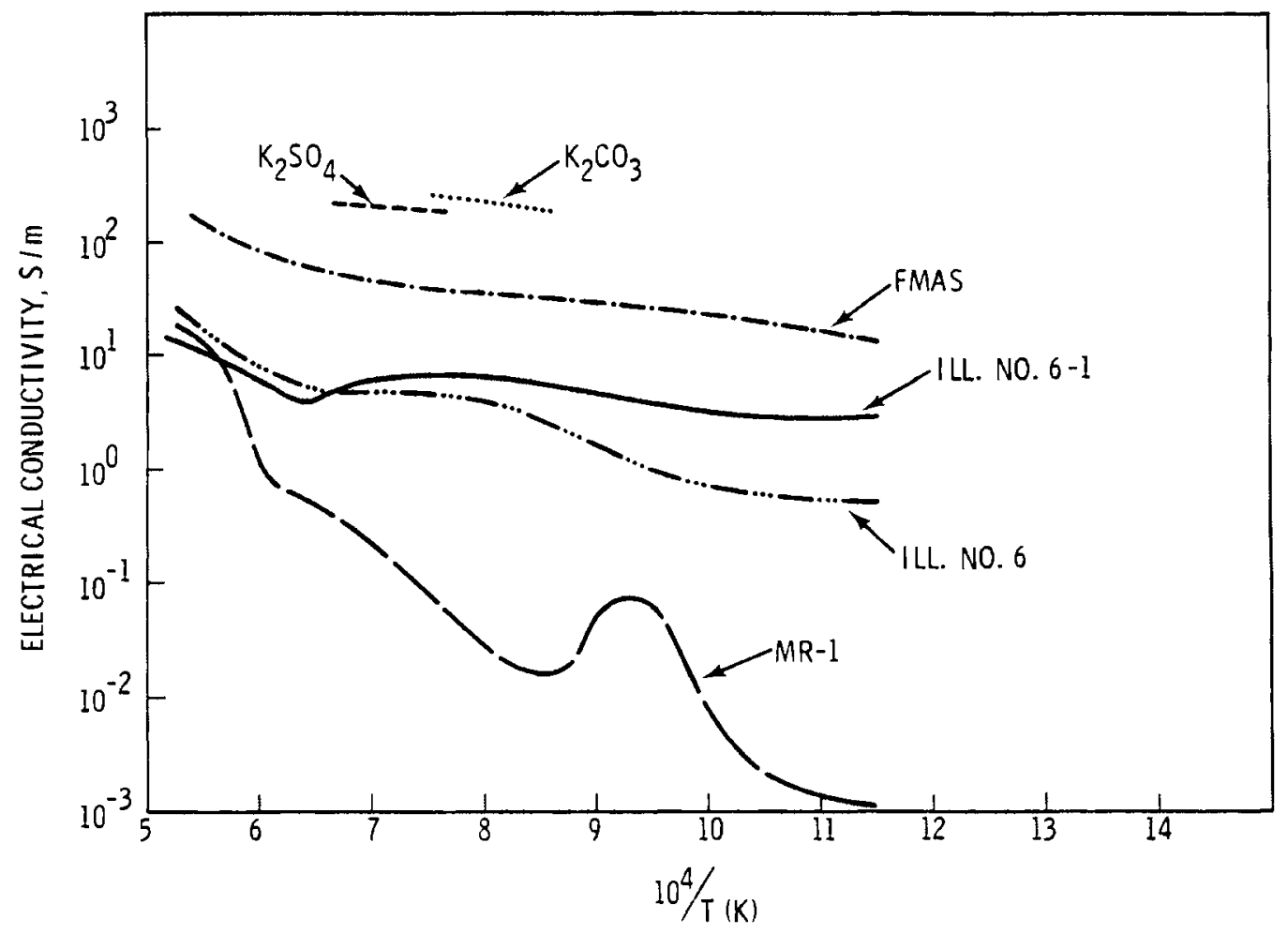

FIGURE 7. Electrical Conductivity of Coal Slag, Potassium Salts and FMAS in Air 


\section{RESULTS AND DISCUSSION}

A summary of the electrochemical tests done in both potassium salts and molten coal slag are listed in Table 4. Only those tests run under sufficiently similar conditions to allow comparisons are recorded in the table. The platinum probe results are not listed in the table but are discussed separately in the text. The current densities for those samples not surrounded by the alumina tubing are not listed in the table, but probably range between $0.6 \mathrm{~A} / \mathrm{cm}^{2}$ and $1.3 \mathrm{~A} / \mathrm{cm}^{2}$, depending on the area assumed to be included in the current transport.

The molten salt and coal slag results will be presented separately in the following text. Details of SEM-EDX compositional analyses are provided in the Appendix.

\section{ELECTROCHEMICAL TESTING IN POTASSIUM SALTS}

The tests in molten $\mathrm{K}_{2} \mathrm{SO}_{4}$ or $\mathrm{K}_{2} \mathrm{CO}_{3}$ were often complicated at the cathodes when the molten salt wetted and coated the sample surfaces above the level of the molten electrolyte. This coating of the cathode undoubtedly occurred because the negative charge of the cathode attracted the electrically conducting potassium ions. This surface coating often reached the platinum wire leads and conducted an unknown portion of the cathode current. Therefore, quantitative evaluations of current densities and corrosion rates are impractical and these rates are not included in Table 4. Examination of the resulting microstructures using SEM-EDX shows that the corrosion is at least as extensive as that found in the MR-1 coal slag. The extensive interaction occurred even though the test temperatures were lower than they were for coal slag.

Control

FMAS tested without electrical current in $\mathrm{K}_{2} \mathrm{CO}_{3}$ at $1373 \mathrm{~K}$ showed no weight loss after $24 \mathrm{~h}$. The $\mathrm{K}_{2} \mathrm{CO}_{3}$ penetrated the sample along the grain boundaries and interacted with the grains. After another $72 \mathrm{~h}$ the sample had fully corroded. Consequently, the corrosion rate is $<0.005 \mathrm{~g} / \mathrm{cm}^{2}-\mathrm{h}$ without electric 
TABLE 4. Electrochemical Test Summary

\begin{tabular}{|c|c|c|c|c|c|c|c|c|c|c|c|c|c|}
\hline \multirow{3}{*}{ Exp \# } & \multicolumn{3}{|c|}{ Electrolyte } & \multirow{3}{*}{$\begin{array}{c}\text { Temp., } \\
\mathrm{K} \\
\end{array}$} & \multirow{3}{*}{$\begin{array}{c}\text { Average } \\
\text { Current, } \\
\text { A }\end{array}$} & \multirow{3}{*}{$\begin{array}{l}\text { Time, } \\
\text { min. }\end{array}$} & \multirow{3}{*}{$\begin{array}{l}\text { Coul } \\
\left(10^{-6}\right)\end{array}$} & \multicolumn{4}{|c|}{ Corrosion Rate } & \multirow{2}{*}{\multicolumn{2}{|c|}{$\begin{array}{l}\text { Current } \\
\text { Density, } \\
\mathrm{A} / \mathrm{cm}^{2} \\
\end{array}$}} \\
\hline & Electrolyte & $\begin{array}{l}\text { mol\% } \\
\mathrm{K}_{2} \mathrm{O} \\
\end{array}$ & $\begin{array}{r}\mathrm{mo}_{1} \% \\
\mathrm{Fe}_{2}{ }_{2}-3\end{array}$ & & & & & \multicolumn{2}{|c|}{$\begin{array}{c}\text { mo } / \text { Coul. } \\
\left(10^{-6}\right) \\
\end{array}$} & \multicolumn{2}{|c|}{$\mathrm{g} / \mathrm{cm}^{2}-\mathrm{h}$} & & \\
\hline & & & & & & & & $\underline{c}$ & $\underline{A}$ & $\underline{c}$ & $\underline{A}$ & $\underline{c}$ & $\underline{A}$ \\
\hline 20 & $\mathrm{~K}_{2} \mathrm{CO}_{3}$ & 68 & NA & 1273 & 0.1 & 60 & 360 & - & - & - & - & (a) & (a) \\
\hline 22 & $\mathrm{~K}_{2}^{2} \mathrm{CO}_{3}$ & 68 & NA & 1273 & 0.05 & 60 & 180 & - & $<0.6^{(c)}$ & - & $<0.05^{(c)}$ & (a) & (a) \\
\hline 314 & $\mathrm{~K}_{2} \mathrm{CO}_{3}$ & 68 & NA & 1273 & 0.0 & 1440 & 0 & - & - & \multicolumn{2}{|c|}{$0.005^{(b, c)}$} & - & - \\
\hline 28 & $\mathrm{~K}_{2} \mathrm{SO}_{4}$ & 54 & NA & 1423 & 0.1 & 60 & 360 & - & 0.6 & \multirow{2}{*}{\multicolumn{2}{|c|}{$\begin{array}{r}0.05 \\
0.005^{(b, c)}\end{array}$}} & (a) & (a) \\
\hline 315 & $\mathrm{~K}_{2} \mathrm{SO}_{4}$ & 54 & NA & 1373 & 0.0 & 1440 & 0 & - & - & & & & - \\
\hline 21 & $M R-1$ & 10 & 3 & 1723 & 0.1 & 64 & 368 & 1.4 & 1.2 & 0.09 & 0.02 & (a) & (a) \\
\hline 42 & MR-1 & 10 & 3 & 1723 & 0.05 & 30 & 90 & 1.7 & 1.8 & 0.06 & 0.07 & (a) & (a) \\
\hline 23 & $M R-1$ & 10 & 3 & 1723 & 0.05 & 65 & 190 & 2.0 & 1.5 & 0.08 & 0.05 & (a) & (a) \\
\hline 41 & MR-1 & 10 & 3 & 1723 & 0.05 & 90 & 270 & 1.6 & 1.4 & 0.06 & 0.07 & (a) & (a) \\
\hline 36 & MR -1 & 10 & 3 & 1723 & 0.1 & 30 & 180 & 2.6 & 2.8 & 0.32 & 0.22 & (a) & (a) \\
\hline 38 & $M R-1$ & 10 & 3 & 1573 & 0.1 & 60 & 352 & 1.0 & 0.9 & 0.05 & 0.10 & (a) & (a) \\
\hline 43 & $M R-1$ & 10 & 3 & 1723 & 0.075 & 61 & 274 & 0.3 & 0.4 & 0.21 & 0.25 & 1.01 & 0.99 \\
\hline 44 & $M R-1$ & 10 & 3 & 1723 & 0.15 & 42 & 378 & 0.5 & 1.1 & 0.63 & 1.34 & 2.00 & 1.99 \\
\hline 46 & MR-1 & 10 & 3 & 1723 & 0.23 & 40 & 552 & 0.5 & 1.4 & 0.91 & 2.54 & 3.01 & 3.01 \\
\hline 26 & MR & 1 & 3 & 1723 & 0.1 & 39 & 234 & 2.6 & 1.9 & 0.36 & 0.19 & (a) & (a) \\
\hline 318 & MR & 1 & 3 & 1723 & 0.0 & 420 & 0 & - & - & \multicolumn{2}{|c|}{$0.03^{(b)}$} & - & - \\
\hline 27 & $M R-1$ & ${ }_{10}^{(e)}$ & 3 & 1723 & 0.1 & 63 & 378 & 0.9 & 0.9 & 0.08 & 0.09 & (a) & (a) \\
\hline 35 & $M R-1$ & 10 & 0 & 1723 & 0.1 & 31 & 186 & 2.8 & 2.4 & 0.25 & 0.21 & (a) & (a) \\
\hline 39 & MR-1 & 10 & 10 & 1723 & 0.1 & 41 & 246 & 0.5 & (d) & 0.05 & (d) & (a) & (a) \\
\hline 303 & $M R-1$ & 10 & 3 & 1723 & 0.0 & 1440 & 0 & - & - & \multicolumn{2}{|c|}{$0.007^{(b)}$} & - & - \\
\hline 33 & I $11-6-1$ & 10 & 12 & 1723 & 0.1 & 40 & 240 & 0.4 & 0.6 & & 0.07 & (a) & (a) \\
\hline 308 & {$[1]-6-1$} & 10 & 12 & 1273 & 0.0 & 1440 & 0 & - & - & \multicolumn{2}{|c|}{$0.003^{(b)}$} & & 0 \\
\hline
\end{tabular}

NA Not applicable.

(a) For those not surrounded by $\mathrm{Al}_{2} \mathrm{O}_{3}$ tube, the current density was between $0.6 \mathrm{~A} / \mathrm{cm}^{2}$ and $1.3 \mathrm{~A} / \mathrm{cm}^{2}$.

(b) Control--no current

(c) Measurement limit

(d) Anode lost

(e) $\mathrm{K}_{2} \mathrm{SO}_{4}$ seed.

current, and is significantly less than those for FMAS tested with an electric current. The initial corrosion mechanism appears to be the result of reactions along the grain boundaries. The boundaries are enlarged and the bonding between the grains weakens until they separate. The partially dissolved grain then sinks to the bottom of the crucible and further dissolves until test termination. 
Large intergranular cracks appear to be another major pathway for potassium penetration and interaction, resulting in larger polycrystalline pieces of FMAS separating from the original sample.

The microstructure of the sample after a 24-h anneal in potassium carbonate at $1273 \mathrm{~K}$ is shown in Figure 8 . The detailed compositional analysis of the several features identified in the figure is given in Table A.1 in the Appendix. The interior matrix grains appear unaffected by the potassium along the grain boundaries. The analyses of the grain boundaries (that probably include some of the matrix) show higher concentrations of aluminum and potassium than were found in the matrix. The surface of the sample contained a layer of reaction product $\sim 25 \mu \mathrm{m}$ thick. The reaction product layer covers the entire sample surface--even the surfaces not submersed in the electrolyte. The reaction product contains mostly iron, but has some aluminum, potassium and magnesium. The matrix next to the reaction product shows no change in composition. The sample is being uniformly corroded by the electrolyte. The high concentration of iron on the surface and of aluminum along the grain boundary may be due to 1) the preferential migration of iron from the grain boundaries
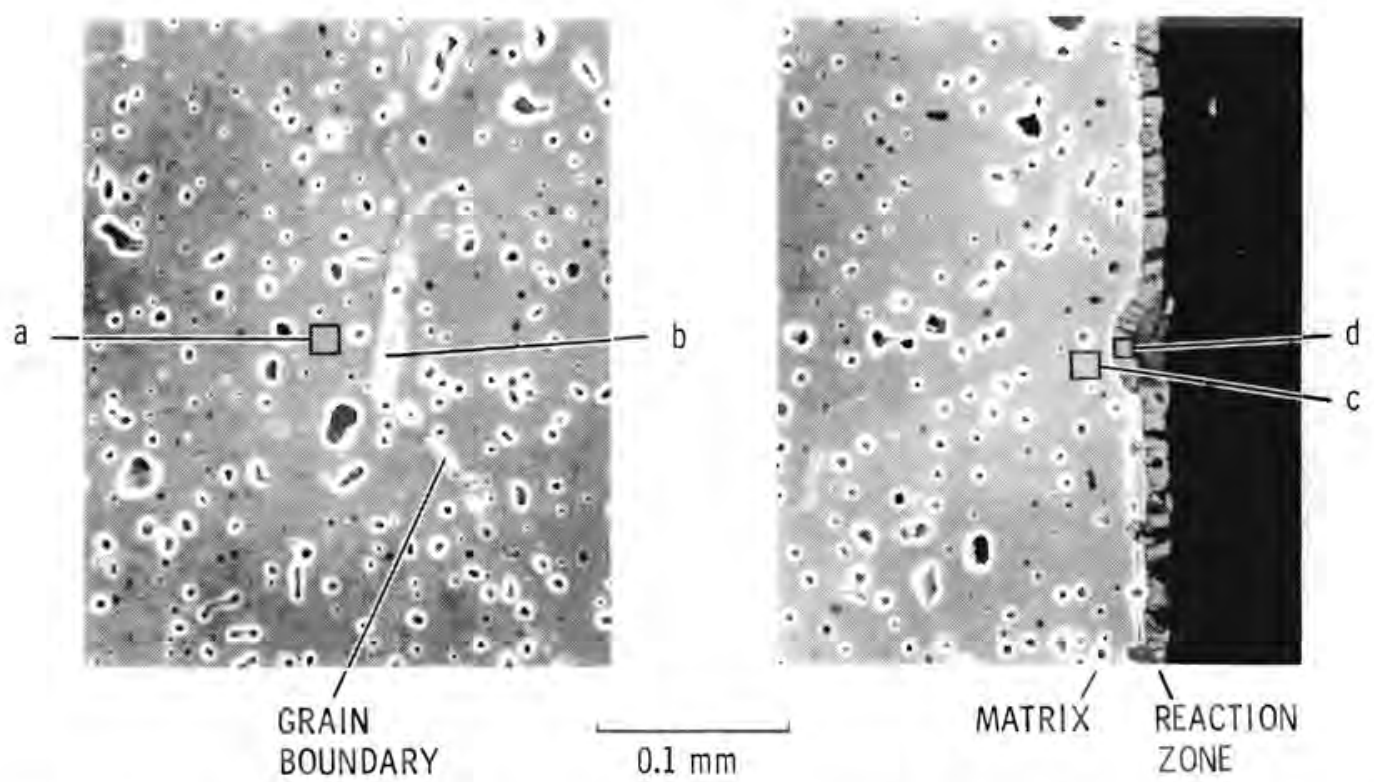

FIGURE 8. SEM Micrograph of FMAS Control After Corrosion Test in $\mathrm{K}_{2} \mathrm{CO}_{3}$ at $1273 \mathrm{~K}$ (Experiment 314) 
and deposition on the surface, or 2) a high solubility of aluminum in the electrolyte. The aluminum leaves the reaction product zone and dissolves in the bulk electrolyte. The electrolyte was not analyzed after the test for reaction products.

FMAS suspended in $\mathrm{K}_{2} \mathrm{SO}_{4}$ at $1373 \mathrm{~K}$ have reaction sequences similar to those suspended in the $\mathrm{K}_{2} \mathrm{CO}_{3}$, but the rate of reaction as measured by geometrical change in the samples is about the same as for $\mathrm{K}_{2} \mathrm{CO}_{3}$. The extent of interaction with the electrolyte as determined by SEM-EDX is greater than in $\mathrm{K}_{2} \mathrm{CO}_{3}$. Part of the increase in the extent of reaction may be due to the higher test temperature.

The microstructure of the sample after a $24-\mathrm{h}$ anneal in $\mathrm{K}_{2} \mathrm{SO}_{4}$ at $1373 \mathrm{~K}$ is shown in Figure 9. Detailed compositional analyses of the several features identified in the figure are given in Table A.2. Potassium sulfate has penetrated along the boundaries through the sample even in the areas not submersed in the electrolyte. The sulfur is only found along the grain boundaries and is associated with potassium. Sulfur was not associated with the potassium that interacted with the sample.

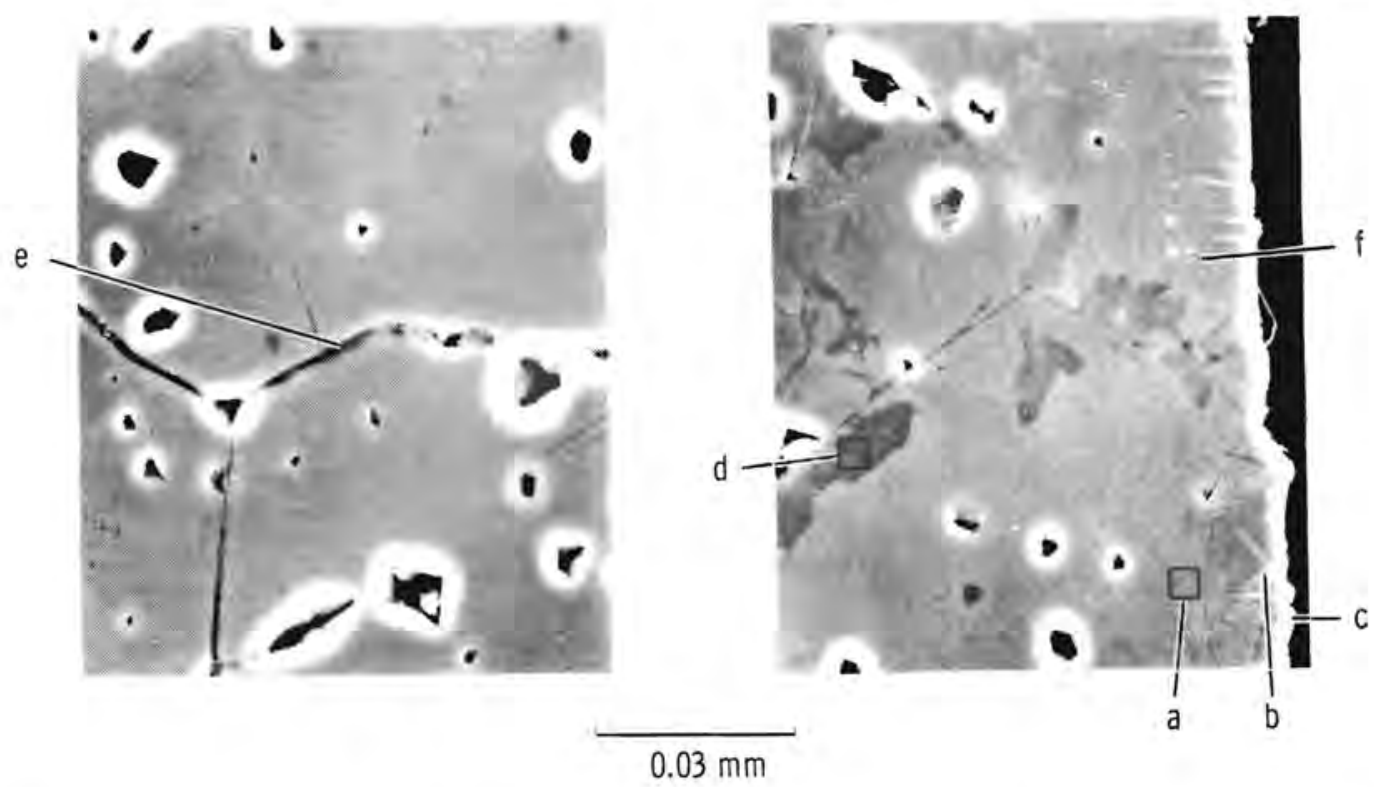

FIGURE 9. SEM Micrograph of FMAS Control After Corrosion Test in $\mathrm{K}_{2} \mathrm{SO}_{4}$ at 1423K (Experiment 315) 
Potassium interacted with the sample. The matrix near the reaction zone (Item 2, Table A.2) contained more potassium than did the matrix in the $\mathrm{K}_{2} \mathrm{CO}_{3}$ test at the same distance from the reaction zone (Item 3, Table A.1). The higher temperature of the test will increase the diffusion of potassium into the matrix. The potassium along the grain boundary interacted with selected areas, partially leaching the iron and leaving a high-aluminum-containing composition (Feature d, Figure 9; Item 5, Table A.2). The iron appears to deposit on the surface, as shown in $c$ of Figure 9 . This iron-rich deposit is not uniform along the surface, as it was in the $\mathrm{K}_{2} \mathrm{CO}_{3}$ test. A high-iron second phase (Feature b, Figure 9) found only in the FMAS at the exterior surfaces of the sample probably results from iron diffusion back into the sample from the ironcontaining deposits on the surface.

Although too small to be analyzed by SEM-EDX, the needle-like precipitates at the surface (Feature $f$, Figure 9) may be an iron-enriched phase that is a precursor to the formation of the iron-rich second phase in the matrix.

\section{Cathodes}

The electrochemical corrosion was more severe on the cathode than on the anode. The penetration of potassium salts is also more severe along the cathode grain boundaries. On removal from either the $\mathrm{K}_{2} \mathrm{SO}_{4}$ or $\mathrm{K}_{2} \mathrm{CO}_{3}$, the FMAS cathodes were bloated--particularly near and above the melt level, as can be seen in Figure 10. The bloating was observed at the higher temperatures immediately upon removal and before near-ambient temperature hydration of the potassium salts could occur. The bloating is caused by reactions of potassium salts along the grain boundaries. The electric potential and current transport in the electrolyte increases the concentration of cations (positive-charged potassium ions) near the cathode. The electric fields electrochemically increase the penetration of the molten salt along the grain boundaries. Since the electrical conductivity of the molten salt is greater than that of the cathode, the electric current will be primarily conducted by the molten salt and not by the portion of cathode submersed in the molten salt (Figure 10). 

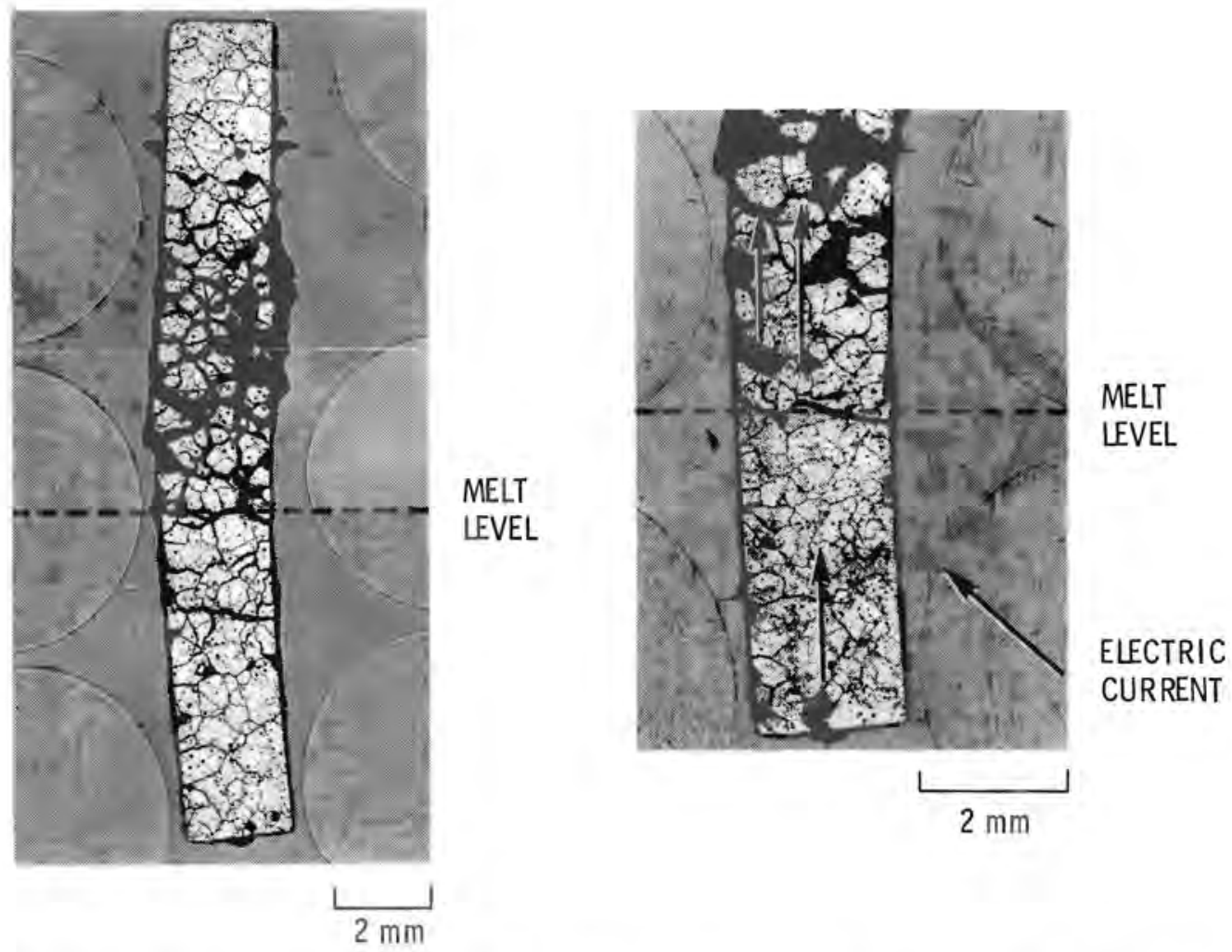

FIGURE 10. Optical Macrograph of FMAS Cathode After an Electrochemical Test in $\mathrm{K}_{2} \mathrm{CO}_{3}$ at $1273 \mathrm{~K}$ (Experiment 20)

Consequently, the current density in the electrode was higher in the area immediately above the level of the electrolyte than in the sample submersed in the electrolyte. Therefore, the penetration of and subsequent reaction with $\mathrm{K}_{2} \mathrm{CO}_{3}$ is greatest in the cathode immediately above the slag level.

The potassium salts migrate along the grain boundaries and probably react initially with the calcium and silicon impurities located along the grain boundaries. After reacting with the impurities at the grain boundaries, the potassium sait reacts electrochemically with the cathode grains. This reaction results in the exsolution of iron from the grains, forming a composition along the grain boundary enriched with iron. Inside the grains, an acicular-phase containing aluminium and potassium forms. The other new phase in the grain 
contains iron and magnesium. The result of the reaction was a loss of grain boundary integrity and the consequent unbonding of the grains and degradation of the sample.

The resulting microstructure from the reaction of the cathode with $\mathrm{K}_{2} \mathrm{SO}_{4}$ at $1423 \mathrm{~K}$ is shown in Figure 11. Like the tests in $\mathrm{K}_{2} \mathrm{CO}_{3}$, the sample is curved due to additional potassium salt deposits on the side closest to the anode where the current is being transferred between the electrode and electrolyte.

One difference was observed between the cathode attacked by $\mathrm{K}_{2} \mathrm{SO}_{4}$ and that subjected to $\mathrm{K}_{2} \mathrm{CO}_{3}$ : the portion of the cathode immersed in molten $\mathrm{K}_{2} \mathrm{SO}_{4}$ was often covered with a reddish deposit, whereas no deposit was observed on

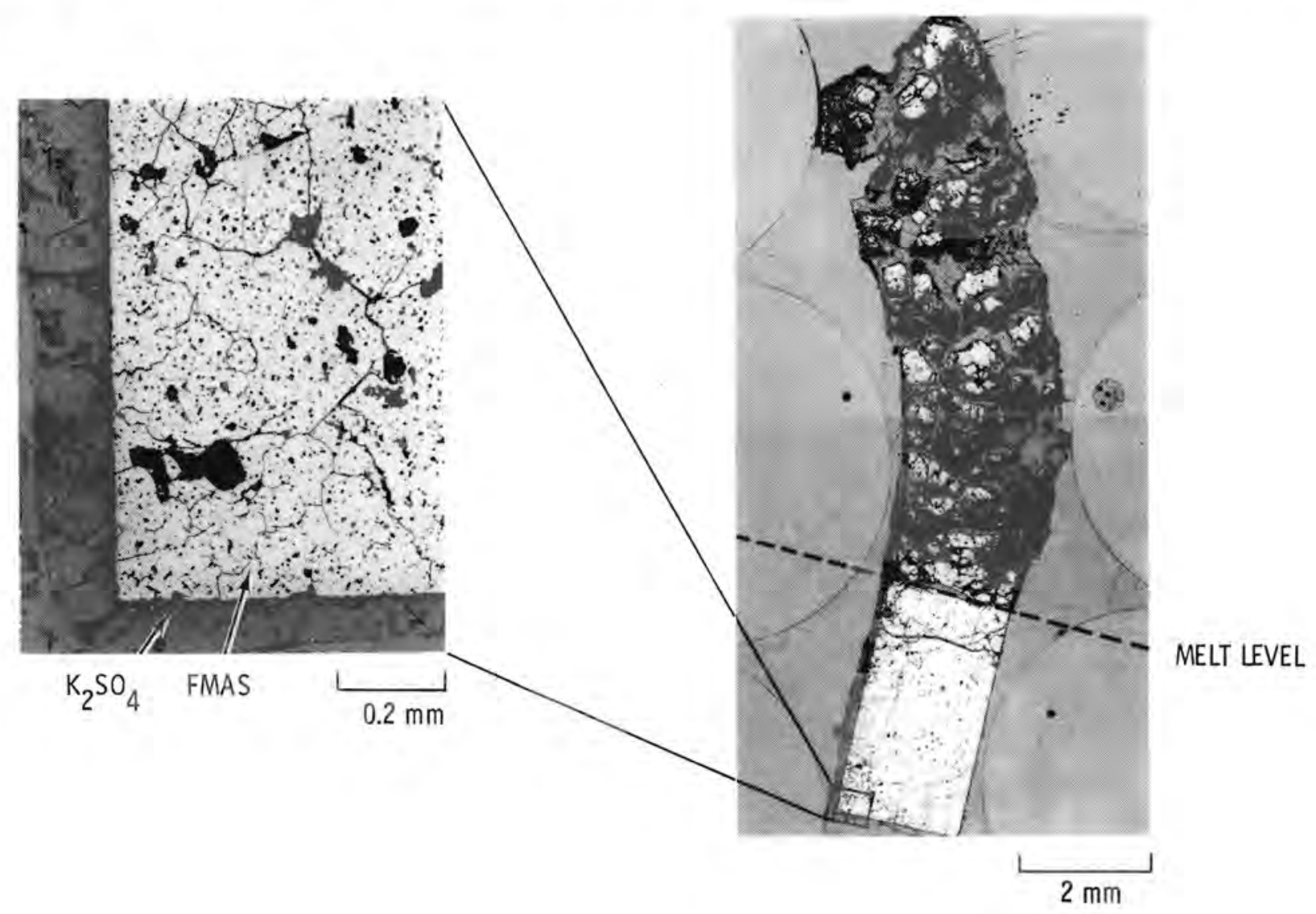

FIGURE 11. Optical Micrograph of the Cathode After an Electrochemical Test in $\mathrm{K}_{2} \mathrm{SO}_{4}$ at $1423 \mathrm{~K}$ (Experiment 28) 
the electrode immersed in $\mathrm{K}_{2} \mathrm{CO}_{3}$. Although the mode of charge transfer (e.g., the transfer of electrons from the cathode to the potassium ion) is probably the same, the red deposit may be caused by the oxidation of iron metal resulting from the exsolution of iron in the FMAS. This metal oxidized when exposed to air. The solubility of iron is higher in molten $\mathrm{K}_{2} \mathrm{CO}_{3}$; consequently, although formed at the surface, the iron dissolved and no red deposit formed.

In general, electrochemical corrosion in molten $\mathrm{K}_{2} \mathrm{SO}_{4}$ is more severe than in $\mathrm{K}_{2} \mathrm{CO}_{3}$. However, direct comparisons of the extent of corrosion between the two potassium salts are difficult, because the tests of sulfates are conducted at temperatures between $100 \mathrm{~K}$ and $150 \mathrm{~K}$ higher than the carbonate tests. In the vapor phase, $\mathrm{K}_{2} \mathrm{CO}_{3}$ is more reactive than is $\mathrm{K}_{2} \mathrm{SO}_{4}$, presumably because of the higher vapor pressure of the $\mathrm{K}_{2} \mathrm{CO}_{3}$. Potassium vapor interactions are more severe on the cathodes than on the anodes, as is expected, since the potassium may concentrate in the vapor near the cathode because of the electric potential.

On long-term experiments, potassium interactions with the platinum current leadouts were also observed. These interactions were possibly the result of the electrochemical reduction of the potassium ion at the cathode-platinum interface (forming potassium metal) and of the diffusion and alloying of the potassium metal with the platinum. Potassium metal begins to attack platinum at 673K (Hansen and Anderko 1958).

Two possible electrochemical reactions at the cathode result in the formation of free iron metal. In the first reaction, iron from the iron-containing spinel is directly reduced:

$$
\mathrm{Fe}^{++}+2 \mathrm{e}^{-} \ddagger \mathrm{Fe}
$$

Alternatively, since potassium ions are involved in the electrical transport in the electrolyte and in the charge transfer to the cathode, electrolysis of potassium ions to potassium metal can occur. The potassium metal (a strong reducing agent) then reduces the iron being exsoluted from the FMAS: 


$$
k^{+}+e^{-} \neq k,
$$

or

$$
2 y K+\mathrm{Fe}_{\mathrm{x}} \mathrm{O} y \neq \mathrm{xFe}+\mathrm{yk}_{2} \mathrm{O}
$$

Anodes

Bloating of the anodes did not occur during tests in either $\mathrm{K}_{2} \mathrm{SO}_{4}$ (Figure 12) or $\mathrm{K}_{2} \mathrm{CO}_{3}$ (Figure 13). However, the anodes below the melt level were white, compared to the originally black color. This whiteness extended into the sample to the same depth as the potassium and is associated with iron depletion.

In contrast to the cathode in the sulfate tests, relatively little $\mathrm{K}_{2} \mathrm{SO}_{4}$ was found along the grain boundaries. The electrochemical reactions are with the grains. As shown in Figure 12, the surface exposed to the $\mathrm{K}_{2} \mathrm{SO}_{4}$ melt had reacted to depths of from 0.1 to $0.3 \mathrm{~mm}$.

The several features in the micrograph in Figure 12 were analzyed using the SEM-EDX. The results of the quantitative analysis are listed in Table A.3. The compositions subsequently referred to are determined by the relative concentrations of the elements in the quantitative analysis and are rounded to whole integers of the analyzed cations and anions.

The unreacted matrix even as close as $50 \mu \mathrm{m}$ from the reaction zone (Figure 12) has the same composition as does the bulk matrix. The reaction zone contains acicular grains of an $\mathrm{Fe}_{2} \mathrm{O}_{3} \cdot \mathrm{Al}_{2} \mathrm{O}_{3}$ solid solution (1:1 ratio) containing some potassium and sulfur. Phase-equilibrium data for the $\mathrm{Fe}_{2} \mathrm{O}_{3} \cdot \mathrm{Al}_{2} \mathrm{O}_{3}$ system (Levin, Robbins and McMurdie 1969) show that at temperatures above 1591K, $\mathrm{Fe}_{2} \mathrm{O}_{3} \cdot \mathrm{Al}_{2} \mathrm{O}_{3}$ (a $1: 1$ ratio) forms a single-phase solid solution in an air atmosphere. In an aluminum-rich composition the single phase is in equilibrium with iron-rich $\mathrm{Al}_{2} \mathrm{O}_{3}$. Below this temperature the phase equilibrium consists of two solid-solution phases: 1) $\mathrm{Fe}_{2} \mathrm{O}_{3}$ (hematite) with up to $15 \% \mathrm{Al}_{2} \mathrm{O}_{3}$, and 2) $\mathrm{Al}_{2} \mathrm{O}_{3}$ with up to $25 \% \mathrm{Fe}_{2} \mathrm{O}_{3}$. This lower-temperature, two-phase equilibrium 


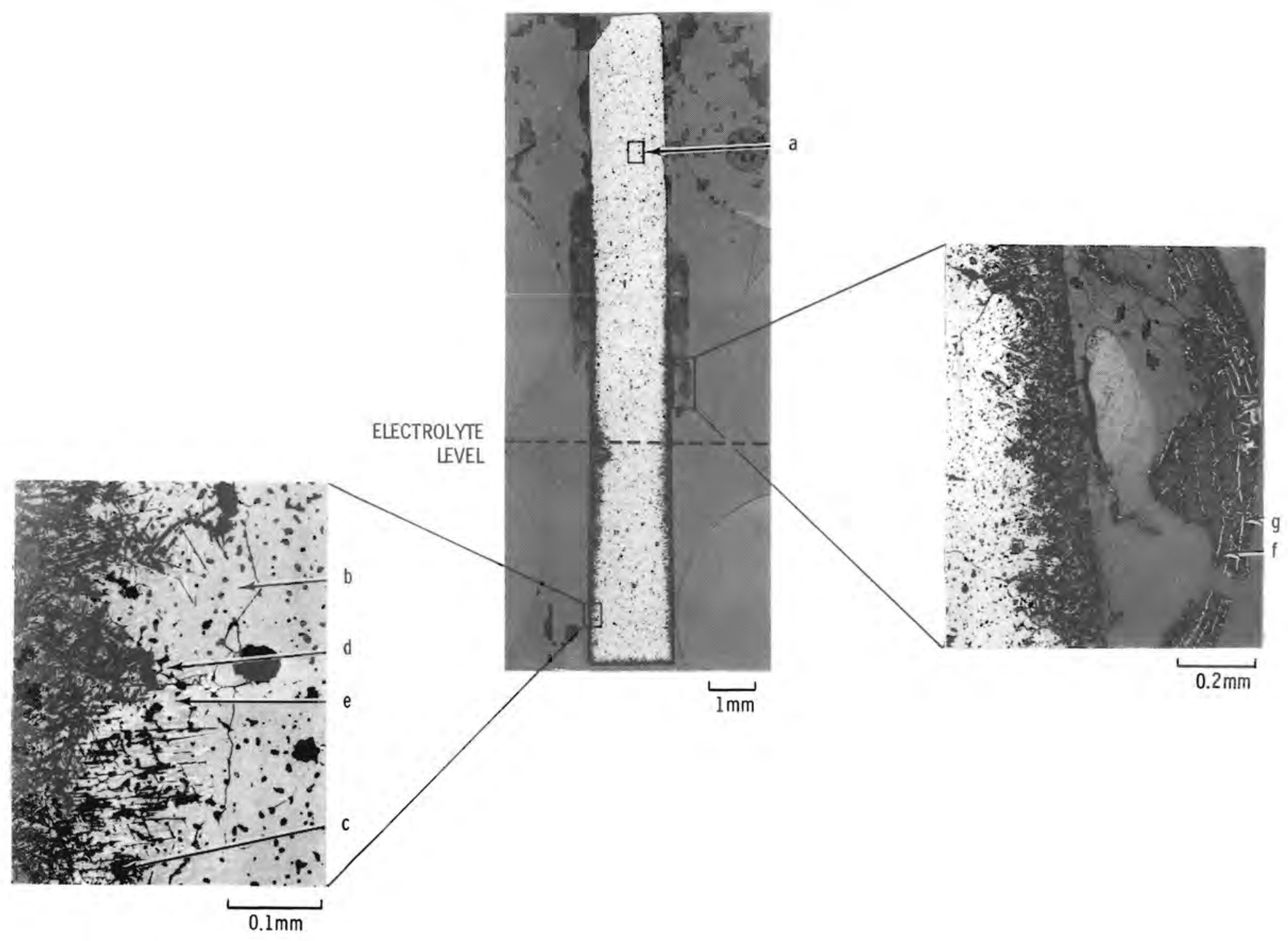

FIGURE 12. Anode After and Electrochemical Test in $\mathrm{K}_{2} \mathrm{SO}_{4}$ at $1423 \mathrm{~K}$ 

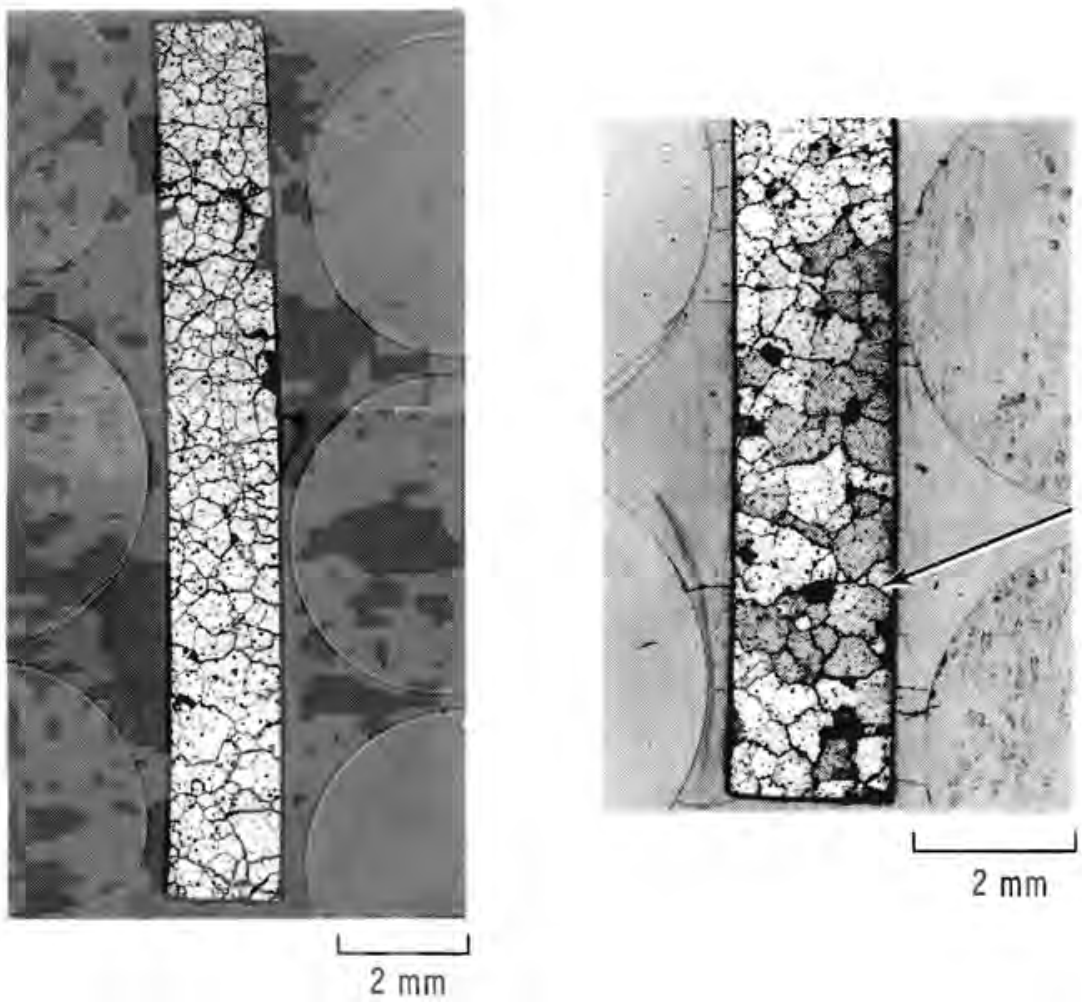

POTASSIUM

ALONG GRAIN

BOUNDARIES

FIGURE 13. Optical Micrograph of Anode After an Electrochemical Test in $\mathrm{K}_{2} \mathrm{CO}_{3}$ at $1273 \mathrm{~K}$ (Experiment 20)

is not found in the reaction zone of the anode. Instead, an acicular phase of $\mathrm{Fe}_{2} \mathrm{O}_{3} \cdot \mathrm{Al}_{2} \mathrm{O}_{3}$ solid solution (1:1 ratio) is found growing into the matrix. Between the acicular phase the matrix is high in aluminum and low in iron. These two phases are similar to the phase equilibrium above $1591 \mathrm{~K}$ for an aluminum-rich composition. The magnesium in the matrix complicates the comparison of the phases in the anode to that predictable by the equilibrium-phase data for the $\mathrm{Fe}_{2} \mathrm{O}_{3} \cdot \mathrm{Al}_{2} \mathrm{O}_{3}$ system. The electrolyte in the reaction zone is $\mathrm{K}_{2} \mathrm{SO}_{4}$ that contains small amounts of the matrix material. In general, $\mathrm{Fe}$ and $\mathrm{Mg}$ are removed from the matrix, leaving a white-colored (visual examination) surface layer. Iron is not as soluble in $\mathrm{K}_{2} \mathrm{SO}_{4}$ as is $\mathrm{Mg}$; consequently, an iron-rich deposit is found in the electrolyte. Magnesium probably forms soluble magnesium sulfate and disperses into the electrolyte. 
The charge transfer at the anode in molten $\mathrm{K}_{2} \mathrm{SO}_{4}$ is postulated to result from the reduction of the sulfate ions--generating sulfur-oxide and/or oxygen gas, e.g.,

$$
\mathrm{SO}_{4}^{=}=\mathrm{SO}_{\mathrm{x}}(\mathrm{g})+\frac{4-\mathrm{x}_{0}}{2} \mathrm{O}_{2}(g)+2 \mathrm{e}^{-} \text {. }
$$

The stresses developed due to nucleation-cavitation of the gas can add to the anode loss as a result of mechanical erosion.

The electrons from the reaction in Equation 6 could reduce the $\mathrm{Fe}^{+++}$to $\mathrm{Fe}^{++}$. The sulfur-oxide gas can then react with the reduced iron ions, forming iron-sulfur compounds; for example:

$$
2 \mathrm{SO}_{2}(\mathrm{~g})+\mathrm{Fe}^{++}=\mathrm{FeS}+\mathrm{SO}_{2}(\mathrm{~g})+\mathrm{O}_{2},
$$

or

$$
\mathrm{SO}_{3}(\mathrm{~g})+\mathrm{FeO}=\mathrm{FeSO}_{4}
$$

It is therefore possible that the iron is leached from the FMAS anode, forming iron sulfate or an iron-potassium compound found in the surface deposits above the electrolyte level. These surface deposits form a reddish brown-black (like hematite) crust (visual) that contained a lath-shaped phase of iron oxide with some aluminum. The phase boundary for maximum solubility of alumina in iron is around 9 at\% (Levin, Robbins and McMurdie 1969), as found in this deposit.

In contrast with $\mathrm{K}_{2} \mathrm{SO}_{4}$, the potassium in molten $\mathrm{K}_{2} \mathrm{CO}_{3}$ penetrates along the grain boundaries, attacking the grain boundaries and weakening the structure (Figure 13).

In studies with platinum electrodes (Smirnov, Tsiovkina and 0lienikova 1966), four mechanisms of charge-transfer between the platinum and molten 
$\mathrm{K}_{2} \mathrm{CO}_{3}$ electrolyte have been proposed. The reactions are given in order of increased electric potential and consequent current density (Table 5). The current density and electric potential are only relative and will not necessarily apply to the test configuration used for the FMAS test. The reactions identified for platinum electrodes may be similar to those for FMAS, since FMAS is an electronic conductor with little oxygen permeability. Some oxygen may be pulled from compounds in the lattice, thereby increasing the lower current density reactions. For the FMAS, the electrochemical charge transfer reaction is probably

$$
\mathrm{CO}_{3}^{=} \rightarrow \mathrm{CO}_{\mathrm{x}}(\mathrm{g})+\frac{3-\mathrm{x}_{0}}{2} \mathrm{O}_{2}(\mathrm{~g})+2 \mathrm{e}^{=} .
$$

The product gas (especially $\mathrm{CO}$ or $\mathrm{CO}_{2}$ ) is less reactive than are the gases of sulfur and neither $\mathrm{CO}$ nor $\mathrm{CO}_{2}$ form new compounds with iron or magnesium, leading to selective leaching from the sample. The iron is not leached from the grains. No acicular phase of $\mathrm{Al}_{2} \mathrm{O}_{3} \cdot \mathrm{Fe}_{2} \mathrm{O}_{3}$ is found at the reaction zone as it was in the $\mathrm{K}_{2} \mathrm{SO}_{4}$ tests. The material losses at the anodes are mostly at the reaction interface, where the stresses caused by gas nucleationcavitation or even gravity lead to the erosion and removal of the grains weakened by grain-boundary attack of the $\mathrm{K}_{2} \mathrm{CO}_{3}$. The SEM-EDX does not detect

TABLE 5. Mechanisms of Charge Transfer Between Potassium Carbonate and Platinum

\begin{tabular}{|c|c|c|}
\hline Reaction & $\begin{array}{r}\text { Current } \\
\text { Density } \\
\text { Range, } \mathrm{A} / \mathrm{cm}^{2} \\
\end{array}$ & $\begin{array}{c}\text { Electric } \\
\text { Potential, V } \\
\end{array}$ \\
\hline $0+2 \mathrm{e}^{-} \rightarrow 0_{\text {melt }}^{2-}$ & $<10^{-3}$ & $<1.46$ \\
\hline $\mathrm{CO}_{3}^{2-}+4 \mathrm{e}^{-} \rightarrow \mathrm{C}_{\mathrm{s}}+30_{\mathrm{melt}}^{2-}$ & $10^{-3}$ to $10^{-2}$ & $1.48-1.88$ \\
\hline $\mathrm{CO}_{3}^{2-}+2 \mathrm{e}^{-} \rightarrow \mathrm{CO}+20_{\text {me } 1 \mathrm{t}}^{2-}$ & $10^{-2}$ to $10^{-1}$ & $1.88-2.4$ \\
\hline $\mathrm{K}^{+}+\mathrm{e}^{-} \rightarrow \mathrm{K}$ & $0.4-1$ & $>2.4$ \\
\hline
\end{tabular}


carbon; consequently, the chemical form of the potassium along the grain boundaries cannot be determined.

\section{ELECTROCHEMICAL TESTING IN COAL SLAGS}

Overa 11

Evaluation of the electrochemical tests shows relationships between corrosion rate and the experimental parameters of 1) time, 2) current density, 3) temperature, 4) slag-iron content, and 5) slag-potassium content. The relationships are summarized below--followed by a review of possible slag reactions. Details concerning microstructural and chemical composition changes are then described for various test conditions.

\section{Effect of Time}

The corrosion at $1723 \mathrm{~K}$ in MR-1 slag increased with time at constant current density $\left(1 \mathrm{~A} / \mathrm{cm}^{2}\right)$, as is shown in Figure 14. The percent of corrosion, when compared with the initial amount of material present, is shown as a function of time. The rate of corrosion, not shown in this figure but related to the corrosion percentage, was initially greater for the anode than for the cathode; however, as the time increased, the corrosion rate for the anode remained approximately constant, while that of the cathode increased, then

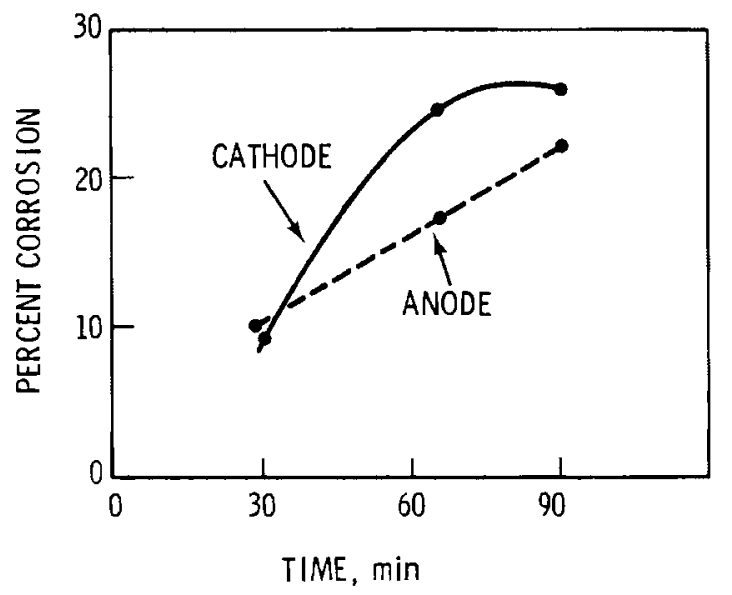

FIGURE 14. Percent Corrosion in MR-1 Slag as a Function of Time, $1 \mathrm{~A} / \mathrm{cm}^{2}, 1723 \mathrm{~K}$ 
decreased. The decrease may be due to the buildup of reaction products at the cathode. At the anode the reaction products are generally swept away by the motion of the slag caused by gas bubble generation and migration.

Effect of Current Density

The corrosion rate in MR-1 slag at $1723 \mathrm{~K}$ increased with current density, as shown in Figure 15; at $1 \mathrm{~A} / \mathrm{cm}^{2}$ it was approximately the same for both electrodes. The corrosion rate of the anode increased much more rapidly than did that of the cathode as the current density increased to $3 \mathrm{~A} / \mathrm{cm}^{2}$. However, part of the corrosion rate increase for the anodes may be affected by the corrosion of the $\mathrm{Al}_{2} \mathrm{O}_{3}$ sleeve and the subsequent interaction of the sleeve and anode at current densities of between 2 and $3 \mathrm{~A} / \mathrm{cm}^{2}$.

\section{Effect of Temperature}

The rate of corrosion increased with temperature (Figure 16), with a very rapid increase between $1723 \mathrm{~K}$ and $1773 \mathrm{~K}$. The samples were tested in $M R-1$ coal slag with a current density of $1 \mathrm{~A} / \mathrm{cm}^{2}$. Both the anode and cathode exhibit similar temperature effects.

\section{Effect of Slag/Iron Content}

The rate of corrosion decreased as the iron content of the slag (expressed as $\mathrm{Fe}_{2} \mathrm{O}_{3}$ ) increased (Figure 17). An addition of $10-\mathrm{mol}_{\mathrm{F}} \mathrm{Fe}_{2} \mathrm{O}_{3}$ decreased the

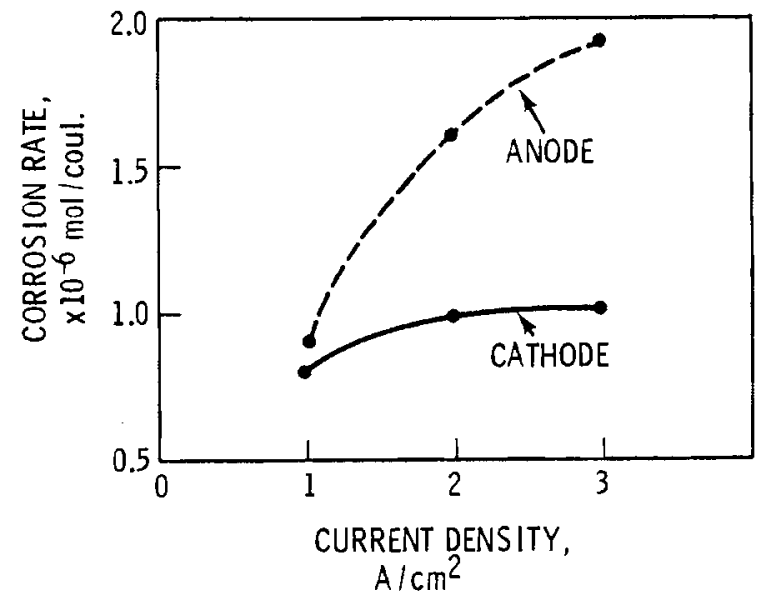

FIGURE 15. Corrosion Rate in MR-1 Slag as a Function of Current Density, 1723K 


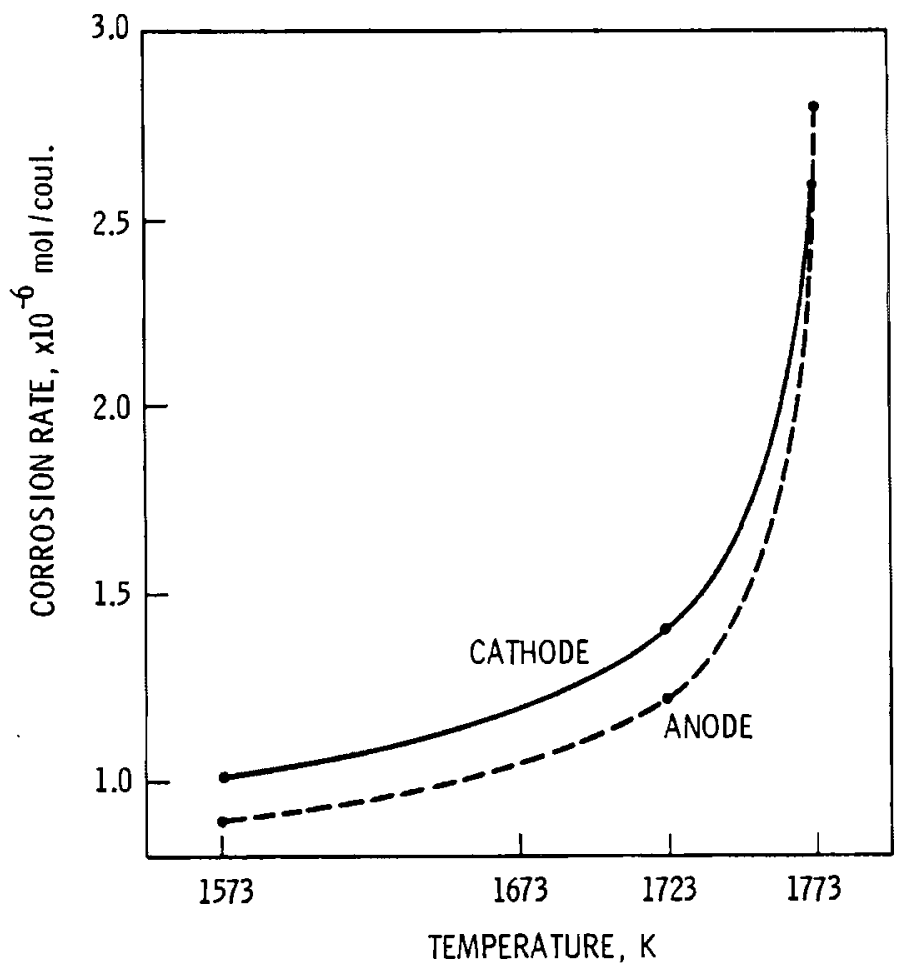

FIGURE 16. Corrosion Rate in MR-1 as a Function of Temperature, $1 \mathrm{~A} / \mathrm{cm}^{2}$

corrosion rate by a factor of 5 to 7 . This decrease appeared to be independent of other variations (except potassium seed) in slag composition since an Illino is No. 6 and Montana Rosebud coal slag with similar iron concentrations corroded at about the same rate. The corrosion rate as a function of iron content for the anodes and cathodes was nearly the same, although the anode corrosion rate was generally lower.

\section{Effect of Slag/Potassium Content}

The corrosion rate of both anodes and cathodes decrease with the addition of potassium to the slag (Figure 18). The decrease in corrosion rates cannot be explained. The addition of up to 10 -mol\% potassium, either as $\mathrm{K}_{2} \mathrm{SO}_{4}$ or $\mathrm{K}_{2} \mathrm{CO}_{3}$, resulted in a decrease.

Sulfur was not detected in the slag seeded with $\mathrm{K}_{2} \mathrm{SO}_{4}$. The sulfur was probably driven off on heating. This would explain the equal laboratory 


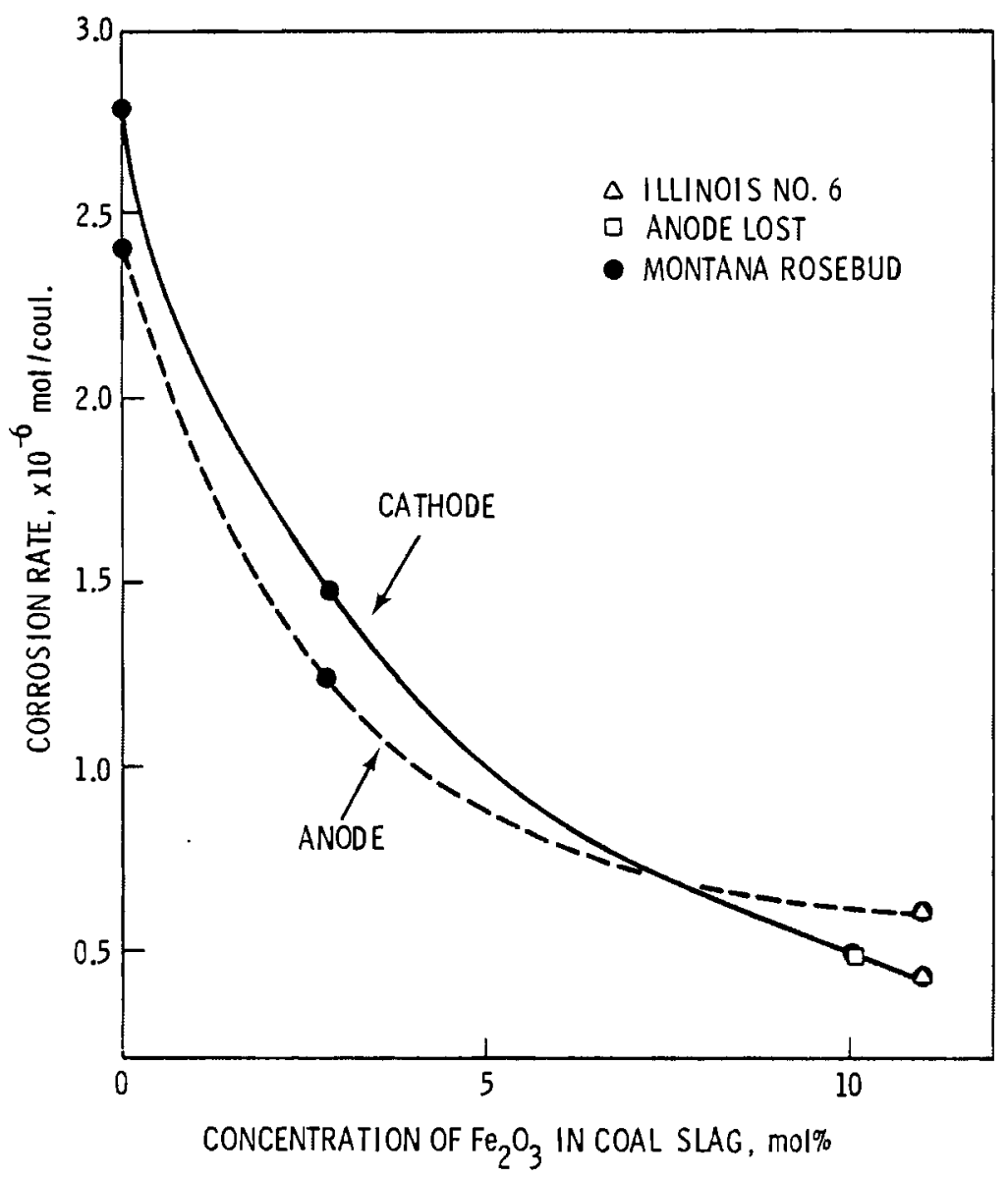

FIGURE 17. Corrosion Rate in Slag as a Function of Slag $\mathrm{Fe}_{2} \mathrm{O}_{3}$ Content, $1 \mathrm{~A} / \mathrm{cm}^{2}, 1723 \mathrm{~K}$

corrosion rates for slag seeded with $\mathrm{K}_{2} \mathrm{CO}_{3}$ or $\mathrm{K}_{2} \mathrm{SO}_{4}$. The effect of the seed anion may be different in an MHD channel, for in a channel the anion overpressure may be sufficient to keep the anions in solution in the coal slag. In the laboratory tests the sulfur overpressure is low, resulting in the evaporation of sulfur compounds.

The increased electrochemical corrosion appears to be complex, with different processes occurring at the anode and cathode. Increased corrosion of and differences between the cathode, anodes and controls caused by electrochemical effects are listed in Table 6 and can be seen in Figure 19. The iron metal (a), the bubbles (b), the $\mathrm{Fe}_{2} \mathrm{O}_{3}$-MgO phase (c), and the slag phases (d) are shown. Details concerning the chemical analysis of the phases will be 


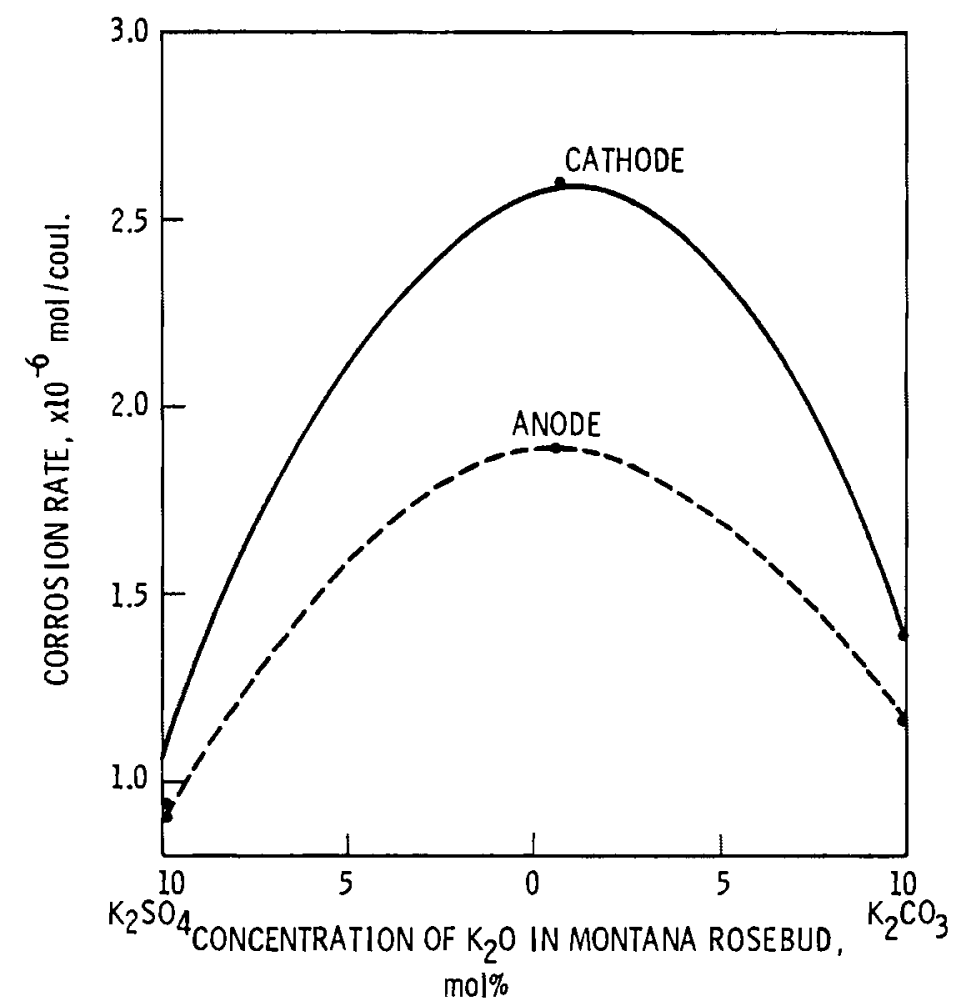

FIGURE 18. Corrosion Rate in Slag as a Function of Slag Potassium Content, $1 \mathrm{~A} / \mathrm{cm}^{2}, 1723 \mathrm{~K}$

given later in the report as the several tests are described. Analysis of the test results have led to hypothesizing slag reactions that may be occurring.

Based upon the results sumarized in Figures 13 through 17, in Table 6, and from the characterization of electrodes and slag from a number of electrochemical tests, some possible reactions can be postulated. These reactions are discussed in the next section.

\section{Overall Reactions}

In the low-iron-containing slags, metallic iron is found at cathode/slag interfaces, along grain boundaries, and in pores. The iron is formed by reduction reactions at the interface. The quantity of metallic iron produced is related to the total amount of current transferred and to the rate of current transfer. However, the amount of iron remaining at the end of the test 
TABLE 6. Observations and Explanations of Features Found in the Cathode and Anode During Electrochemical Testing in Coal Slags

\begin{tabular}{|c|c|c|c|}
\hline \multicolumn{2}{|r|}{ Cathode } & \multicolumn{2}{|c|}{ Anode } \\
\hline Observations & Explanations & Observations & Explanations \\
\hline Iron metal detected & $\begin{array}{l}\text { - Reducing conditions } \\
\text { - Low } \mathrm{PO}_{2}\end{array}$ & No metal detected & $\begin{array}{l}\text { - Oxidizing conditions } \\
\text { - High } \mathrm{PO}_{2}\end{array}$ \\
\hline $\begin{array}{l}\text { Slag penetration } \\
\text { of the grain } \\
\text { boundaries }\end{array}$ & $\begin{array}{l}\text { - Reaction with impurities } \\
\text { - Enhanced by dc field } \\
\text { - Possibly: } \\
\text { - wetting affect } \\
\text { - viscosity affect } \\
\text { - greater chemical } \\
\text { reactivity at the } \\
\text { grain boundaries }\end{array}$ & $\begin{array}{l}\text { Less slag penetration } \\
\text { of grain boundaries } \\
\text { than cathode }\end{array}$ & $\begin{array}{l}\text { - Cations repelled by } \\
\text { anode, therefore } \\
\text { less cation reaction } \\
\text { with impurities }\end{array}$ \\
\hline $\begin{array}{l}\mathrm{Fe}-\mathrm{Mg} \text { phase } \\
\mathrm{Fe} \text { depletion of FMAS }\end{array}$ & $\begin{array}{l}\text { - Precipitated on cooling } \\
\text { - Diffusion into the slag } \\
\text { electrochemically } \\
\text { increased }\end{array}$ & $\begin{array}{l}\text { No } 2 \text { nd-phase formation } \\
\text { No Fe depletion }\end{array}$ & $\begin{array}{l}\text { - Different reactions } \\
\text { occurring at the } \\
\text { anode vs cathode }\end{array}$ \\
\hline $\begin{array}{l}\text { Two slag phases } \\
\text { high Ca, high } \mathrm{K}\end{array}$ & $\begin{array}{l}\text { - Cations migrate towards } \\
\text { cathode }\end{array}$ & $\begin{array}{l}\text { One slag phase: } \\
\text { slight Ca depletion } \\
\text { and no } K \text { depletion } \\
\text { of the slag }\end{array}$ & $\begin{array}{l}\text { - Mixing action from } \\
\text { bubble generation }\end{array}$ \\
\hline Bubbles & $\begin{array}{l}\text { - Reduction of iron oxide } \\
\text { - Migration from a high } \\
\mathrm{Po}_{2} \text { (anode) to low } \mathrm{PO}_{2}\end{array}$ & Bubbles & $\begin{array}{l}-\quad \text { oxidation }-\mathrm{O}_{2} \text { gas } \\
\text { generation } \\
\mathrm{SiO}_{4}=\mathrm{SiO}_{2}+\mathrm{O}_{2}(\mathrm{~g}) \\
+4 \mathrm{e}^{-}\end{array}$ \\
\hline
\end{tabular}

may be considerably less than that produced during the test, since the tests are run in air and reoxidation of the iron will occur--especially if long annealing periods are allowed between metal formation and quenching. The rate of reoxidation depends upon a variety of conditions including test geometry, distance between metal and slag/air interface, and the amount of movement of the slag. Consequently, other test conditions may not result in post-test metallic iron, even though iron was formed during the test. The same reduction reactions may occur with other elements, but the reoxidation may be so rapid that the metallic specie is not observed--as may be the case with potassium or sodium.

The source of the metallic iron appears to be both the FMAS and the slag. The relative amounts from each source depend upon such variables as 1) relative iron activity in the slag and FMAS, 2) relative electrical conductivity of slag and FMAS, 3) the degree of ionic and electronic conduction of the 


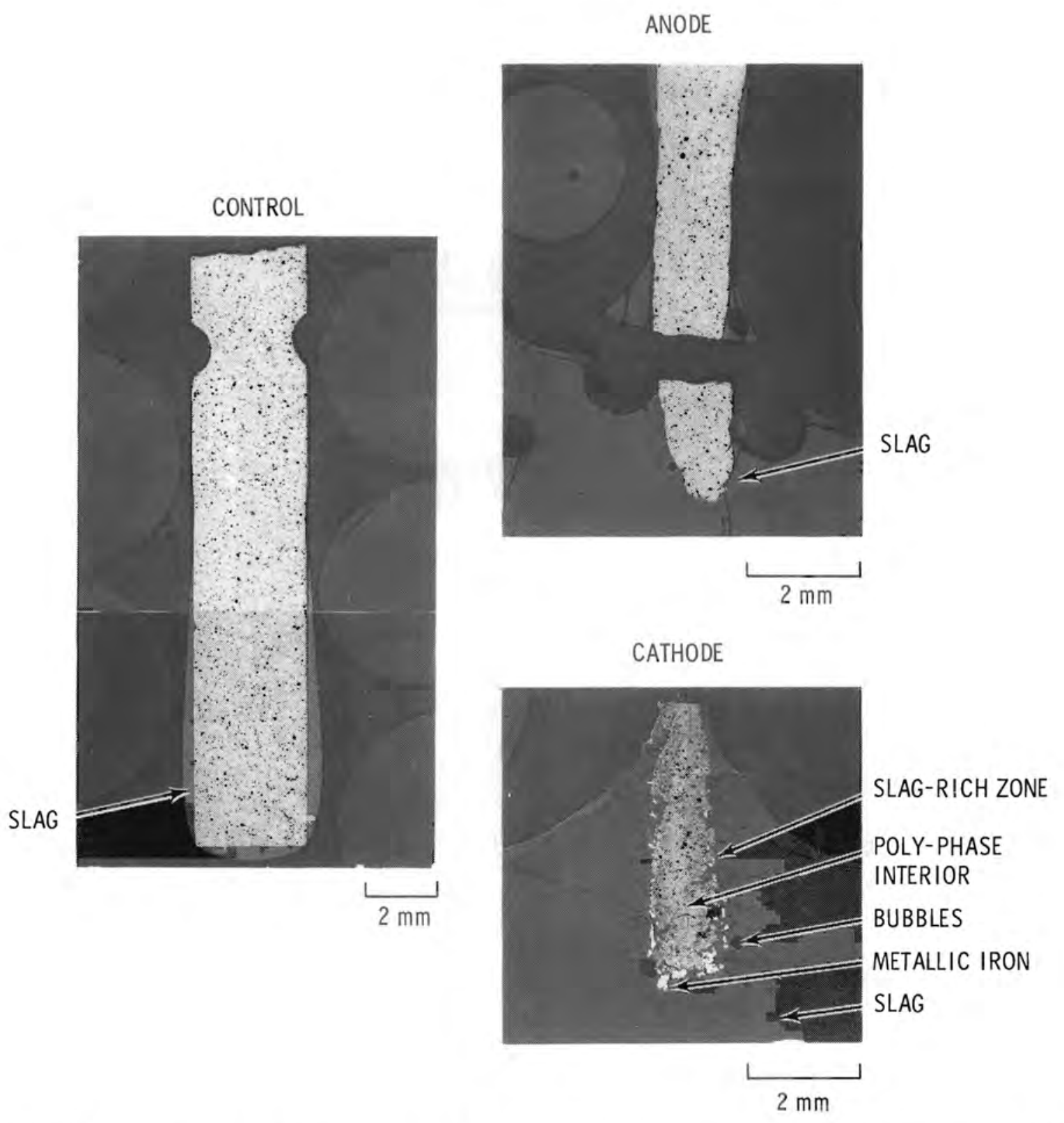

FIGURE 19. Anode, Cathode, and Control (no current) After a Test in MR-1 at $1723^{\circ} \mathrm{C}$

slag, 4) the difference in the ionic and electronic conductivity of the slag compared to the cathode, and 5) potassium content of the slag. 
In an electrochemical test in an iron-free slag, the metallic iron that formed came solely from the FMAS. In this test, iron was only found along the cathode grain boundaries, where iron had leached from the matrix. Possibly potassium concentrating at the cathode due to the current transport may have contributed to the leaching of the iron. Greater amounts of metallic iron were found in this test than in the tests with the iron-containing coal slags.

The charge transfer from the cathode to the slag takes place electrochemically by the reduction of chemical specie(s) in the electrolyte. The electrochemical series does not exist for coal slags; the closest data is for single solid and molten oxides (Hamer 1965) and lead silicates (Didtschenko and Rochow 1954). Use of the aqueous electrochemical potentials (Latiner 1952) represents a severe approximation.

From the experimental results (i.e., the formation of metallic iron) a favorable reduction species is the $\mathrm{Fe}^{+3}$ or $\mathrm{Fe}^{+2}$ ion. The ions could be reduced directly by the equations

$$
F e^{3+}+e^{-}=F e^{2+}
$$

and

$$
F e^{2+}+2 e^{-}=F e
$$

The ions could also be reduced by reaction with another specie that was reduced and has a stronger electrochemical potential to oxidize. For instance, part of the electron transfer from the FMAS to the slag may be accomplished through the reduction of alkali ions--i.e., potassium or sodium ions. Reduction of potassium ion to potassium metal would result in a very strong reducing agent. The potassium metal could immediately reduce the iron ions, as shown in the reactions

$$
k^{+}+e^{-} \rightarrow k
$$

and 


$$
\mathrm{K}+\mathrm{Fe}^{3+} \rightarrow \mathrm{K}^{+}+\mathrm{Fe}^{2+}
$$

Consequently, reduced potassium is not found in the microstructure--only the reduced iron. Without further experimentation it is not possible to determine the mode of charge transfer between the slag and the cathode, nor to identify the actual reduction reactions.

In the electrochemical tests a fixed amount of current needs to be transferred between the cathode and $\mathrm{slag}$. If sufficient $\mathrm{Fe}^{3+}$ ions exist at the interface, the charge transfer will mainly be by reduction of the iron ions. If insufficient $\mathrm{Fe}^{3+}$ exists, other reduction reactions must occur, as proposed in Equations 12 and 13.

The absence of iron metal in high-iron slags suggests that sufficient $\mathrm{Fe}^{3+}$ ions are available to handle the current transfer by Equation 10. Furthermore, the slag conduction was more electronic. Consequently, the current transport in the slag is mostly by the electron transfer identified in Equation 10. The electronic conductivity of coal slags has been observed to increase as the iron content increases (Simnad, Derge and George 1954; Yen 1977). The higher the electronic transference, the fewer the cations pulled to the cathode. If potassium reduction is required to initiate $\mathrm{Fe}$ formation Equations 12 and 13), then less iron metal will form at the cathode, since less potassium will be reduced in the electronic conducting slag.

A few bubbles were observed in the slag near the cathode and at the grain boundaries of the cathode. These bubbles are probably oxygen gas, possibly resulting from the reduction of iron compounds in the slag:

$$
\begin{aligned}
\mathrm{Fe}_{2} \mathrm{O}_{3} & \rightleftarrows 2 \mathrm{FeO}+1 / 2 \mathrm{O}_{2}(\mathrm{~g}), \\
\mathrm{FeO} & \neq \mathrm{Fe}+1 / 2 \mathrm{O}_{2}(\mathrm{~g})
\end{aligned}
$$

The mechanism of corrosion at the cathode appears to be a combination of grain-boundary penetration by the slag and the electrochemical formation of the iron metal, iron-magnesium compounds, and gas bubbles. As the slag 
penetrates the cathode and reacts with the surfaces of the grains, the strengths of the grain boundaries are reduced. The grain boundaries may also be widened by the increased volume required for some reaction products, making the grain boundaries more susceptible to further grain-boundary penetration and chemical reaction. Finally, the grain erodes easily away due to the weakened intergrain bonds and is incorporated into the slag. If slag penetration of the grain boundaries within the cathode can be minimized (e.g., by removing reactive impurities, increasing the intergranular bonding, or by adding material to those grain boundaries whose reaction products restrict further slag penetration), the life of the cathode in an MHD channel could be prolonged.

Slag/Anode

The anode was not depleted in iron, as was found in the cathode. Although slag had penetrated the anode along the grain boundaries, the anode remained single-phase. Increased amounts of iron found in the slag below the anode are presumably the result of solution of the anode. There was a lack of corrosion products at the anode surfaces because the reaction products were gases, were easily dissolved in the slag, or were moved by slag motion caused by the generation and migration of gas bubbles. The lack of corrosion products made it difficult to evaluate the corrosion process.

Gas bubbles were often observed at the anode surfaces. During testing, gas bubbles would escape from the anode surface and boil out of the slag. The number of bubbles generated depended on the current density and the degree of ionic conductivity in the slag. These bubbles are believed to be oxygen gas generated by the charge transfer from the slag to the anode by

$$
0^{--} \rightarrow 1 / 2 O_{2}(g)+2 e^{-}
$$

or

$$
\mathrm{SiO}_{2} \rightarrow \mathrm{Si}+1 / 2 \mathrm{O}_{2}
$$


The generation of oxygen created a region of high oxygen pressure around the anode. The source of the $\mathrm{O}^{--}$in Equation 16 is probably $\mathrm{SiO}_{4}{ }^{=}$(Simnad, Derge and George 1954), instead of $\mathrm{CO}_{3}{ }^{=}$or $\mathrm{SO}_{4}{ }^{2}$. The latter two anions probably vaporized as the slag was heated to $1723 \mathrm{~K}$.

From Faraday's Law (Latiner 1952), the amount of oxygen generated at the cathode is proportional to the quantity of ionic charge being transferred. The high-iron slags have a higher electronic transference than do the low-iron slags; consequently, more electric current can be passed electronically without causing gas bubbles to form. The greater proportion of electronic conduction leads to less oxygen-gas generation, less erosion caused by bubble formation and migration, and subsequently a lower corrosion rate for the anode.

Although the corrosion rates of the cathode and anode are approximately equal at low current densities $\left(\leq 1 \mathrm{~A} / \mathrm{cm}^{2}\right)$, the anode appears to retain its integrity better than does the cathode. At higher current densities ( $>1 \mathrm{~A}$ ) $\mathrm{cm}^{2}$ ), the rate of generation of oxygen gas increases. This increased generation rate may cause the slag to "boil," thereby increasing the mechanical erosion and resulting in the increased anode corrosion rates at high temperatures.

\section{ELECTROCHEMICAL CORROSION}

The remainder of the report summarizes the microstructural analysis and the phase chemical analysis by SEM-EDX for several of the tests. Also included are comparisons between the tests.

Electrochemical Corrosion in MR-1 at $1723 \mathrm{~K}$

Experiment 21 represents the reference electrochemical corrosion test-i.e., MR-1 electrolyte at $1723 \mathrm{~K}$ and an electrode current density of approximately $1 \mathrm{~A} / \mathrm{cm}^{2}$. The control was run separately to eliminate the effects of the electric fields. The control results are discussed first, followed by those obtained from the cathode and anode. 


\section{Control}

The control was partially submerged in the electrolyte for $24 \mathrm{~h}$. The polished cross section in Figure 20 shows the generally uniform corrosionerosion of the sample as evidenced by the reduced cross section. From Table 4, the corrosion rate is about an order of magnitude lower than either the anode or cathode. The SEM-EDX analysis of several features in the figure is given in Table A.4 of the Appendix. Overall, both the FMAS and the slag remain single-phase. The reference area (approximately $1.7 \mathrm{~cm}$ above the electrolyte level) did not have slag components along the grain boundary. No reaction zone was observed on the control surface above the obvious reaction zone that lies immediately above the slag level. No iron depletion of the electrode surface in the reaction-free area was measured due to exposure to air at 1723K for $24 \mathrm{~h}$.

Included in Figure 20 is a micrograph of the polished area in the reaction zone. The slag next to the reaction zone has not changed from the bulk slag. The FMAS material that dissolved into the slag is removed from the interface both by chemical diffusion and by the bulk migration resulting from slag convection currents.

Although slag penetration is found along the grain boundaries near the immediate interface, the corrosion reaction appears to be at the grain/slag interface. The interface consists of rough, angular protrusions; these protrusions indicate varied reaction rates along differing crystallographic orientations. The composition of the FMAS at the interface shows a leaching of the iron and a small amount of silicon and calcium incorporation. The effect of the diffusion of iron can be seen further into the grain $(\sim 130 \mu \mathrm{m})$ by the small depletion of iron. Silicon and calcium impurities have also diffused into the FMAS to this distance. At a distance of $\sim 520 \mathrm{\mu m}$ from the reaction zone no iron depletion (and hence no diffusion) has occurred. Some calcium and potassium impurity has migrated into the FMAS in this area.

\section{Cathode/Slag}

The post-test microstructure of cathode and anode (Figure 21) show several phases in the cathode that are not in the anode. The slag at the cathode is 


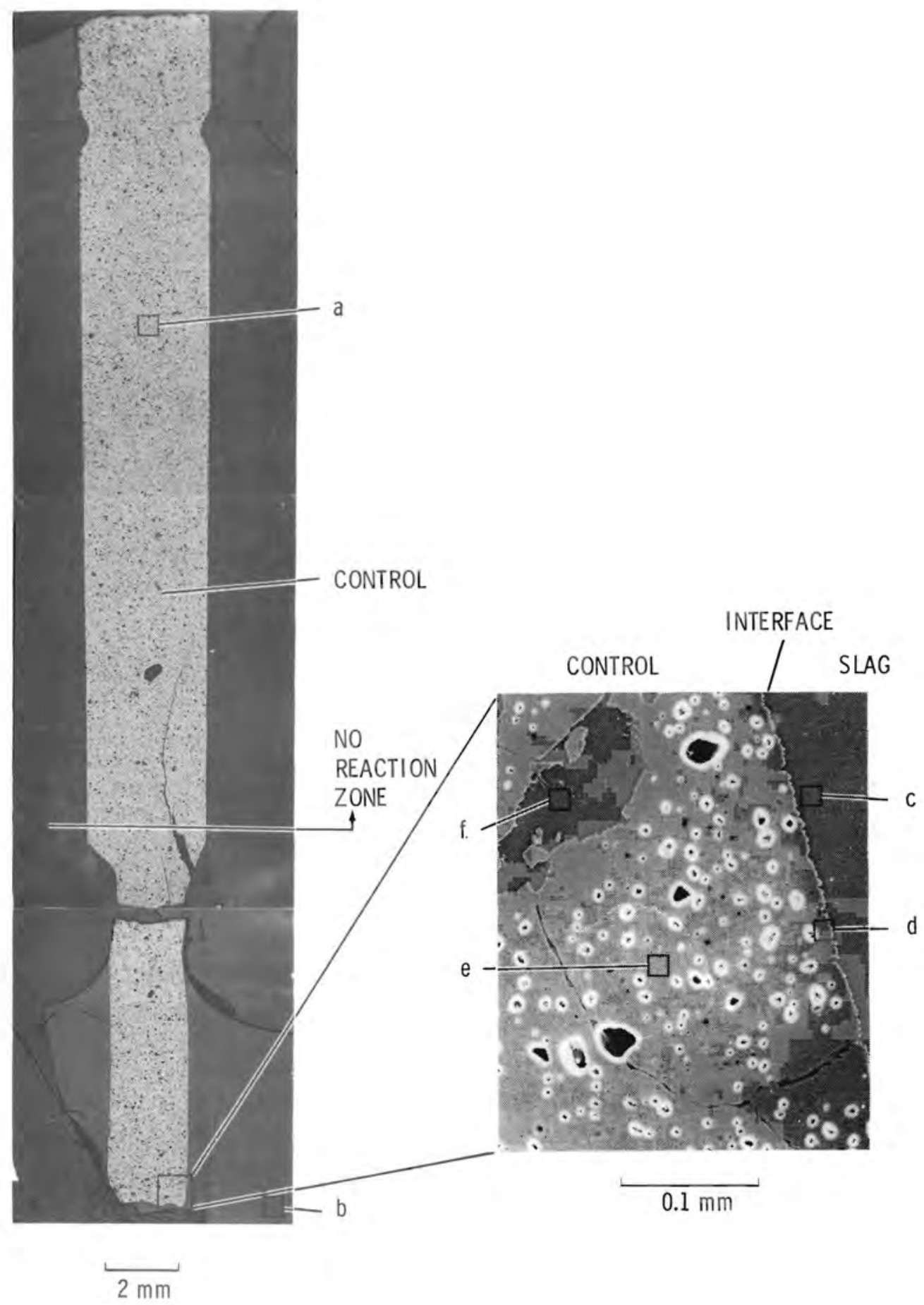

FIGURE 20. Macrograph and Micrograph of Control Tested in MR-1 Slag, 1723K, $24 \mathrm{~h}$ (Experiment 303) 
multiphase, as compared to the single-phase slag at the anode and in the bulk slag away from either the anode or cathode. The SEM-EDX chemical composition of various features of Figure 21 is given in Table A.5.

The degree of accuracy obtained with the SEM-EDX quantitative analys is is illustrated by comparing the composition of the slag calculated by using the initial mixing of components (Item 1, Table A.5) to the SEM-EDX analysis (Item 2).

The slag composition at the cathode-slag interface had altered because of the migration of the doubly charged magnesium and calcium cations. The concentration of calcium and magnesium was $84 \%$ and $81 \%$, respectively, greater than the respective concentrations in the bulk. (Increase in concentration cannot be fully determined from Table A.5, since the table is expressed in atom\% and not absolute amounts of each atomic specie). Both of these ions, being doubly charged, migrated more slowly than did the singly charged potassium and were consequently not as likely to redistribute as rapidly during cooldown after the electric fields are removed. The potassium decrease may be due to vaporization. The iron-oxide content in the area of the slag had decreased, but the decrease appeared to be the result of metallic iron precipitate formations not included in the area analysis. The overall iron content of the slag, including precipitates, probably increased slightly.

The small amounts of magnesium and aluminum in the metallic iron found in the slag near the cathode/slag interface and along grain boundaries where slag is analytically insignificant (Items 9 and 10, Table A.5). In contrast to the particles along grain boundaries, the metallic particles in the slag were partially oxidized. As expected, the metallic iron is only found in the slag where current is being transferred between cathode and slag. Of course, this transfer will occur at grain boundaries filled with slag. Consequently, any degrading reactions occurring via current transfer will only be increased by slag penetration along grain boundaries.

The slag along the grain boundaries was also multiphase, as was the slag near the slag interface. The multiphases are due to excess concentration of cation species. A granular oxide phase was found intermixed in the cathode in 

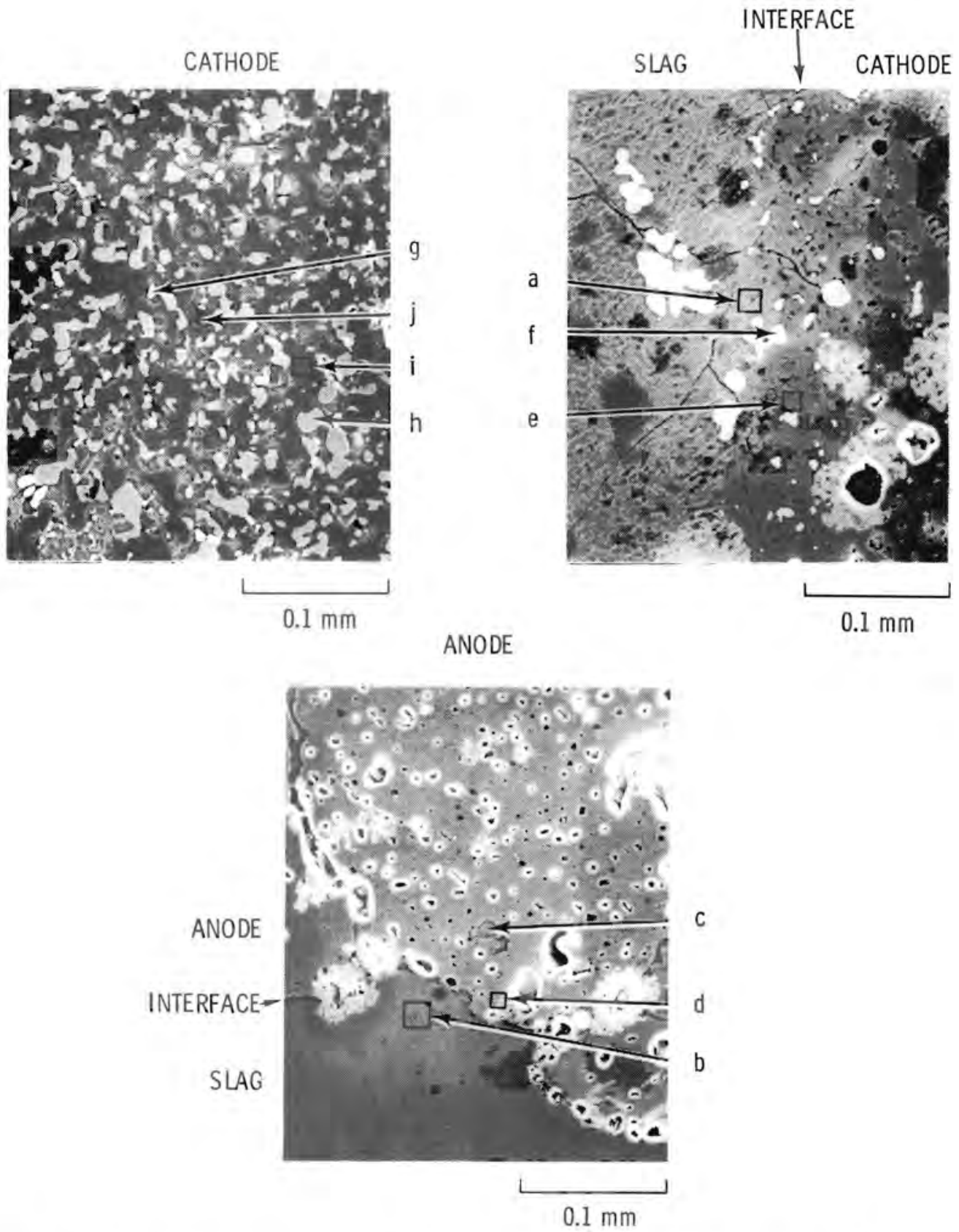

FIGURE 21. Scanning Electron Micrographs of Anode and Cathode in MR-1, 1723K (Experiment 21)

that portion of the sample immersed in the electrolyte and involved in current transport. The second phase was always found in areas of slag/electrode interfaces--i.e., at grain boundaries and amid porosity. This oxide phase 
(Item 11, Table A.5) is probably Fe0-MgO solid solution. The reduced oxide state is assumed, since the oxygen content determined by differences in the SEM-EDX analysis is lower in this phase than the oxygen content in the FMAS matrix. Equilibrium phase relations show that Fe0-MgO form a complete solid solution (commonly called magnesiowustite). If the iron is in the oxidized state $\left(\mathrm{Fe}_{2} \mathrm{O}_{3}\right)$ as expected in an air environment, the equilibrium phase relationship is a two-phase mixture of magnesiowustite and magnesioferrite $\left(\mathrm{MgO} \cdot \mathrm{Fe}_{2} \mathrm{O}_{3}\right)$. This two-phase equilibrium was not observed.

The matrix grains next to the magnesiowustite second phase are partially depleted in iron and magnesium. The slag (along grain boundaries and pores) adjacent to the metal precipitate and the magnesiowustite has an iron content similar to that of the untested slag. Therefore, the iron in both the metallic and magnesiowustite phase appears to come mainly from the spinel and not from the slags, even though these phases appear to be growing in the slag. Part of the electrochemical degradation of the electrode seems to include dissolution of magnesium and iron from the FMAS, leaving the more resistant $\mathrm{Al}_{2} \mathrm{O}_{3}$. Perhaps the reduced iron in the spinel does not have as high a solubility and is exsoluted from the matrix. The iron then reacts with the reduced cations formed from current transport and further reduces to the metallic state. Some of the exsoluted $\mathrm{FeO}$ may also react with the spinel matrix, forming the magnesiowustite. The resulting high-alumina-containing grain may further degrade because of its higher electrical resistivity (joule heating). The high resistivity may also force more current to channel along grain boundaries than through the grains.

As expected, the aluminum, potassium and magnesiun concentrations in the grain boundary slag are higher. These slag components are driven into the cathode via elecric fields. The effect of the elecric field is greatest on potassium and magnesium, for they are more mobile and consequently will contribute more to the conductivity than will silicon or even aluminum. Therefore, potassium and magnesium are expected to be found concentrated in the grain-boundary slag. The effect of the additional cation concentration on 
the wetting behavior or viscosity is unknown, although additional cations probably should decrease the viscosity by breaking up the larger Si-0 bonding chains in the slag.

\section{Anode/Slag}

The slag at the anode/slag interface (Item 4, Table A.5), unlike that at the cathode/slag interface, is single-phase. The concentration of calcium had decreased by 34 wt\%, with the magnesium and potassium concentration remaining nearly constant. However, the compositional analysis of the slag at the interface may be misleading, due to the continual agitation and motion of the slag along the electrode/slag interface caused by the formation and migration of gas bubbles. The motion and agitation will lead to mixing with the bulk slag. Also, potassium diffuses rapidly in the slag and may have re-equilibrated during cooldown after the electric current was eliminated. The slag found in internal pores may better reflect the slag composition at the slag/ anode interface, for this slag was at the immediate interface during current transport prior to migrating into the pores. The slag composition inside the pores (Item 5; Table A.5) exhibited the following decreases over the bulk slag composition: 69 wt\% magnesium, 43 wt\% potassium, and $23 w t \%$ calcium. The iron content has not changed.

The anode composition near the slag interface is single-phase and is simi1 ar to the composition before testing (compare Item 7 to Item 6, Table A.5). The anode surface appears to be corroding/eroding uniformly, with on $1 y$ minor penetration of slag along grain boundaries. The corrosion/erosion mechanisms may be due to arcing between slag and electrode and to erosion caused by bubble formation and migration during current transport.

Electrochemical Corrosion in I11-6-1 at 1723K

Experiment 33 is representative of tests in $111-6-1$ coal slag. The electrochemical corrosion rate in this slag was less than in MR-1. This coal slag has a higher iron content and lower calcium content than does MR-1. The inside surfaces of the alumina crucibles above the bulk level are wetted by the 
I17-6-1 slag. This extensive wetting is not found in MR-1 slag. On cooldown the slag always appeared polyphase, with crystalline phases nucleating and growing throughout the slag. The control was run separately to eliminate the effects of the electric field. The control results will be reviewed first, then the cathode and anode data will be discussed.

\section{Control}

The control was partially submerged in the electrolyte for $24 \mathrm{~h}$. The control corroded uniformly in the slag. The slag also penetrated along the grain boundaries. This penetration is more extensive than in the control sample tested in MR-1 slag. The microstructure of the control-slag interface and inside the control is shown in Figure 22. The SEM-EDX analysis of the several features in Figures 22 is given in Table A.6 of the Appendix.

The slag along the grain boundaries has reacted with the grains, as is evidenced by the widened grain boundaries. The slag is enriched in magnesium and partially depleted in both iron and potassium as compared to the composition of the bulk slag away from the control samples. The potassium and iron are probably migrating into the grains. The small amount of material migrating into the matrix from the grain boundary is probably less than can be detected in the matrix by the SEM-EDX analysis. The matrix next to the grain boundary does not show an increase in either the iron or potassium content.

The extent of iron depletion in the slag is determined by the time the slag is at the grain boundaries. The slag found at grain boundaries $\sim 1.2 \mathrm{~mm}$ from the slag-control interface contains $\sim 10$ atom\% iron compound to slag $0.5 \mathrm{~mm}$ for the interface, which contains 3 atom\% iron.

At the slag-control interface, both the slag and the matrix are altered. The slag is devoid of second phase and is partially depleted of iron. The second phase is an iron-rich precipitate. The low iron content may be close to the equilibrium concentration between the slag and the control. The control matrix next to the slag is enriched in iron and contains small amounts of silicon, calcium, and potassium. The grains at the interface are separating 


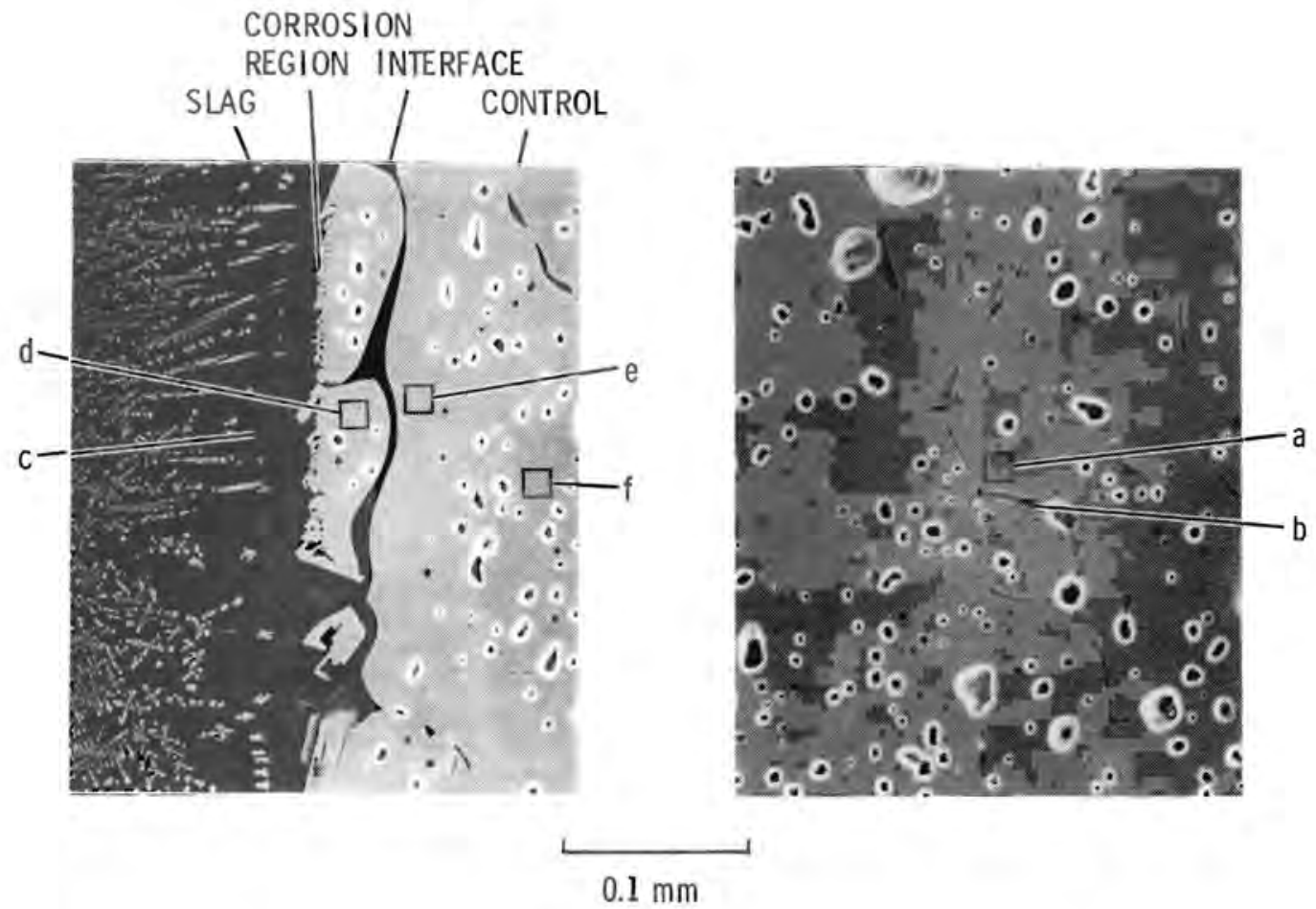

FIGURE 22. Control Tested in I1l-6-1 Slag for $24 \mathrm{~h}$ at $1723 \mathrm{~K}$ (Experiment 308)

from the control due to grain-boundary interactions. Also, the grains are being uniformly corroded, as is shown by the corrosion region on the surface of the grains.

Since external electric fields are not present during the control test, the migration of cations and the reduction of cations at the electrode-slag interfaces are not observed. The control remained single-phase during the corrosion. The change in composition of the slag is due to diffusion of species into the matrix and the dissolution of the matrix into the slag.

\section{Cathode/Slag}

The post-test cathode and anode microstructures are shown in Figure 23. The SEM-EDX-determined chemical compositions for the several features of the figure are in Table A.7.

The slag at the cathode/slag interface was two-phase, with dendritic crystalline growth surrounded by the glassy matrix. The growth occurred 

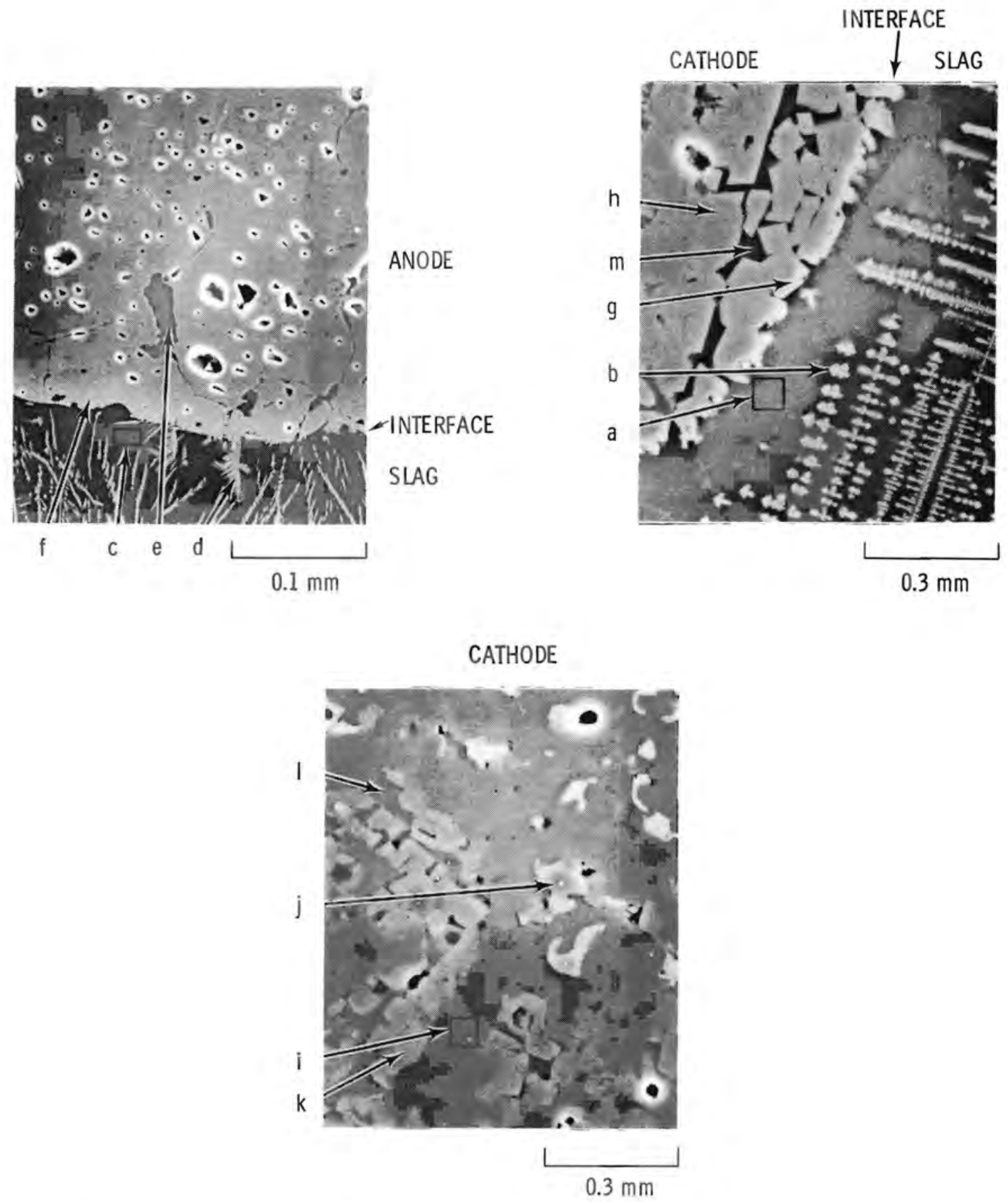

FIGURE 23. Scanning Electron Micrographs of Anode and Cathode in I11-6-1 at 1723K (Experiment 33) 
during cooldown. The glassy slag matrix (Item 4, Table A.7) was slightly higher in silicon, aluminum and calcium and lower in potassium and iron concentrations than was the overall slag. The slag immediately inside the cathode at an area where grains are separated from the cathode had a decrease only in iron. The dendritic crystalline oxide phase in the slag was iron-rich, containing additional magnesium (Item 5, Table A.7). Since the phase is small, the SEM-EDX analysis may also contain components of the surrounding slag matrix, resulting in the high values of aluminum, silicon, etc.

The cathode grains at the slag/cathode interface (Item 12, Table A.7) were slightly depleted in magnesium and iron, resulting in an increase in the aluminum content. It appears that the magnesium and iron had been dissolved by the slag.

The interior of the cathode was multiphase, but did not contain the metallic iron found in the cathode tested in MR-1 slag. The four phases are 1) the matrix (Item 14, Table A.7) slightly depleted of iron, 2) a granular phase thought to be an FeO-MgO (magnesiowustite) solid solution (Item 15, Table A.7), 3) a granular phase (probably a spinel [Item 16, Table A.7]), and 4) a magnesium-iron-silicate phase (Item 17, Table A.7).

Slag is found along the grain boundaries and has partially reacted with the matrix. The magnesiowustite and the magnesium-iron-silicate are found in the slag along the grain boundaries.

Examination of the phase equilibria data (Levin and McMurdie 1975) for the three-component system $\mathrm{FeO}-\mathrm{MgO}-\mathrm{SiO}_{2}$ shows that at $1473 \mathrm{~K}$ (a reasonable temperature for "solidification" of the silicates) two phases are in equilibrium: 1) olivine $\left[2(\mathrm{Mg}, \mathrm{Fe}) \mathrm{O}^{\cdot} \mathrm{SiO}_{2}\right]$, and 2) magnesiowustite $[(\mathrm{Mg}, \mathrm{Fe}) 0]$. The compositions shown by the tie lines at $1473 \mathrm{~K}$ are very close to the two phases described in Items 15 and 17 of Table A.7. Silica from the slag is reacting with the cathode matrix to form these two equilibrium compositions.

Neither potassium nor calcium are found incorporated into the matrix of the two compounds or in any of the multiphase grains. These two elements do 
not appear to be part of the silica reaction process. Calcium remains in the grain boundary, resulting in concentrations greater than those in the bulk slag.

Perhaps the small amount of slag penetration along the grain boundary is due to the lower amounts of cations in the slag than were found in MR-1. Another parameter that may influence grain-boundary penetration is the degree of ionic conductivity which is lower in the I11-6-1 slag than the MR-1 slag. The highly ionic slags require ionic movement for the conduction of current. Therefore, as current is being conducted along grain boundaries, ions are continually being forced to move in the direction of current flow. Of course, the amount of current being transported by each component is dependent upon the volume and the relative electrical conductivity of that component (slag, matrix, grain-boundary region).

\section{Anode/Slag}

The slag near the anode/slag interface of Figure 23 was two-phase. The dendritic phase was differently shaped (more feather-like) than was the dendritic shape found in the bulk slag. This anode dendritic growth (Item 7 , Table A.7) was higher in iron and lower in aluminum, silicon and potassium than was the phase at the cathode. The slag matrix between the dendrites was depleted of iron, but contained additional silicon and aluminum. Fewer dendritic growths are found at the immediate anode/slag interface because of the lower iron content of the slag.

To evaluate the effect of slag circulation caused by bubble formation and migration, the slag at the exterior of the anode was compared to that which migrated into the anode through the open porosity. In a pore inside the anode the slag is single-phase and shows iron depletion (Item 8, Table A.7). The resulting concentration is close to that found in the control in the slag at the immediate control-slag interface and along grain boundaries. The feathery iron-rich precipitates are not found. The composition of the slag in the porosity is probably closer to the slag at the anode/slag interface than that measured at the interface. The movement of slag due to the bubble formation did affect the exterior slag composition. 
Iron is diffusing from the slag into the anode matrix grains. The grains next to the slag are enriched in iron (Item 10, Table A.7). The additional iron in the matrix is only found to a depth of $100 \mu \mathrm{m}$.

\section{COMPARISON OF CORROSION BETWEEN MR-1 AND I11-6-1}

The corrosion rates are significantly less in I11-6-1 than in MR-1. Part of the reduced corrosion rate is attributed to the decrease in the slag penetration along grain boundaries. In I11-6-1 slag the corrosion was more uniform, with less weakening of grain boundaries resulting in the removal of grains from the matrix. Iron is leached from the cathode in MR-1 slag but not in I1l-6-1 slag. The leaching of iron resulted in an area of lower electrical conductivity and consequently higher electric potential difference--a difference that may lead to increased electrochemical breakdown of the surface layers. The migration of other cations is greater in MR-1 slag, resulting in a cation-rich slag at the cathodes. The super-saturation of cations at the cation interface resulted in a two-phase MR-1 slag. The slag in $111-6-1$ is also two-phase as a result of the super-saturation of iron.

The cathode in I11-6-1 contains four phases with two $\mathrm{FeO}_{-} \mathrm{MgO}-\mathrm{SiO}_{2}$ compositions that appear to be tie-line compositions on an equilibrium diagram. The other two phases are iron-rich and iron spinel (slightly depleted). The excess iron perhaps helped in the formation of their compositions. In MR-1 these compositions do not exist; the two-phase areas consist of Mgo-Feo solid solution and a somewhat depleted matrix.

The anode in both slags remained single-phase. The I11-6-1 anode contained additional iron in the matrix at the slag interface, whereas the MR-1 anode was partially leached of iron.

\section{ELECTROCHEMICAL CORROSION IN MR-1+Fe $2-_{3}$ (MR-1-Fe) AT $1723 \mathrm{~K}$}

The electrochemical corrosion rates were less in high-iron slags like I11-6-1 and the slag in this test (which consists of MR-1 with enough $\mathrm{Fe}_{2} \mathrm{O}_{3}$ added to make the concentration equivalent to $\mathrm{Fe}_{2} \mathrm{O}_{3}$ content of $111-6-1$ ) than in MR-1 slags. The additional iron increased the iron activity and electronic 
conductivity of the slag, requiring both less cation migration for a given quantity of current transfer and fewer oxidation-reduction reactions with species other than the $\mathrm{Fe}^{3+}-\mathrm{Fe}^{2+}$ ions. The SEM microstructure of both the anode and cathode is shown in Figure 24, and the SEM-EDX analys is of several features in the micrograph are given in Table A.8. More iron reacted with the $\mathrm{Al}_{2} \mathrm{O}_{3}$ crucible in this test than in the normal MR-1 slag.

Cathode/Slag

The slag near the cathode was changed in composition from that of the bulk composition and contained oxide dendritic growths. These growths were not found in the slag near the anode. The composition of the dendrite (Item 4, Table A.8) was similar to the overall slag at the cathode, except for increased magnesium $(+74 \%)$ and aluminum $(+25 \%)$. Since the dendrites are small, the electron beam may have penetrated through to the surrounding slag matrix, and the analysis may include elements of the surrounding matrix. The slag around the denritic growths has a 34\% decrease in magnesium and a $64 \%$ decrease in iron. This two-phase slag showed an overall net decrease in iron. No metallic iron precipitates were found in the slag.

The slag penetrated into the cathode along the grain boundaries. The grain boundary enlargement and attack was not as severe in this slag as with MR-1. The major degradation reaction appears to be grain-boundary attack, with resulting loss of individual grains. The slag in the grain boundaries may be multiphase, but could not be determined with the SEM. In the slag at the grain boundary (Item 14, Table A.8), the magnesium, calcium and iron concentrations were higher than in the bulk slag, while the aluminum, silicon and potassium concentrations were lower. Part of the decrease in the silica along the grain boundaries is due to silicon migration into the grains. The cathode adjacent to the slag/cathode interface contained some silica, 21\% more iron and $17 \%$ less aluminum than did the original electrode (Item 12, Table A.8). Immediately below this surface reaction zone $(\sim 6 \mu \mathrm{m})$, the cathode matrix was iron-depleted by $25 \%$ and aluminum-enriched by $28 \%$ (Item 13, Table A.8). As in MR-1, the granular second phase (Item 15, Table A.8) was an iron-magnesium 

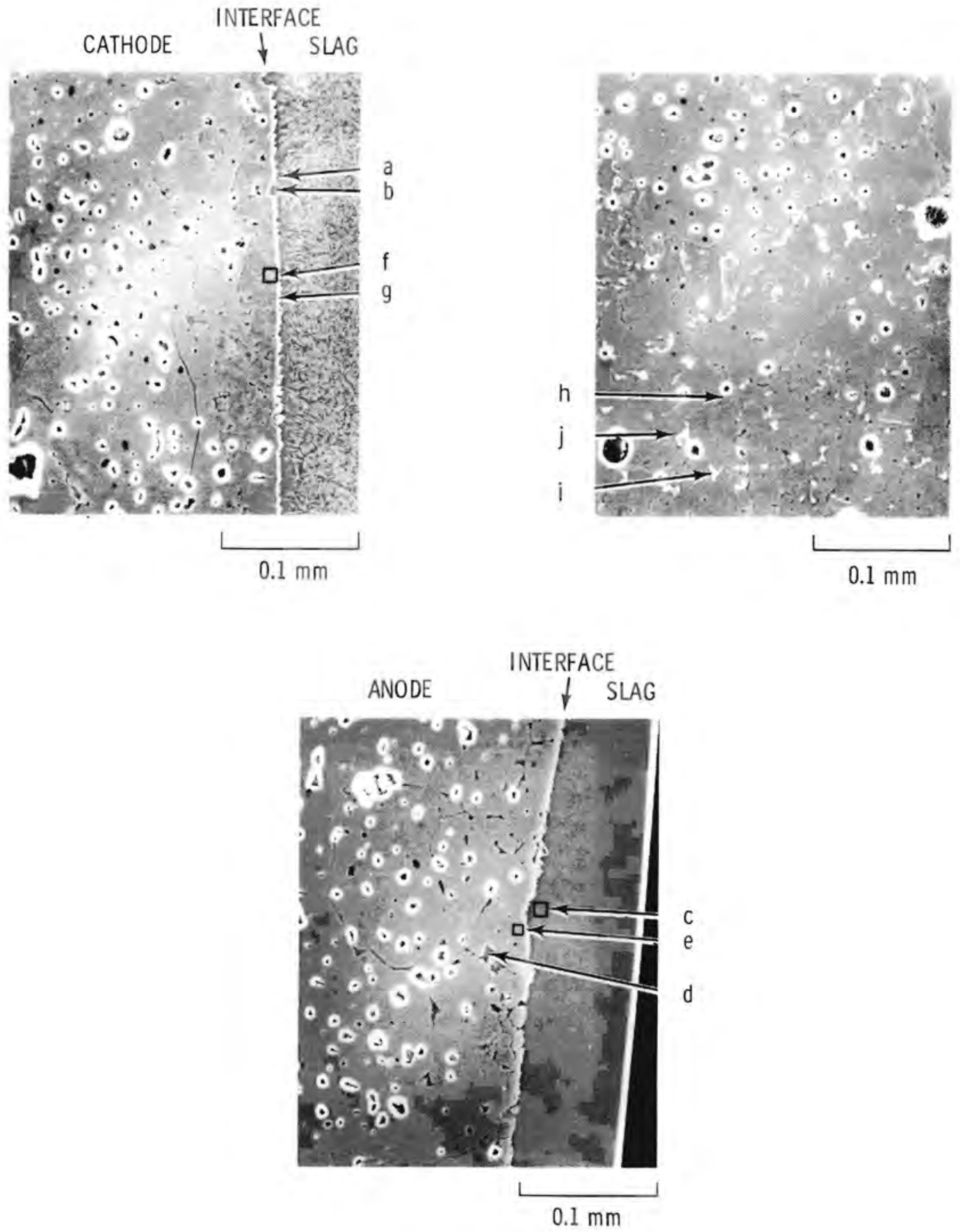

FIGURE 24. Scanning Electron Micrograph of Anode and Cathode in MR-1-Fe at $1723 \mathrm{~K}$ (Experiment 39) 
compound (probably magnesiowustite MgO-FeO solid solution). The matrix in the multiphase area condensed $20 \%$ less in iron and $20 \%$ less in aluminum (Item 16 , Table A.8) than did the initial spinel. The decrease in iron was not as great as was found in MR-1.

Anode/Slag

Unlike the cathode, the slag near the anode was single-phase. However, the slag (Item 6, Table A.8) contained 48\% less magnesium, 33\% less calcium, $29 \%$ less iron, and $22 \%$ more aluminum than did the bulk slag. The decrease in iron was not due to iron migration into the anode. Slag that had penetrated along some of the anode grain boundaries and open porosity (Item 7, Table A.8) was different from the slag at the surface, with even larger decreases in the iron and magnesium contents, and also had decreases in potassium and calcium.

The anode is single-phase with the composition at the anode-slag interface unchanged from that in the bulk. The anodes, like those tested in MR-1, were uniformly corroded/eroded at the surface and not degraded by grain-boundary corrosion. However, the corrosion/erosion was less at this anode than for the MR-1 anode. Less bubble formation is expected in this slag than in MR-1 due to the higher electronic conduction.

\section{COMPARISON OF TESTS IN MR SLAG WITH AND WITHOUT ADDITIONAL IRON}

The electrochemical corrosion rates of FMAS in molten coal slag were 5 to 7 times lower when 10\% iron was added to the slag. In I1l-6 slag with an iron content similar to MR-1-Fe, the corrosion rates are similar. The additional iron in the slag increased the amount of current transported electronically, therefore decreasing the number of ions transported by the passage of current. Consequently, the increased cation concentration at the cathode and cation depletion at the anode is less in the slag in MR-1 without additional iron.

The increase in electrical conductivity caused by the addition of iron also decreases the electric potential drop through the slag required to maintain a constant electric current, hence decreasing the probability of 
electrolysis, and may consequently reduce the amount of metal formation. The increased iron activity at the slag/electrode interfaces reduced the exsolution of iron from the electrode and increased the iron content of the cathode.

For comparison, Table 7 summarizes several features on the anodes, cathodes and slag for tests conducted in MR-1 and MR-1-Fe. No major differences were found at the anodes. The slag at the anodes remain single-phase, with depletion in some cations. Iron depletion was greatest in the MR-1-Fe slag. At the cathode, no metallic iron phase was found in high-iron MR-1-Fe $\mathrm{slag}$, and less of the FeO-MgO phase had formed. Iron enrichment occurred in the MR-1-Fe slag, whereas in the MR-1 slag, iron was leached from the cathode. The potassium content of the MR-1-Fe slag was less along the grain boundaries than in the bulk. This potassium may have been a factor in the formation of metallic iron and part of the degradation mechanism. The potassium also may be a reactive specie for other electrochemical interactions. Therefore, the decrease in potassium reduced some electrochemical interactions and may be the reason for the lower corrosion rates in the high-potassium slags.

\section{COMPARISON OF TESTS BETWEEN MR-1-Fe AND I11-6-1}

The electrochemical corrosion results of FMAS in MR-1-Fe and I11-6-1 show some similarity. A comparison of several test features in the two slags are presented in Table 8. Even though the iron content is the same, the iron activities are not, as is evidenced by 1) the diffusion of iron into the anode matrix in I11-6-1 and not in MR-1-Fe, 2) the extra iron-containing phases in the 111-6-1 cathode, and 3) the higher iron content of the I11-6-1 slag dendrites. Slag penetration in the cathode and anode in I11-6-1 slag is less than in MR-1-Fe, which may be partially due to a decrease in the calcium content that would increase viscosity. The chemical properties of iron is different in the two slags. In the MR-1-Fe slag, iron diffused into the cathode. In I11-6-1, the iron remained in the slag and partially precipitated into a dendritic phase. At the anodes, iron diffused into the anode in $111-6-1$ and not in MR-1-Fe. More iron migrated toward the cathode in the MR-1-Fe tests than in the I11-6-1 tests. 
TABLE 7. Comparison Summary Between Tests in MR-1 and MR-1-Fe

Slag Cathode STag, MR-1

Cathode Slag, MR-1-Fe

1. Metallic Fe phase

1. No metallic phase

2. Two-phase slag

Ca concentration increased

2. Two-phase slag

Glassy matrix decrease in $\mathrm{Fe}$ and $\mathrm{Mg}$

Dendrites increase in $\mathrm{Mg}$ and $\mathrm{Al}$

3. Green-ye110w precipitate

Anode Slag, MR-1

Anode Slag, MR-1-Fe

1. Single-phase

1. Single-phase

2. Composition decrease in $\mathrm{Ca}, \mathrm{K}$ and $\mathrm{Mg}$

2. Composition decrease in $\mathrm{Fe}, \mathrm{Ca}$, $\mathrm{Mg}$ and $\mathrm{K}$

Cathode

\section{MR -1}

1. Fe leaching at slag/cathode interface

2. Interior region polyphase:

Fe metallic

$\mathrm{MgO}-\mathrm{FeO}$ solid solution

Matrix decrease in $\mathrm{Fe}$

3. Slag penetration along grain boundary--wide grain boundaries, polyphase slag Increase in $\mathrm{Mg}, \mathrm{Al}$ and $\mathrm{K}$

\section{MR-1-Fe}

1. Fe enrichment at immediate slag/ cathode interface

2. Interior region polyphase:

No metallic $\mathrm{Fe}$

MgO-FeO solid solution

Matrix decrease in $\mathrm{Fe}$ (less

(than that in MR-1)

3. Slag penetration along grain boundary single-phase slag (not as much grain boundary attack as in $M R-1$ )

Increased $\mathrm{Mg}, \mathrm{Ca}$ and $\mathrm{Fe}$

Anode

\section{MR-1}

1. No Fe leaching at anode/slag interface

2. Single-phase

3. Little grain-boundary penetration of slag

\section{$\mathrm{MR}-1-\mathrm{Fe}$}

1. No Fe leaching at anode/slag interface

2. Single-phase

3. Little grain-boundary penetration of slag 
TABLE 8. Comparison Summary Between Tests in MR-1-Fe and I11-6-1

Slag

Cathode Slag, MR-1-Fe

1. No metallic Fe phase Cathode Slag, [1]-6

2. Two-phase slag (dendrites in matrix):

glassy matrix decrease in $\mathrm{Mg}$ and $\mathrm{Fe}$ dendrites increased in $\mathrm{Mg}$ and $\mathrm{Al}$

Anode slag, MR-1-Fe

1. Single-phase decrease in $\mathrm{Mg}, \mathrm{Ca}$, $\mathrm{K}$ and $\mathrm{Fe}$

1. No metallic Fe phase

2. Two-phase slag (dendrites in matrix): matr $i x$ decrease in $\mathrm{K}$ and $\mathrm{Fe}$ dendrites increased in $\mathrm{Fe}$ and $\mathrm{Mg}$ (contains more $\mathrm{Fe}$ than do dendrites in MR-1-Fe)

Anode Slag, I11-6

1. Single-phase, slightly depleted in $\mathrm{Fe}$

2. Slag penetrated along grain boundary more than in MR-1-Fe

Cathode

MR-1-Fe

1. Fe enrichment at immediate slag/ cathode interface

2. Interior polyphase:

matrix decrease in $\mathrm{Fe}$

$\mathrm{MgO}-\mathrm{FeO}$ solid solution

(magnesi owustite)

3. Slag penetration along grain boundary, increase in $\mathrm{Mg}, \mathrm{Ca}$ and $\mathrm{Fe}$
I11-6

1. Fe and $\mathrm{Mg}$ depletion at immediate slag/cathode interface

2. Interior polyphase: matrix decrease in $\mathrm{Fe}$ $\mathrm{MgO}-\mathrm{FeO}$ (magnesiowustite) Spinel rich in $\mathrm{Fe}$ $2(\mathrm{MgO} \mathrm{Fe}) 0 \cdot \mathrm{SiO}_{2}$ (01ivine)

3. Slag penetration along grain boundary (less than in MR-1-Fe)

Anode

MR-1-Fe

1. No Fe leaching at anode/slag interface

2. Single-phase

3. Little grain-boundary penetration of slag

\section{$[1]-6$}

1. Fe enrichment at anode/slag interface

2. Single-phase 
ELECTROCHEMICAL CORROSION IN MR-1 AT 1573K

The electrochemical testing in MR-1 slag at $1573 \mathrm{~K}$ poses several problems: 1) the viscosity of the slag is high, 2) the electrical conductivity is low, and 3) precipitation of additional phases is increased because of the decreased solubility of the slag. For initial homogenization the slag was first held at $1723 \mathrm{~K}$ for several hours before the test specimen was inserted and cooled to the test temperature of 1573K. After testing, small precipitates were uniformly distributed through the slag except at the immediate location of the anode and cathode. Larger brown precipitates were found to be distributed non-uniformly on the surface of the slag. The greatest concentration of the precipitate was near the cathode. Also, immediately around the cathode to a distance of $\sim 2 \mathrm{~mm}$ was green-yellow precipitate. Evidence of bubbles was detected around the anode. The SEM microstructures of the anode and cathode are shown in Figure 25. The SEM-EDX compositional analys is is given in Table A.9.

Cathode/Slag

The slag near the cathode had been significantly altered. Instead of a slag with small second-phase precipitates, as was found in the bulk slag, the slag consisted of two polyphase regions, as shown in Figure 25. The first polyphase region extended $\sim 0.23 \mathrm{~mm}$ from the cathode. The second polyphase region extended $\sim 0.4 \mathrm{~mm}$ out from the first region and consisted of large precipitate growth in the glass matrix. The crystallite growth (Item 6, Table A.9)--the same composition as the growth found near the anode (Item 5, Table A.9)--has a composition close to that of $\mathrm{K}_{2} \mathrm{O} \cdot \mathrm{Al}_{2} \mathrm{O}_{3} \cdot 2 \mathrm{SiO}_{2}$. The slag matrix surrounding the precipitation is depleted of aluminum and potassium and has increased concentrations of sodium, magnesium, calcium and iron when compared to the overall slag composition. The large amount of high-potassium second phase indicates potassium concentration near the cathode.

The first polyphase region is the reaction product zone between the slag and the cathode and it contains three phases. The first is metallic iron (Item 8 , Table A.9). The metal in this reaction zone contains less magnesium 


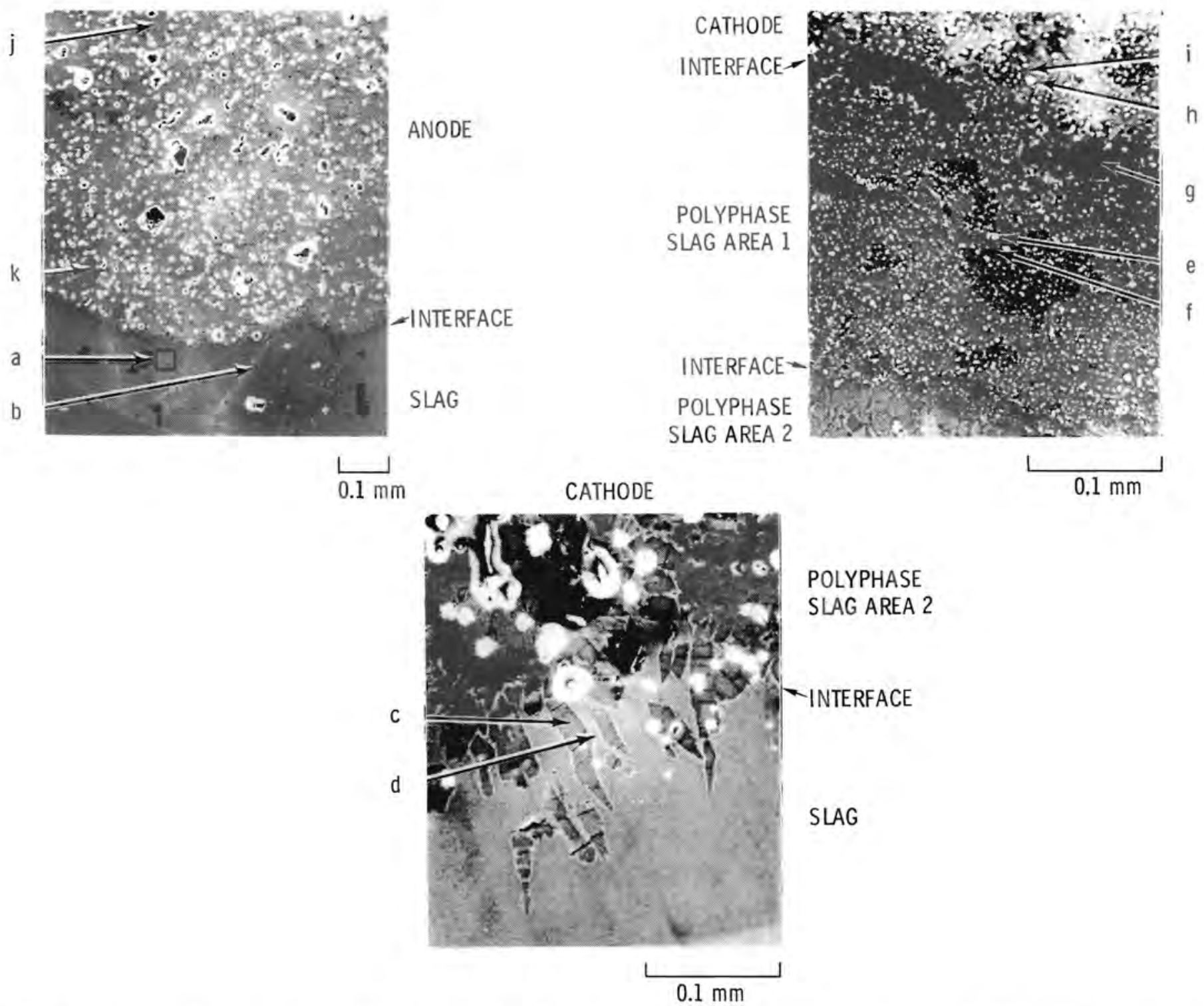

FIGURE 25. Scanning Electron Micrograph of Anode and Cathode in MR-1 at 1573K (Experiment 38) 
than do the metallic deposits inside the sample (Item 12, Table A.9). The second phase is granular and is intermixed with the third phase. Both phases are found in areas like feature $f$ in Figure 25. This second phase (Item 9 , Table A.9) contains magnesium, silicon and calcium with atomic ratios close to that of merwinite $\left[\mathrm{Ca}_{3} \mathrm{Mg}\left(\mathrm{SiO}_{4}\right)_{2}\right]$ (melting point $\sim 1623 \mathrm{~K}$ ). The third phase is the potassium-aluminum silicate $\left(\mathrm{K}_{2} \mathrm{O} \cdot \mathrm{Al}_{2} \mathrm{O}_{3} \cdot 2 \mathrm{SiO}_{2}\right)$ found in the slag in the second polyphase area in the cathode slag.

Two phases are found in the cathode near the reaction interface. The first phase is the FMAS matrix depleted of iron. The second phase is the metallic iron deposit containing magnesium (Item 12, Table A.9). The matrix phase surrounds each of the isolated grains of metal; consequently, current must pass through the more resistive matrix (due to the iron depletion) as it passes between metal grains. Localized heating may occur, which could have increased the local temperature and the reaction rates.

Farther into the sample, in the area above the electrode/slag interface, calcium and potassium are found along the grain boundary. The potassium interacted with the cathode, resulting in the formation of two potassiumaluminates that have precipitated at the grain boundaries (Items 14, 15 in Table A.9). One of the potassium-alumina compounds has a composition ratio (Item 15, Table A.9) close to that found for $\beta$-aluminas.

Anode/Sl ag

The slag near the anode interface is mostly single-phase. The small precipitates found in the bulk slag are not found within a distance of $1 \mathrm{~mm}$ from the anode. The large crystalline second phase found in abundance at the cathode interface is found in much smaller concentrations at the anode, and most of these are located at least $0.5 \mathrm{~mm}$ from the anode, with the notable exception of the feature shown in Figure 25. The slag composition near the anode has not changed from the bulk except for the isolated large crystalline second-phase growth. The 1 ack of the small precipitates and the second-phase growths indicate a depletion in cations. The large second-phase precipitates 
located at a distance from the anode could give an indication of the beginning of the cation-enriched regions due to cation repulsion caused by the electric fields at the anode.

The anode is generally single-phase, with little penetration of slag along the grain boundaries. In some locations, though, greater amounts of slag penetration and interaction are found. The slag composition (Item 17, Table A.9) is high in magnesium and aluminum and low in iron, potassium and calcium. The accuracy of the analysis is questionable because of the size of the secondphase deposits and the possibility of the SEM-EDX electron beam penetration through the slag layer.

COMPARISONS OF TESTS IN MR-1 AT 1723K AND 1573K

Comparing the tests in MR-1 at the two tempertures show the temperature effects. At lower temperatures the corrosion rate is less. The lower corrosion rate is not always expected, since a bulk of the corrosion is caused by the passage of current. The slag at this lower temperature was more viscous and tended to have some phase separation using the same cooling rate as on the higher-temperature tests. The lower-temperature slag will have a greater tendency to become inhomogeneous by precipitation of second phases, etc., at the test temperature than will the higher-temperature slag. With the increased viscosity, the reaction products may not migrate away from the reaction zone as rapidly. Keeping the reaction products near the reaction zone can reduce the reaction rates.

The lower-temperature slag did have a phase separation upon quenching. It is not known if the slag was homogeneous at the test temperature. It was homogeneous immediately prior to the test because the slag was heated to $1773 \mathrm{~K}$, after which the samples were inserted and the slag was cooled to the test temperature.

The electrical conductivity of the coal slag at $1573 \mathrm{~K}$ is about one order of magnitude less than at $1723 \mathrm{~K}$ (Figure 7 ). The relative decrease in the electrical conductivity of the electrode is less; consequently, the differences in 
the electrical conductivity of the slag and the electrode is greater at the low temperatures. The lower conductivity requires a greater electrical potential to pass the same electric current. This greater electric potential can result in a greater possibility of electrolys is of various components. The mode of conductivity can change--i.e., the lower the temperature, the less the mobility of the ions and the greater the conductance by electronic mechanisms.

A summary of several comparisons between the two tests is found in Table 9. The quenched slag was different between the two tests. The lowtemperature slag had a fine, uniformly dispersed second phase. The uniformly dispersed second phase found in the bulk slag was not found near the anode interface. The higher-temperature slag was single-phase at the anode with a compositional change due to a decrease in the cation concentration. Also at the anode, the low-temperature slag was multiphase and the higher-temperature slag was single-phase. The multiple phases result from large islands of potassium alumina silicate.

The cathode/slag interface in the lower-temperature slag contained several more phases than were found in the high temperature test. Both of the slags contained the yellow-green precipitate--a potassium alumina-silicate. The lower-temperature slag contained the additional compound of a calcium-magnesium silicate (merwinite). The metallic deposits in the cooler slag were generally smaller in size than were those in the hotter slag.

Within the cathode, less slag penetration was found in the cooler slag. Also, no MgO-FeO solid solution was found in the cooler slag test. The formation of the solid solution may be the result of slag along the grain boundaries, which is less prevalent in the low-temperature slag. Also, sufficient temperature may be needed for cation diffusion and second-phase growth.

ELECTROCHEMICAL CORROSION IN MR AT 1476K

Test 44 is a test in MR slag at 1476K. The MR slag does not contain additional potassium. The test was conducted at $97 \mathrm{~K}$ below that of the coolest 
TABLE 9. Comparison Summary Between Tests in MR-1 at $1723 \mathrm{~K}$ and $1573 \mathrm{~K}$

Cathode $51 \mathrm{ag}, \mathrm{MR}-1$

$1723 \mathrm{~K} \quad$ Cathode S1 ag, MR-1 $1573 \mathrm{~K}$

1. Metallic Fe phase

2. Two-phase slag; Ca concentration increased

3. Green-yellow precipitate
1. Metallic Fe phase

2. Two areas of different multiphase slag: outer area slag increase in $\mathrm{Na}, \mathrm{Mg}, \mathrm{Ca}$ and $\mathrm{Fe}$ $\mathrm{K}_{2} \mathrm{O} \cdot \mathrm{Al}_{2} \mathrm{O}_{3} \cdot \mathrm{SiO}_{2}$ precipitate

inner area

metallic $\mathrm{Fe}$

$\mathrm{Caz} \mathrm{Mg}\left(\mathrm{SiO}_{4}\right)_{2}$

(merwinite)

$\mathrm{K}_{2} \mathrm{O} \cdot \mathrm{Al}_{2} \mathrm{O}_{3} \cdot \mathrm{SiO}_{2}$

3. Green-yellow precipitate

Anode Slag, MR-1

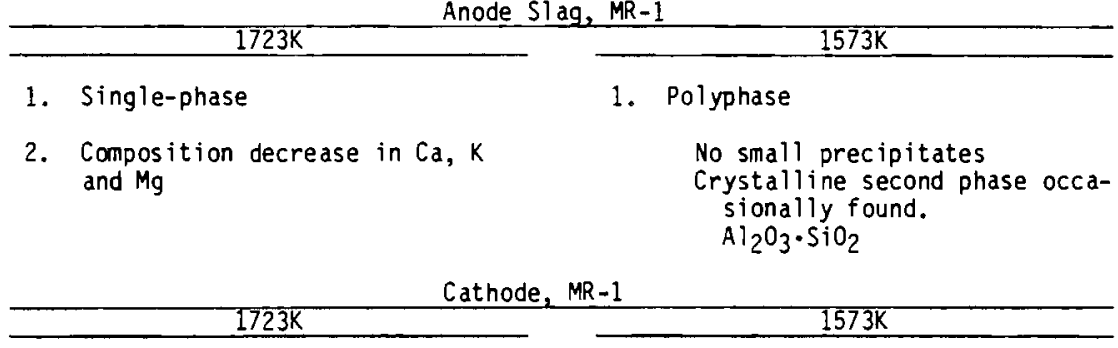

1. Fe leaching at cathode/slag interface

2. Interior region polyphase Metallic Fe $\mathrm{MgO} \cdot \mathrm{FeO}$ solid solution Matrix decrease in $\mathrm{Fe}$

3. Slag penetration along grain boundary

Wide grain boundaries

Polyphase slag

Increase in $\mathrm{Mg}, \mathrm{Al}$ and $\mathrm{K}$

4. No compounds above slag line
1. Fe leached from matrix to form metallic Fe precipitate

2. Interior region multiphase Metallic Fe

No $\mathrm{FeO} \cdot \mathrm{MgO}$ solid solution

Matrix Fe depletion

less $\mathrm{Fe}$ depletion than at $1723 \mathrm{~K}$

3. Slag penetration along grain boundary less than at $1723 \mathrm{~K}$

4. Potassium reactions along grain boundaries above slag line:

Potassium $B-a l u m i n a$

Potassium aluminate

Anode, MR - 1

\begin{tabular}{|c|c|}
\hline $1723 \mathrm{~K}$ & $1573 \mathrm{~K}$ \\
\hline ing at anode/slag & $\begin{array}{l}\text { 1. No Fe leaching at anode/slat } \\
\text { interface }\end{array}$ \\
\hline & 2. Single-phase \\
\hline $\begin{array}{l}\text { in-boundary penetra- } \\
\text { lag }\end{array}$ & $\begin{array}{l}\text { 3. Grain-boundary slag phase: } \\
\text { Decrease } \mathrm{Fe}, \mathrm{K} \text { and } \mathrm{Ca} \\
\text { Increase in } \mathrm{Mg}, \mathrm{Al}\end{array}$ \\
\hline
\end{tabular}


test in MR containing additional potassium. The lower temperature may lead to additional phase separation. The electrical conductivity of the slag is lower than in MR-1 at 1573K; therefore, a higher electric potential is required for electric current conduction and a greater possibility for electrolysis can occur. Both low temperature and low concentration of potassium results in lower electrical conduction. The test also differs from other tests, in that the electrodes were removed from the slag after testing. To facilitate the removal, the slag was briefly heated to $1723 \mathrm{~K}$. The electrodes remained suspended in air during the quench. Not being quenched in the slag may result in the oxidation of metallic precipitates. The precipitate in the center of the electrode may not be as affected by the air due to the diffusion distance and the limited length of time the sample was at high temperature. Metal precipitates remained in the slag surrounding the cathode; consequently, the oxidation of the slag after testing and during cooldown was not complete.

The representative microstructures are shown in Figure 26 . The compositions of several features on the micrographs are in Table A.10. Flake-shaped precipitates in the slag are found near both the anodes and cathodes, except at the immediate anode interface. The precipitate (Item 2, Table A.10) analyzed near the cathode (no anode analysis was performed) is a calcium-aluminummagnesium silicate. Examination of phase equilibrium diagrams from these components shows that the composition is located in a multiphase area containing anorthite $\left(\mathrm{CaAl}_{2} \mathrm{Si}_{2} \mathrm{O}_{8}\right)$, diopside $\left(\mathrm{CaMgSi}_{2} \mathrm{O}_{6}\right)$, forsterite $\left(\mathrm{Mg}_{2} \mathrm{SiO}_{4}\right)$, and melilite, which is a solid solution containing calcium, magnesium, aluminum and silicon. The solid temperature is 1498K. This composition is only found in this test. The matrix around the second phase is a calcium-aluminum silicate. The overall calcium content near the cathode appears to be greater in the bulk. The amount metallic iron precipitate found in the slag at the cathode is approximately the same as was found in MR-1 at 1573K.

Cathode/Slag

The cathode is polyphase at the reaction zone. Several of the phases are found in the slag along the grain boundaries. The slag had penetrated along 
ANODE

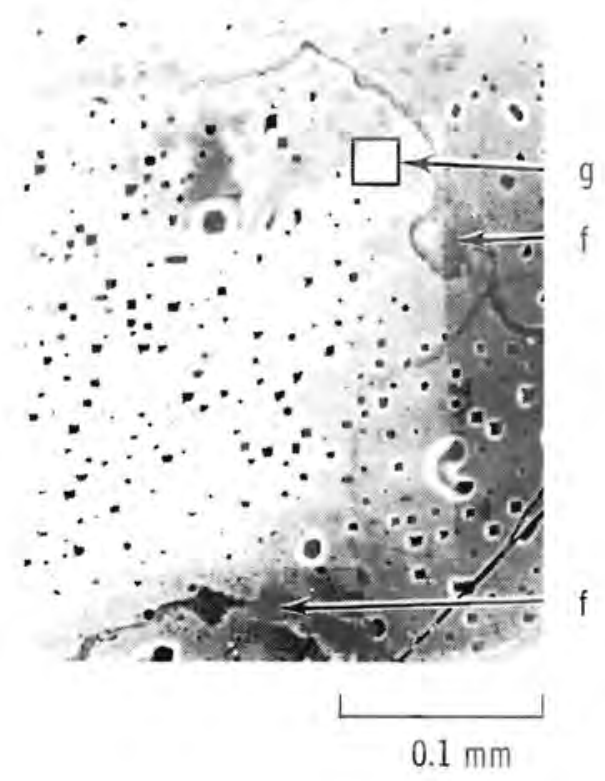

CATHODE

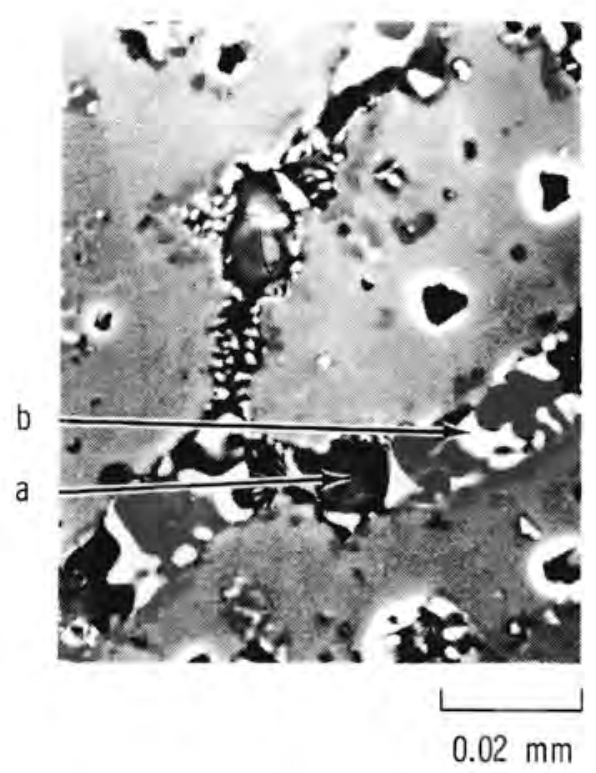

CATHODE

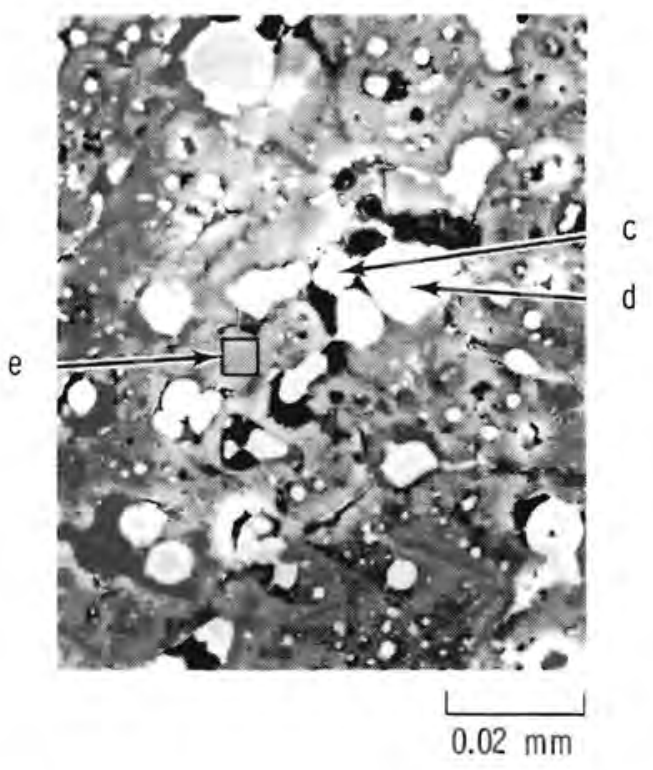

FIGURE 26. Scanning Electron Micrograph of Anode and Cathode in MR-1 at 1476K (Experiment 44)

the grain boundaries and widened the grain boundaries in some areas. A widened grain boundary is shown in Figure 26. Only two of the four phases found in the grain boundaries were analyzed. The first phase is a sodium aluminate 
(Item 5, Table A.10). These high-sodium phases are only found in the cathode. Apparently, large amounts of sodium are being pulled from the slag by the passage of electric current. In this slag the potassium concentration is only slightly greater than that for the sodium. For the MR-1 slag, in which the potassium concentration is much greater than the sodium concentration, the effects of sodium are overshadowed by the effects of potassium. The conduction of a low-iron slag is mostly ionic, with the mobile cations, i.e., potassium, sodium and calcium, carrying the bulk of the current. Sodium is a more mobile specie; therefore, sodium migration and interaction will be more prevalent. The potassium content has also increased in the grain-boundary deposits. The slag around the cathode has sodium depletion.

The second phase along the grain boundary is a magnesium ferrite. The oxygen ratio estimated by difference in the SEM-EDX analysis appears to be too high to be the $\mathrm{MgO}-\mathrm{FeO}$ solid solution. Farther in from the reaction interface, the cathode is polyphase with three distinct phases: 1) metallic iron (Item 8, Table A.10), 2) $\mathrm{MgO}^{-} \mathrm{Fe}_{2} \mathrm{O}_{3}$ (Item 9, Table A.10), and 3) FMAS (Item 10, Table A.10) with some iron depletion.

Anode/Slag

Not enough slag remained at the anode to allow a reliable analysis of the composition. The slag is single-phase within $20 \mu \mathrm{m}$ of the interface. The anode is also single-phase except for slag penetration along the grain boundaries near the reaction interface. This slag is high in aluminum and iron and lower in calcium, potassium, and silicon than is the overall slag (Item 12, Table A.10). The matrix next to the grain boundary containing slag does not have any compositional changes.

\section{COMPARISON BETWEEN TESTS IN MR AT 1476K AND MR-1 SLAGS AT 1573K}

A summary of the comparison between testing in MR at $1476 \mathrm{~K}$ and MR-1 at $1573 \mathrm{~K}$ is given in Table 10. The major difference is the increased amount of cations (sodium, calcium and magnesium) found at the cathode tested in MR. The polyphase nature of the cathode slag consists of two phases containing 
TABLE 10. Comparision Summary of Tests in MR at $1476^{\circ} \mathrm{K}$ and MR-1 at $1573 \mathrm{~K}$ Cathode Slag MR at $1476 \mathrm{~K}$

1. No metallic Fe phase

2. Polyphase

Precipitate $\mathrm{MgO} \cdot \mathrm{Al}_{2} \mathrm{O}_{3} \cdot 2 \mathrm{CaO}$. $4 \mathrm{SiO}_{2}$

Slag matrix with depleted $\mathrm{Ca}$, Si

3. No green-yellow precipitate MR-1 at $1573 \mathrm{~K}$

1. Metallic Fe phase

2. Two areas of different polyphase slag:

Outer area

$\mathrm{Slag}$ increase in $\mathrm{Na}, \mathrm{Mg}, \mathrm{Ca}$ and $\mathrm{Fe}$

$\mathrm{K}_{2} \mathrm{O} \cdot \mathrm{Al}_{2} \mathrm{O}_{3} \cdot \mathrm{SiO}_{2}$ precipitate

Inner area

Metallic Fe

$\mathrm{Ca}_{3} \mathrm{Mg}\left(\mathrm{SiO}_{4}\right)_{2}$ (merwinite)

$\mathrm{K}_{2} \mathrm{O} \cdot \mathrm{Al}_{2} \mathrm{O}_{3} \cdot \mathrm{SiO}_{2}$

3. Green-yellow precipitate of $\mathrm{K}_{2} \mathrm{O} \cdot \mathrm{Al}_{2} \mathrm{O}_{3} \cdot \mathrm{SiO}_{2}$

Anode Slag

MR at $1476 \mathrm{~K}$

1. Single-phase
MR-1 at $1573 \mathrm{~K}$

1. Polyphase

no small precipitate

crystallize second phase

$\mathrm{K}_{2} \mathrm{O} \cdot \mathrm{Al}_{2} \mathrm{O}_{3} \cdot 2 \mathrm{SiO}_{2}$

Cathode

\section{MR at $1476 \mathrm{~K}$}

1. Fe partially leached from matrix around metallic precipitate

2. Interior region polyphase Metallic Fe $\mathrm{MgO} \cdot \mathrm{Fe}_{2} \mathrm{O}_{3}$ (magnesioferrite) Matrix decrease in $\mathrm{Fe}$ less than that at $1573 \mathrm{~K}$

3. Slag penetration along grain boundary sodium-aluminate $\mathrm{MgO}-\mathrm{Fe}_{2} \mathrm{O}_{3}$ MR-1 at $1573 \mathrm{~K}$

1. Fe partially leached from matrix to form metallic $\mathrm{Fe}$ precipitate

2. Interior region polyphased Metallic Fe containing $\mathrm{Mg}$ No $\mathrm{FeO}-\mathrm{MgO}$ solid solution Matrix decrease in $\mathrm{Fe}$

3. Slag penetration along grain boundary

4. Above slag line

Potassium $K-\beta$-alumina

Potassium aluminate 
TABLE 10. (contd)

\begin{tabular}{|c|c|}
\hline \multicolumn{2}{|c|}{ Anode } \\
\hline MRC $1476 \mathrm{~K}$ & MR-1 at $1573 \mathrm{~K}$ \\
\hline 1. No Fe leaching & $\begin{array}{l}\text { 1. No Fe leaching at anode/slag } \\
\text { interface }\end{array}$ \\
\hline 2. Single-phase & 2. Single-phase \\
\hline $\begin{array}{l}\text { 3. Grain-boundary slag phase; } \\
\text { decrease in } \mathrm{Ca}, \mathrm{K} \text { and } \mathrm{Si}\end{array}$ & $\begin{array}{l}\text { 3. Grain-boundary slag phase; } \\
\text { decrease in } \mathrm{Fe}, \mathrm{K} \text { and } \mathrm{Ca} \text {; } \\
\text { increase in } \mathrm{Mg}, \mathrm{Al}\end{array}$ \\
\hline
\end{tabular}

high calcium concentrations. Large amounts of sodium have migrated from the slag into the grain-boundary region of the cathode. Potassium has also been removed from the slag near the cathode.

No potassium-aluminum silicate is found as a precipitate in the MR slag either at the cathode or anode as found in MR-1. The anode slag remains single-phase in the MR test. Both slags penetrated along the anode grain boundaries and both slags had decreases in the concentration of some cations.

\section{CHEMICAL CORROSION IN MR SLAG AT 1723K}

Only a control was tested in MR slag at 1723K. The sample was tested for only $7 \mathrm{~h}$, since the 24-h test resulted in the complete loss of the sample. The corrosion rate (Table 4) is about four times that in MR-1 slag. The SEM microstructure is shown in Figure 27. The SEM-EDX compositional analys is if given in Table A.11 of the Appendix.

The slag penetrated the grain boundaries and reacted with the grains. Both magnesium and iron from the FMAS matrix appears to selectively dissolved in the slag. The matrix in the reaction zone is partially depleted in both magnesium and iron (Item 6, Table A.11). With continued depletion, the FMAS eventually becomes an iron-containing aluminum oxide. The composition of this phase is close to that predicted for the aluminum-rich side of the $\mathrm{Al}_{2} \mathrm{O}_{3}-\mathrm{Fe}_{2} \mathrm{O}_{3}$ phase equilibrium in an air atmosphere (Levin, Robbins and McMurdie 1969). 

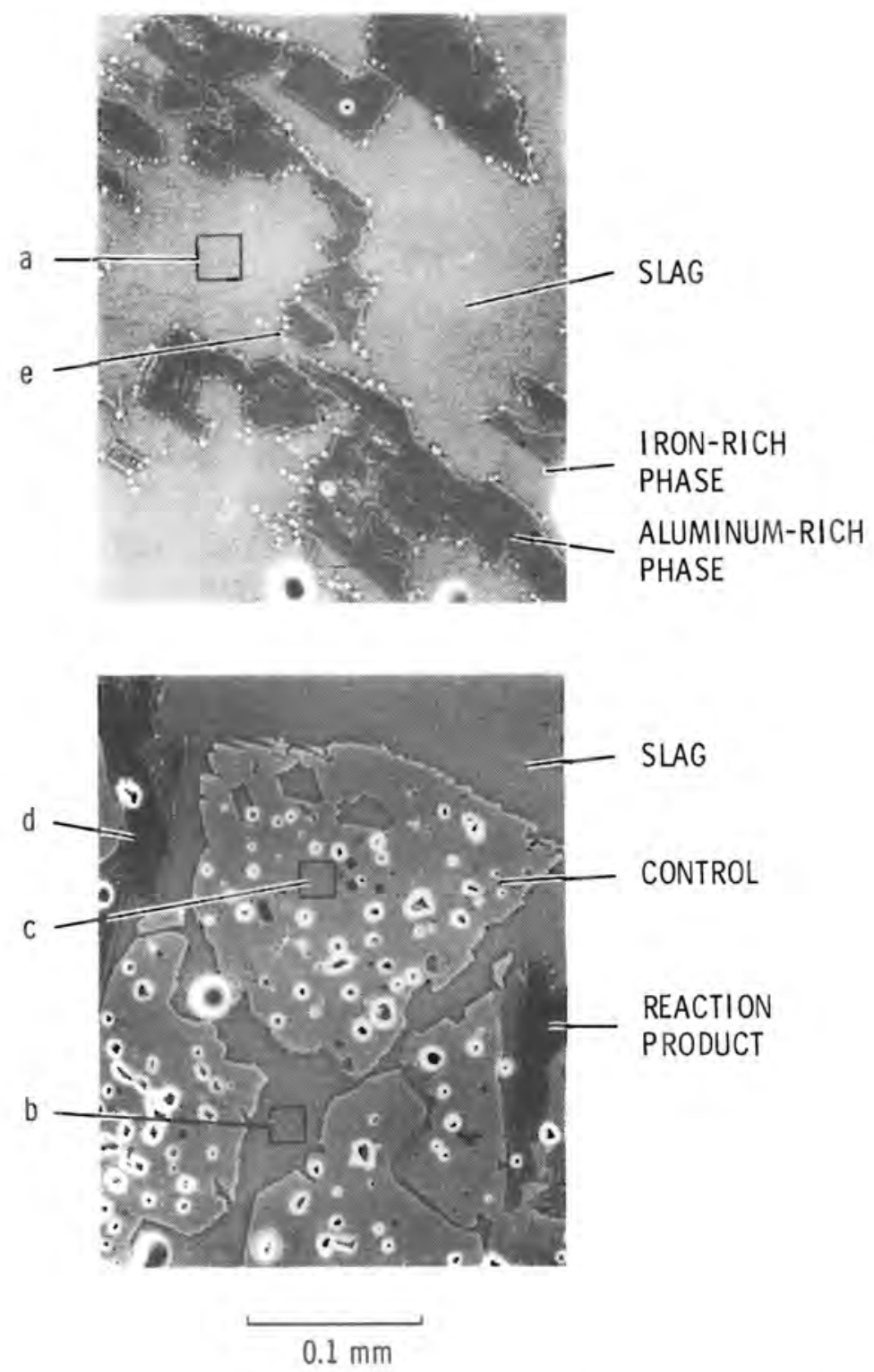

FIGURE 27. Scanning Electron Micrograph of Control in MR at $1723 \mathrm{~K}$ (Experiment 318)

The dissolved magnesium from the FMAS distributes uniformly about the slag, as is shown by the slag compositions from several locations. The iron from the FMAS does not seem to uniformly distribute in the slag, as the slag's iron content remains constant. The iron precipitates as a third phase along the exterior of the aluminum-rich second phase. This iron-rich phase appears 
only as a growth around the second-phase particles and is not found near the FMAS. This iron-rich phase contains more aluminum than predicted for phase equilibrium with the aluminum-rich phase.

\section{PLATINUM PROBE RESULTS}

In several tests, a platinum probe was inserted into the slag at fixed equidistances from the anode and cathode. Electric potentials between both the anode and cathode and the platinum probe were monitored during the test. Since constant current is maintained during the test, the electric potential changes indicated changes in resistivity in both the slag and the electrode materials.

A summary of electric potential measurements are given in Table 11 . The anode-to-cathode separation is about $2 \mathrm{~cm}$. The electric potential increases during the test. The bulk of the increase is due to increases in resistance at the anode. In all the slags, the cathode does not have a large increase in electrical potential. The increase observed in the MR slags may be due to both corrosion-product buildup and the leaching of iron from the electrode. The removal of iron increases the resistivity of the FMAS. This increase is not found in the I11-6 slag; little corrosion-product buildup occurred and iron was not leached from the FMAS.

Included in the table is a statement about electric potential instabilities. The tests are run in galvanostatic mode (i.e., constant current); consequently, the electric potential fluctuates to maintain the current. The fluctuations are greatest with MR and MR-1 slags. The two main phenomena that lead to potential fluctuations are 1) bubble generation and migration and 2) arcing across the resistive slag layer. The more ionic slags have the greatest numbers of bubbles produced per unit of current transported. Bubbles on the surface of the anode are electrical insulators and reduce the area available for current transport--hence increasing the effective resistance. of course, as the bubbles enlarge they reach a size at which they migrate to the surface of the slag. The migration removes the insulating barrier and replaces the area with fresh slag, thereby reducing the resistance. A 
TABLE 11. Summary of Platinum Electric Potential Probe Data

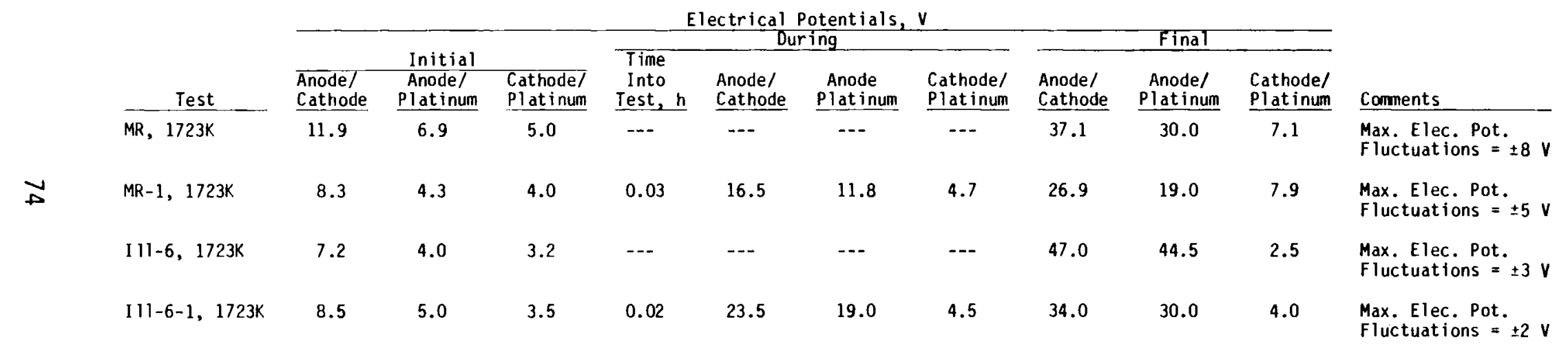


resistive layer also develops at the anode due to the migration of cations. This resistive layer grows to an equilibrium condition, depending on back diffusion along concentration gradients and the forward diffusion due to the passage of current. The resistive layer is essentially a relatively high-purity alumina-silicate, with most of the mobile cations removed. Adequate electric potential is required to pass current through the resistive layer. Instabilities in the electrical conductivity of the slag and in the electric potential in the anode can lead to current channelling and arcing. The phenomena is somewhat like dielectric breakdown in solid materials. The arcing is a rapid activity and general will not be seen on the strip-chart record, but can be seen on an oscilloscope. An oscilloscope was used in an MR-1 test at 1723K, during which evidence of arcing was seen. The arcing generally occurred at the higher electric potentials during the potential instabilities. Arcing can lead to increased corrosion of the anode due to locally high current and consequent temperature changes.

Arcing has not been observed on the cathode. Current transfer on the cathode should not be through a resistive layer, since cations should concentrate at the cathode interface. Very little instability is observed for current transfer at the cathode. For example, in I11-6 the maximum instabilities for the cathode-platinum is $\pm 0.5 \mathrm{~V}$ compared to $\pm 3 \mathrm{~V}$ for the anode. 


\section{CONCLUSIONS/RECOMMENDATIONS}

1. Iron-doped magnesium-alumina spinel (FMAS) is easily fabricated and results in a material that has adequate electrical conductivity for use in an MHD electrode over a temperature range from 400K to 1900K. Anomalies in the thermal conductivity and electrical conductivity data at temperatures above $1400 \mathrm{~K}$ indicate some phase instabilities probably associated with the exsolution of iron. Hysteresis in the data during temperature cycles indicate that the exsolution is reversible.

2. Electrochemical corrosion rates induced by an external electric field and the consequent passage of electric current are greater in both anodes and cathodes than are the corrosion rates without the external electric field. These electrochemical corrosion rates can be as much as two orders of magnitude greater than corrosion rates without the external electric field.

3. Cations such as $\mathrm{K}^{+}, \mathrm{Ca}^{++}$and $\mathrm{Na}^{+}$subjected to a direct electrical field in coal slags migrate to the cathode, causing a depletion of cations in the slag at the anode and a concentration of cations in the slag at the cathode.

4. Cation diffusion to the cathode and from the anode results in electric potential changes between the anode and cathode. Electric potential measurements between a neutral platinum probe and the anode or the cathode show that during an electrochemical corrosion test, increases in electric potential between the anode and the probe are greater than increases between the cathode and probe. In the Illinois No. 6 slags the electric potential decreases between the cathode and probe. For the Montana Rosebud slags, the electric potential can increase by a factor of 5 over the life of the test.

5. Fluctuations in electric potential occur during the test due to changes in electrical resistivity in either the slag or the electrodes. The largest fluctuations occur between the platinum and anode and are 
partially due to the generation of gas bubbles at the anode. Greater fluctuations occur in Montana Rosebud slag than in Illinois No. 6 slag.

6. Penetration of the slag into the cathode is much greater than into the anode in both Illinois No. 6 slag and Montana Rosebud slag.

7. The anode corrosion/erosion in coal slag is more uniform than in the cathode. Part of the erosion is the result of cavitation stress at the formation and coalescence of bubbles; part is due to current channelling because of the electrical insulating properties of the bubble.

8. The corrosion rates of both anodes and cathodes are lower in Illinois No. 6 slag than in Montana rosebud slag.

9. The corrosion rates decrease as the iron content of the slag increases. This decrease is attributed to the higher activity of iron in the slag, higher electrical conductivity of the slag, and lower ionic/higher electronic conductivity of the slag. The corrosion rates are lower for Illinois No. 6 slag than for Montana Rosebud slag with equivalent iron content.

10. The corrosion rate in Montana Rosebud coal slag increases as the temperature increases.

11. In Montana Rosebud coal slag an increase of potassium in the slag decreases the corrosion rates.

12. In Montana Rosebud coal slag the corrosion rates increase with increasing current density.

13. In both Illinois No. 6 and Montana Rosebud coal slags, the cathodes become multiphase. In Montana Rosebud slag, the slag contains such phases as metallic iron and magnesiowustite solid solutions. Metallic iron is not found in the cathode in Illinois No. 6 slag. In general, the anodes remain single-phase, except for slag penetration along the grain boundaries.

14. Potassium sulfate is more electrochemically reactive than is potassium carbonate at the cathode in the potassium salt tests. At the anode, potassium carbonate is more reactive. 
15. In both potassium salts, grain-boundary penetration and interaction is more extensive in the cathodes than in the anodes. The cathodes are generally multiphase (compared to essentially single-phase anodes). In the anodes, where grain-boundary penetration is not as extensive, potassium carbonate penetrates more than potassium sulfate.

16. FMAS has too-high an electrochemical corrosion rate to be considered as MHD electrodes when Montana Rosebud slag or only molten potassium salts are present.

17. Even though the electrochemical corrosion rates are high, FMAS may be considered as an MHD electrode in high-iron-containing slag such as Illinois No. 6. 
, 


\section{REFERENCES}

Bates, J. L. 1975. Properties of Molten Coal Slags Relating to Open Cycle

MHD. BNWL-B-466, Pacific Nor thwest Laboratory, Richland, Washington.

Bates, J. L. 1976. Development and Characterization of Material for Open Cycle MHD. Quarter1y Report, Apri1-June, 1976, BNWL-2004-3, Pacific Northwest Laboratory, Richland, Washington, pp. 12-21.

Capps, W. and D. A. Kauffman. 1978. "Viscosity of Coal Slags." In Development Testing and Evaluation of MHD-Materials. EA-77-A-01-6010-13, Quarterly Report, July-September 1978, W. R. Hosler, T. Negas and S. J. Schneider, Editors, National Bureau of Standards.

Delimarskii, I. U. K. and B. F. Markov. 1961. Electrochemistry of Fused Salts, Translated from Russian, The Sigma Press, Publishers, Washington, DC.

Didtschenko, R. and E. G. Rochow. 1954. "Electrode Potentials in Molten Silicates." J. Amer. Chem Soc. 76:3291-3294.

Frederikse, H. P. R. and W. R. Hosler. 1973. "Electrical Conductivity of Coal Slag." J.Amer. Cer. Soc. 56(8):418.

Hamer, W. J. 1965. "Theoretical Electromotive Forces for Cel1s Containing a Single Solid or Molten Oxide." J. of Electroanalytical Chemistry. 10:140-150.

Hansen, M. and K. Anderko. 1958. Constitution of Binary Alloys. 2nd Edition, McGraw-Hi11 Book Co., New York, New York.

Hosler, W. R., A. J. Armstrong and H. P. R. Frederikse. 1976. "Electrical Conductivity." In Development, Testing and Evaluation of MHD-Materials. E-(49-1)-3800-4, Quarterly Report ApriT-June 1976, June 30, 1976, H. P. R. Frederikse, T. Negas and S. J. Schneider, eds., National Bureau of Standards.

Janz, G. J. et al. 1968. Molten Salt: Volume 1, Electrical Conductance, Density and Viscosity Data. NSRDS-NBS 15, National Bureau of Standards.

Latiner, W. M. 1952. Oxidation Potentials. Prentice-Ha11, Inc., New York, p. 7 .

Levin, E. M. and H. F. McMurdie. 1975. Phase Diagrams for Ceramists, 1975 Supplement. American Ceramic Society, Columbus, Ohio.

Levin, E. M., C. R. Robbins and H. F. McMurdie. 1964. Phase Diagrams for Ceramists. American Ceramic Society, Columbus, Ohio. 
Levin, E. M., C. R. Robbins and H. F. McMurdie. 1969. Phase Diagrams for Ceramists. 1969 Supplement, American Ceramic Society.

Plante, E. R. 1978. "Vaporization Studies." In Development, Testing and Evaluation of MHD-Materials. EA-77-A-01-6010-13, Quarterly Report JulySeptember 1978, W. R. Hos Ter, T. Negas and S. J. Schneider, eds., National Bureau of Standards.

Romanov, A. I. et al. 1973. "Investigation of the Properties of AlkaliResistant Refractory Materials for the Lining of Various Units of MHD Installations." Teplofizika Vysokikh Temperatur. II:4(858-864), JulyAugust, Translated 1974 Consultant Bureau.

Smirnov, M. V., L. A. Tsiovlcina and V. A. 0leinikova. 1966. "Process Occurring on Platinum and Nickel Cathodes During Electrolys is of Molten Carbonates." Electrochemistry of Molten and Solid Electrolytes. 3(61-65), A. N. Baraboshtein, ed., Consultants Bureau, New York.

Simnad, M. T., G. Derge and I. George. 1954. "Ionic Nature of Liquid IronSilicate Slage." J. of Metals. Dec.: 1386-1390.

Westinghouse Electric Corporation. 1978. Final Report on the Joint US-USSR Test of the US MHD Electrode System in the U-02 Facility--Phase II. DOE, FE-2248-16, Dist. Cat. UC-909.

Yen, C. F. 1977. "Electrical Conductivity in the $\mathrm{FeO} \mathrm{Fe}_{2} \mathrm{O}_{3} \mathrm{Al}_{2} \mathrm{O}_{3} \mathrm{SiO}_{2} \mathrm{System}$." Ph.D. Thesis. Mass. Institute of Technology. 
APPENDIX

QUANTITATIVE ANALYSIS RESULTS FROM THE SEM-EDX 
APPENDIX

\section{QUANTITATIVE ANALYSIS RESULTS FROM THE SEM-EDX}

The results of the SEM-EDX are presented in the following tables. The results are expressed as the atomic percent of the respective element. Since only elements with atomic numbers $>10$ can be identified, only these elements are included in the tables. The oxidation state of these elements can, in some cases, be estimated by the measured concentration of the elemental species in the features of interest. The difference between this measured concentration and the measured concentration for both metal and oxide standards (of known oxidation states) is used as the amount of oxygen present. This difference method of determining the amount of oxygen present and consequently the oxidation state of the elemental species is a good method as long as carbides, nitrides, etc. are not present. It is assumed that all elemental species are either metallic or oxides. In the tables of SEM-EDX compositional analysis, all the elements are assumed to be oxides unless identified as being metallic.

The relative accuracy of the atomic concentrations is generally better than $10 \%$ of the amount present (e.g., $13 \pm 1.3 \%$ ). The detection limit is $0.1 \mathrm{wt} \%$ for the elemental species listed in the tables. The data is listed in the tables as relative proportions of only those elements detected and does not include the oxygen content determined by the difference method.

The atomic concentrations are generally accurate to \pm 1 atom\%. In general, the sensitivity is $\pm 0.1 \mathrm{wt} \%$. The atomic concentrations are rounded to the nearest unit percent except with those quantities less than one unit. The sum of the atomic concentrations might not be equal to 100 because of either rounding errors or trace amounts of elements not listed in the tables.

In each table, the identifying feature on the micrograph is included. Some analyses are included in the table that have a written description but not an identification on the micrograph.

Each feature identified generally represents a number of similar features on the micrograph and is so listed to show general trends. 
TABLE A.1. Atomic Composition of Features in Figure 8 (Experiment 314 Control $\left(n, \mathrm{~K}_{2} \mathrm{CO}_{3}\right.$ at $1273 \mathrm{~K}$ ) in Atom\% of Elemental Species

Item No. and Description

1. Matrix--interior, feature a

2. Grain boundary in interior, feature b

3. Matrix at reaction zone, feature $c$

4. Reaction zone, feature d
Element, atom\%

Na $\underline{M g} \quad \underline{A l} \quad \underline{S i} \quad K \quad \underline{C a} \underline{I i} \underline{F e}$

$\begin{array}{llllllll}26 & 49 & - & 0.2 & -- & - & 24\end{array}$

$\begin{array}{llll}19 & 55 & 0.4 & 5\end{array}$

21

$\begin{array}{llll}27 & 48 & 0.7 & 0.6\end{array}$

23

$\begin{array}{llll}7 & 19 & 3 & 6\end{array}$

61

(a) Includes only elements with atomic numbers greater than 10.

TABLE A.2. Atomic Composition of Features in Figure 9 (Experiment 315 Control $j_{\text {Detected }} \mathrm{K}_{2} \mathrm{SO}_{4}$ at 1373K) in Atom\% of Elemental Species

Item No. and Description

1. Matrix

2. Matrix at reaction zone, feature a

3. Second phase in matrix at reaction zone, feature $b$

4. Reaction product, feature $c$

5. Third phase in matrix, feature $d$

7. Grain boundary, feature e

\begin{tabular}{|c|c|c|c|c|c|c|c|}
\hline \multicolumn{8}{|c|}{ Element, atom\% } \\
\hline$\underline{\mathrm{Na}}$ & $\mathrm{Mg}$ & Al & $S i$ & $\mathrm{~K}$ & $\mathrm{Ca}$ & $T i$ & $\mathrm{Fe}$ \\
\hline & 27 & 49 & & & & & 23 \\
\hline & 26 & 47 & 1 & 3 & & & 23 \\
\hline
\end{tabular}

$\begin{array}{llll}27 & 41 & 1 & 1\end{array}$

31

$\begin{array}{lllll}4 & 14 & 3 & 1 & 0.2\end{array}$

78

$\begin{array}{llll}13 & 65 & 1 & 8\end{array}$

$19 \quad 33 \quad 1 \quad 12(b)$

27

(a) Includes only elements with atomic numbers greater than 10 .

(b) 9 atom\% sulfur detected but not included. 
TABLE A.3. Atomic Compositions of Features in Figure 12 (Anode Tested in $\mathrm{K}_{2} \mathrm{SO}_{4}$ at $1423 \mathrm{~K}$, Experiment 28) in Atom\% of Elemental Species Detected (à)

Item No. and Description

$\begin{array}{lllllll}\frac{\mathrm{Mg}}{27} & \frac{\mathrm{A} T}{47} & \frac{\mathrm{Si}}{0.8} & \frac{\mathrm{S}}{0.3} & \frac{\mathrm{K}}{0.4} & \frac{\mathrm{Ca}}{-} & \frac{\mathrm{Fe}}{24}\end{array}$

2. Overall composition $26 \quad 49$ near reaction zone, feature $b$

1. Overall composition away from reaction zone, feature a

3. Electrolyte at reaction zone, feature $c$

4. Light-colored acicular growth, feature $d$

5. Matrix between acicular growths, feature $e$

6. Electrolyte away from reaction zone and above meit level, feature $f$

7. Light-colored lath phase in electrolyte, above melt level, feature $g$

0.2

0.1

$4 \quad 45 \quad 2$

2

5

0.3

$\begin{array}{llll}1 & 3 & - & 35\end{array}$

58

1

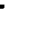


TABLE A.4. Atomic Compositions of Features in Figure 20 (Experiment 303 Control in MR-1 S1ag at 1723K) in Atom\% of Element Species Detected $(a)$

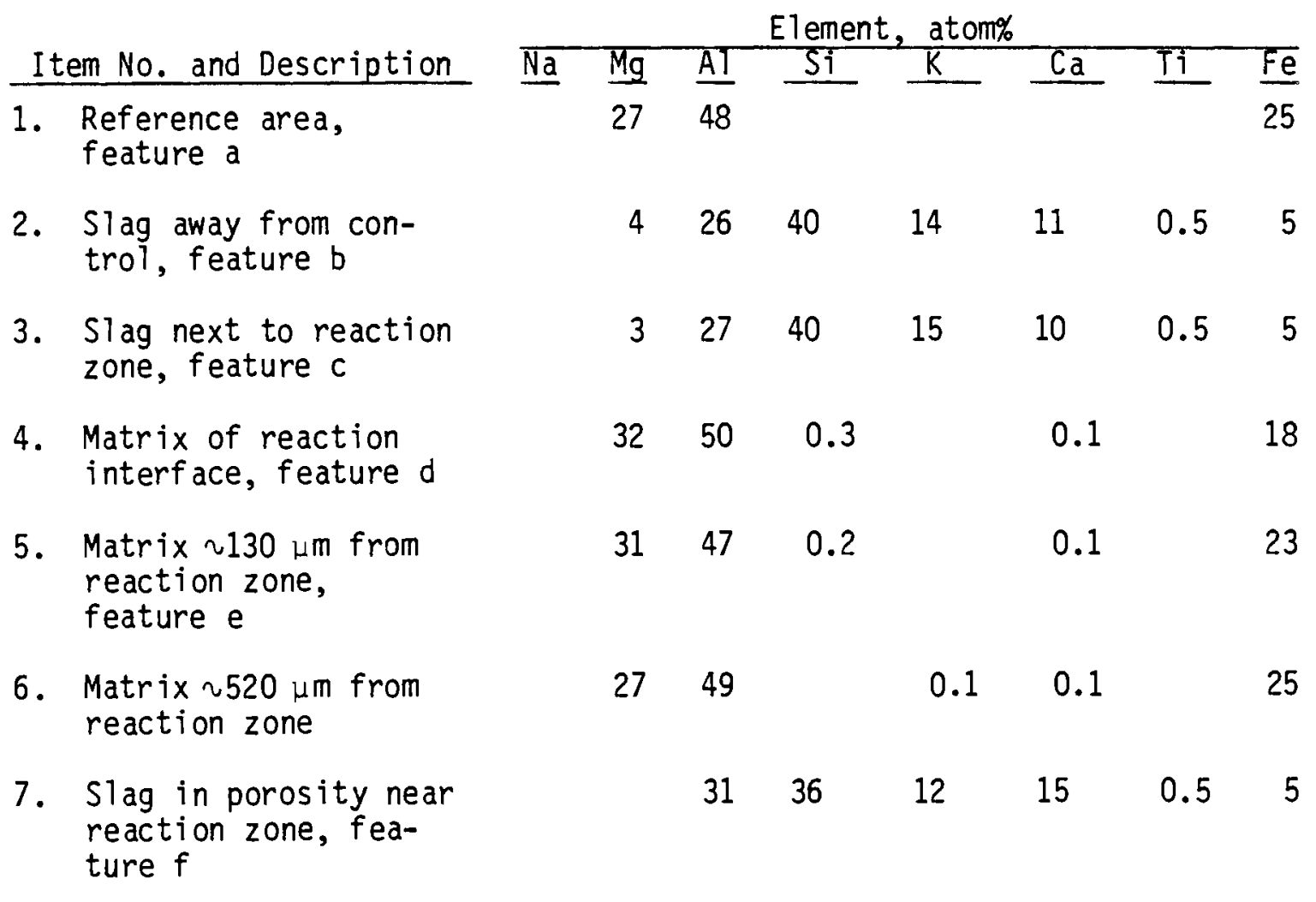

(a) Includes only elements with atomic numbers greater than 10 . 
TABLE A.5. Atomic Composition of Features in Figure 21 (Experiment 21 in MR-1 at 1723K) in Atom\% of Elemental Species Detected(a)

Item No. and Description

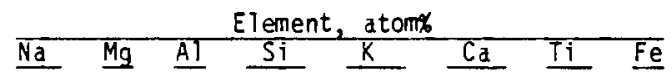
$\underline{\text { slag }}$

1. Slag--overall calculated by mixtures of initial components

$\begin{array}{llllllll}0.6 & 6 & 21 & 39 & 16 & 13 & 0.5 & 5\end{array}$

2. Slag--overall by SEM-

$\begin{array}{lllllll}6 & 22 & 39 & 16 & 13 & 0.1 & 4\end{array}$

3. Slag (two-phase) at cathode interface,

$\begin{array}{llllll}10 & 23 & 31 & 13 & 22 & 1\end{array}$
feature a

4. Slag at anode inter$f$ ace, feature b

$\begin{array}{rrrrrrr}5 & 23 & 43 & 16 & 9 & & 4 \\ 2 & 29 & 46 & 9 & 10 & 0.1 & 4\end{array}$
anode, feature $c$

Anode

6 Overall (both anode

$27 \quad 46 \quad 0.2$

26

7. Matrix at electrode/ slag interface,

$25 \quad 48 \quad 0.6 \quad 0.2$

27

\section{Cathode}

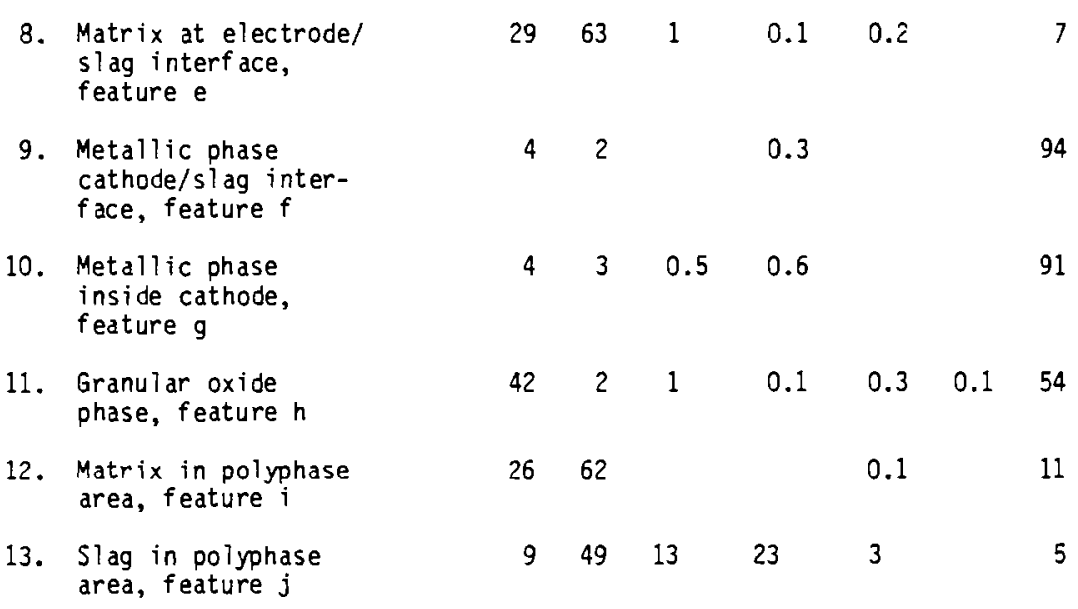

(a) Includes oniy elements with atomic numbers greater than 10 . 
TABLE A.6. Atomic Composition of Features in Figure 22 (Experiment 308 Control in I11-6-1 S1 ag at 1723K) in Atom\% of Elemental Species Detected $(\bar{a})$

Element, atom\%

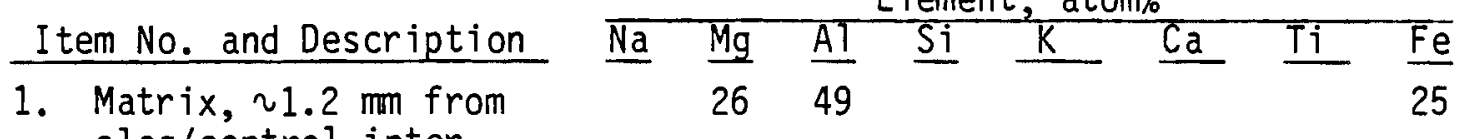
slag/control interface, feature a

2. Slag in grain boundary 21.2 $\mathrm{mm}$ from slag/con-

$\begin{array}{lllll}7 & 32 & 38 & 9 & 4\end{array}$

10 trol interface, feature $b$

3. Slag bulk away from control

4. Slag at slag/control interface, feature c

$\begin{array}{llllll}30 & 39 & 12 & 5 & 0.7 & 14\end{array}$

$\begin{array}{llllll}30 & 44 & 14 & 6 & 0.5 & 5\end{array}$

5. Matrix at slag/control interface, feature d

$\begin{array}{lllll}14 & 29 & 1 & 0.1 \quad 56\end{array}$

6. Matrix $0.05 \mathrm{~mm}$ from slag/control interface, feature e

7. Matrix $0.1 \mathrm{~mm}$ from slag/control interface, feature $f$

8. Slag in grain boundary $0.5 \mathrm{~mm}$ from slag/control interface

(a) Includes only elements with atomic numbers greater than 10. 
TABLE A.7. Atomic Composition of Features in Figure 23 (Experiment 33 in 11]-6-1 at 1723K) in Atom\% of Elemental Species Detected (a)

Item No. and Description $\overline{\mathrm{Na}} \mathrm{Mg} \quad \underline{\mathrm{Al}} \stackrel{\mathrm{Si}}{\mathrm{K}} \mathrm{Ca} \quad \mathrm{Ti} \quad \underline{\mathrm{Fe}}$ Slag

1. Overall--by mixture $\begin{array}{lllllllll}1 & 2 & 21 & 39 & 15 & 5 & 0.6 & 16\end{array}$

2. Overall--anode $\quad \begin{array}{lllllll}26 & 40 & 13 & 5 & 0.5 & 15\end{array}$

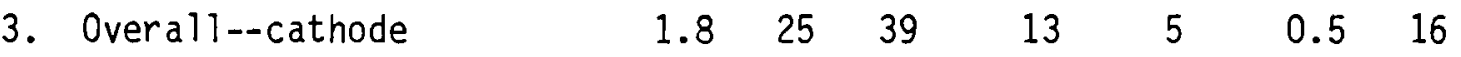

$\begin{array}{llllllll}\text { 4. Slag matrix at } & 3 & 28 & 43 & 10 & 9 & 0.5 & 6\end{array}$ cathode interface, feature a

$\begin{array}{lllllllll}5 . & \text { Dendritic phase in } & 6 & 28 & 32 & 7 & 3 & 0.5 & 25\end{array}$ slag at cathode, feature $b$

6. Slag matrix at anode interface, feature $c$

7. Dendritic phase in slag at anode, feature $d$

8. Open porosity in anode, feature e

$\begin{array}{lllllll}2 & 28 & 45 & 14 & 6 & 0.4 & 5\end{array}$

$\begin{array}{lllllll}2 & 18 & 23 & 7 & 2 & 1 & 48\end{array}$

Anode

9. Overall

$25 \quad 48 \quad 0.4$

10. Anode/slag inter-

$17 \quad 41$

40

Cathode
11. Overall
$26 \quad 48$
0.7
26
12. Cathode/slag interface,
$20 \quad 57 \quad 0.9$
feature $g$
13. Cathode $0.2 \mathrm{~mm}$
from interface, feature $h$

$\begin{array}{llllll}23 & 57 & 1 & 0.1 & 0.1 & 19\end{array}$


TABLE A.7. (contd)

\begin{tabular}{|c|c|c|c|c|c|c|c|c|c|}
\hline & & & & & leme & atom\% & & & \\
\hline Item & No. and Description & $\underline{\mathrm{Na}}$ & $\mathrm{Mg}$ & $\underline{A T}$ & Si & $K$ & $\underline{\mathrm{Ca}}$ & $T i$ & $\underline{F e}$ \\
\hline 14. & $\begin{array}{l}\text { Matrix in poly- } \\
\text { phase area, } \\
\text { feature } i\end{array}$ & & 27 & 51 & 1 & 0.1 & & 0.1 & 21 \\
\hline 15. & $\begin{array}{l}\text { Second phase in } \\
\text { polyphase area, } \\
\text { feature } j\end{array}$ & & 26 & 2 & 2 & 0.1 & 0.1 & & 69 \\
\hline 16. & $\begin{array}{l}\text { Third phase in } \\
\text { polyphase area, } \\
\text { feature } k\end{array}$ & & 23 & 42 & 2 & 0.1 & 0.1 & & 33 \\
\hline 17. & $\begin{array}{l}\text { Fourth phase in } \\
\text { polyphase area, } \\
\text { feature } 1\end{array}$ & & 46 & 5 & 28 & 0.6 & 2 & & 19 \\
\hline 18. & $\begin{array}{l}\text { Slag in center of } \\
\text { cathode on grain } \\
\text { boundary }\end{array}$ & & 2 & 21 & 41 & 7 & 10 & 0.1 & 19 \\
\hline 19. & $\begin{array}{l}\text { Slag at interface, } \\
\text { feature } m\end{array}$ & & 2 & 32 & 41 & 11 & 7 & 1 & 8 \\
\hline
\end{tabular}

(a) Includes only elements with atomic numbers greater than 10 . 
TABLE A.8. Atomic Concentrations of Features in Figure 24 (Experiment 39 in MR-1-Fe at 1723K) in Atom\% of Elemental Species Detected(a)

Element, atom\%

Item No. and Description $\underline{\mathrm{Na}} \underline{\mathrm{Mg}} \stackrel{\mathrm{Al}}{\mathrm{Si}} \underline{\mathrm{K}} \mathrm{Ca} \quad \mathrm{Ii} \quad \underline{\mathrm{Fe}}$ Slag

$\begin{array}{lllllllll}\text { 1. Overal1--by mixtures } & 1 & 5 & 18 & 34 & 14 & 11 & 0.4 & 16\end{array}$

$\begin{array}{llllllll}\text { 2. Overall--cathode } & 5 & 21 & 36 & 12 & 12 & 0.5 & 14\end{array}$

3. Overal1--anode $\quad 20 \quad 6 \quad \begin{array}{lllllll}21 & 35 & 13 & 11 & 0.5 & 13\end{array}$

4. Dendritic growths $\quad \begin{array}{llllllll}8 & 25 & 35 & 9 & 11 & 0.5 & 13\end{array}$ at cathode/slag interface, feature a

5. Slag between dendritic growth, fea$\begin{array}{lllllll}3 & 26 & 35 & 13 & 13 & 0.4 & 5\end{array}$ ture b

6. Slag at anode interface, feature $c$

7. Slag in open pore near interface anode, feature d

$\begin{array}{lllllll}3 & 26 & 40 & 13 & 8 & 0.5 & 9\end{array}$

$\begin{array}{lllllll}1 & 31 & 42 & 12 & 8 & 0.5 & 5\end{array}$

Anode

8. Overall

9. Matrix at anode/ slag interface, feature $e$

10. Slag in center of anode

Cathode

11. Overall

12. Matrix at cathode/ slag interface, feature $f$ $\begin{array}{lll}26 & 48 & 0.7\end{array}$

25

$\begin{array}{lll}29 & 43 \quad 2\end{array}$

0.1

$0.1 \quad 0.1 \quad 26$

$\begin{array}{llll}3 & 34 & 37 & 10\end{array}$

$8 \quad 0.1 \quad 9$

$\begin{array}{lll}26 & 47 & 0.7\end{array}$ 26

$\begin{array}{lllllll}25 & 39 & 2.5 & 0.5 & 0.3 & 0.1 & 33\end{array}$ 
TABLE A.8. (contd)

\begin{tabular}{|c|c|c|c|c|c|c|c|c|c|}
\hline \multirow{2}{*}{\multicolumn{2}{|c|}{ Item No. and Description }} & \multicolumn{8}{|c|}{ Element, atom\% } \\
\hline & & Na & $\overline{M g}$ & A1 & $5 i$ & $\mathrm{~K}$ & $\mathrm{Ca}$ & $T i$ & Fe \\
\hline 13. & $\begin{array}{l}\text { Matrix at slag } \\
\text { interface, feature } g\end{array}$ & & 26 & 55 & 1 & 0.1 & 0.1 & & 17 \\
\hline 14. & $\begin{array}{l}\text { Slag along grain } \\
\text { boundaries, fea- } \\
h\end{array}$ & & 28 & 12 & 26 & 2 & 17 & & 17 \\
\hline 15. & $\begin{array}{l}\text { Second phase, fea- } \\
\text { ture } i\end{array}$ & & 24 & 5 & 2 & & 0.3 & & 70 \\
\hline 16. & $\begin{array}{l}\text { Matrix in poly- } \\
\text { phase area, fea- } \\
\text { ture } j\end{array}$ & & 28 & 52 & 1 & 0.1 & 0.1 & & 19 \\
\hline
\end{tabular}

(a) Includes only elements with atomic numbers greater than 10 . 
TABLE A.9. Atomic Composition of Features in Figure 25 (Experiment 38 in MR-1 at 1573K) in Atom\% of Elemental Species Detected(a).

\begin{tabular}{|c|c|c|c|c|c|c|c|c|c|}
\hline \multirow{2}{*}{\multicolumn{2}{|c|}{ Item No. and Description }} & \multicolumn{8}{|c|}{ Element, atom\% } \\
\hline & & $\underline{\mathrm{Na}}$ & $\mathrm{Mg}$ & A1 & $\mathrm{Si}$ & $\mathrm{K}$ & $\mathrm{Ca}$ & $\mathrm{Ti}$ & $\mathrm{Fe}$ \\
\hline \multicolumn{10}{|l|}{ Slag } \\
\hline 1. & Overal1--by mixture & 1 & 6 & 21 & 39 & 16 & 13 & 0.5 & 5 \\
\hline 2. & Overall--anode & 3 & 6 & 22 & 38 & 13 & 12 & 0.4 & 5 \\
\hline 3. & Overal1--cathode & & 6 & 21 & 39 & 15 & 13 & 0.5 & 6 \\
\hline 4. 1 & $\begin{array}{l}\text { Near anode interface } \\
\text { single-phase, fea- } \\
\text { ture a }\end{array}$ & & 5 & 22 & 41 & 14 & 12 & 0.4 & 6 \\
\hline 5. & $\begin{array}{l}\text { Crystallite growth } \\
\text { polyphase area } \\
\text { anode, feature b }\end{array}$ & & & 33 & 36 & 29 & 0.1 & & 2 \\
\hline 6. & $\begin{array}{l}\text { Crystallite growth } \\
\text { polyphase area } \\
\text { cathode, feature c }\end{array}$ & & 2 & 32 & 36 & 28 & 0.5 & & 2 \\
\hline 7. 1 & $\begin{array}{l}\text { Matrix polyphase } \\
\text { area cathode, fea- } \\
\text { ture d }\end{array}$ & 3 & 12 & 15 & 39 & 5 & 17 & 1 & 8 \\
\hline 8. $N$ & $\begin{array}{l}\text { Metal polyphase area } \\
\text { cathode, feature e }\end{array}$ & & & 2 & 2 & 0.3 & 0.4 & & 94 \\
\hline 9. 6 & $\begin{array}{l}\text { Granular second-phase } \\
\text { cathode, feature } f\end{array}$ & 3 & 18 & 2 & 32 & & 44 & & 0.2 \\
\hline 10. & $\begin{array}{l}\text { Slag at cathode } \\
\text { interface, feature } \mathrm{g}\end{array}$ & & 4 & 34 & 28 & 31. & 2 & 0.1 & 0.1 \\
\hline
\end{tabular}

Cathode

11. Overal1--near top surface

$\begin{array}{llll}3 & 44 & 0.2 & 3\end{array}$

26

12. Metallic deposits at reaction zone, feature $h$

$\begin{array}{lllll}13 & 3 & 1 & 0.2 & 0.2\end{array}$

82

13. Matrix next to reaction zone, feature $i$

$4 \quad 28 \quad 45$

4

4

8

1 
TABLE A.9. (contd)

\begin{tabular}{|c|c|c|c|c|c|c|c|c|c|}
\hline \multirow{2}{*}{\multicolumn{2}{|c|}{ Item No. and Description }} & \multicolumn{8}{|c|}{ Element, atom\% } \\
\hline & & $\underline{\mathrm{Na}}$ & $\mathrm{Mg}$ & A1 & Si & $\mathrm{K}$ & $\mathrm{Ca}$ & $\mathrm{Ti}$ & $\mathrm{Fe}$ \\
\hline 14. & $\begin{array}{l}\text { Grain boundary reac- } \\
\text { tion product }\end{array}$ & 8 & 3 & 50 & & 22 & 2 & & 14 \\
\hline 15 . & $\begin{array}{l}\text { Grain-boundary reac- } \\
\text { tion product }\end{array}$ & 3 & 2 & 85 & & 8 & 0.3 & & 1 \\
\hline
\end{tabular}

Anode

16. Overall--near top surface

$\begin{array}{llllll}25 & 47 & 1 & 1 & 0.1 & 26\end{array}$

17. Phase along grain boundary

$\begin{array}{llll}12 & 57 & 1 & 8\end{array}$

22

18. Matrix $0.7 \mathrm{~mm}$ from reaction interface, feature $j$

19. Matrix $0.05 \mathrm{~mm}$ from reaction interface, feature $k$

(a) Includes only elements with atomic numbers greater than 10 . 
TABLE A.10. Atomic Concentration of Features in Figure 26 (Experiment 44 in MR at 1476K) in Atom\% of Elemental Species Detected(a)

\begin{tabular}{|c|c|c|c|c|c|c|c|c|}
\hline \multirow[b]{2}{*}{ Item No. and Description } & \multicolumn{8}{|c|}{ Element, atom\% } \\
\hline & $\overline{\mathrm{Na}}$ & $\mathrm{Mg}$ & AT & Si & $\mathrm{K}$ & $\mathrm{Ca}$ & Ti & $\mathrm{Fe}$ \\
\hline 1. Overal1--by mixtures & 1 & 7 & 24 & 46 & 1 & 15 & 1 & 6 \\
\hline $\begin{array}{l}\text { 2. Flake precipitate } \\
\text { in slag (cathode) }\end{array}$ & & 13 & 18 & 41 & 0.1 & 21 & 1 & 7 \\
\hline $\begin{array}{l}\text { 3. Slag matrix around } \\
\text { flakes (cathode) }\end{array}$ & & 4 & 34 & 42 & 0.2 & 18 & 0.1 & 2 \\
\hline $\begin{array}{l}\text { 4. Metallic precipitate } \\
\text { (cathode) }\end{array}$ & & 2 & 3 & 2 & & 0.6 & & 92 \\
\hline $\begin{array}{l}\text { 5. Phase in slag on } \\
\text { cathode grain bound- } \\
\text { ary, feature a }\end{array}$ & 22 & & 54 & 5 & 3 & 13 & & 4 \\
\hline
\end{tabular}

6. Phase in slag on cathode grain boundary, feature b

$\begin{array}{lllll}17 & 6 & 2 & 0.2 & 2\end{array}$

73

Cathode

7. Overall

8. Metallic precipitate, feature $c$

9. Granular deposit, feature d

10. Matrix, feature e

Anode

11. Overall

12. Phase along grain boundary, feature $f$

13. Matrix by grain boundary, feature $\mathrm{g}$
$25 \quad 45 \quad 0.9$

29

$\begin{array}{lll}1 & 3 & 2\end{array}$

0.5

94

$\begin{array}{lll}26 & 3 & 2\end{array}$

1

68

$\begin{array}{lllll}31 & 42 & 1 & 0.1 & 0.6\end{array}$

25

$\begin{array}{lll}25 & 45 & 1\end{array}$

30

$\begin{array}{lllll}6 & 36 & 35 & 0.1 & 8\end{array}$

15

$\begin{array}{lll}26 & 45 & 0.4\end{array}$

0.1

29

(a) Includes only elements with atomic numbers greater than 10. 
TABLE A.11. Atomic Composition of Features in Figure 27 (Experiment 318

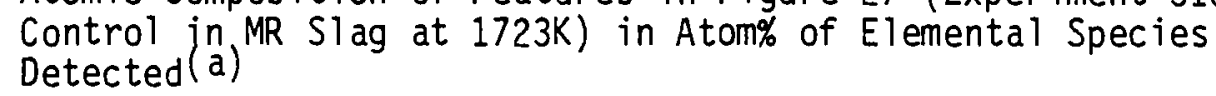

Item No. and Description $\frac{\text { Element, atom\% }}{\mathrm{Na}} \mathrm{Mg} \quad \frac{\mathrm{Al}}{37} \quad \underline{\mathrm{Si}} \quad \underline{\mathrm{K}}$

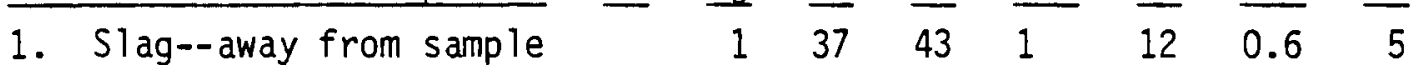
(single-phase)

2. Slag near secondphase growth, feature a

3. Slag along widened grain boundary, feature $b$

4. Slag along narrow grain boundary in interior of sample

5. Matrix away from

$\begin{array}{lll}21 & 57 & 1\end{array}$ reaction zone

$\begin{array}{lllllll}3 & 33 & 44 & 0.7 & 13 & 0.5 & 6\end{array}$

6. Matrix in reaction $\begin{array}{lll}13 & 73 & 1\end{array}$ zone, feature $c$

7. Second phase growing from matrix, feature d

8. Third phase growing by second phase, fea$\begin{array}{lllllll}4 & 25 & 16 & 0.3 & 3 & 2 & 50\end{array}$ ture e

(a) Includes only elements with atomic numbers greater than 10. 


\section{ACKNOWLEDGMENTS}

The authors acknowledge the contributions of D. H. Parks for preparation of the micrographs, J. E. Coleman for examination of the samples using the scanning electron microscope, and J. L. Daniel for establishing procedures and obtaining standards for the SEM quantitative analysis.

We appreciate the assistance of D. I. Boget and W. M. Gerry in conducting the electrochemical tests, as well as the assistance of $F$. D. Hobbs and R. W. Stephens.

Finally, the authors acknowledge the editing, writing and production services provided by M. H. Henry and G. B. Long. 


\section{DISTRIBUTION}

No. of

Copies

OFFSITE

A. A. Churm

DOE Chicago Patent Group

9800 South Cass Avenue

Argonne, IL 60439

2 Dr. M. Petrick

Argonne National Laboratory

9700 S. Cass Avenue

Argonne, IL 60439

R. F. Staff, PWT/PT

ARO, Inc.

AECD Division

Arnold Air Force

Station, TN 37389

Dr. R. Detra

AVCO Everett Research Lab., Inc. 2385 Revere Beach Parkway

Everett, MA 02149

Dr. D. Swallom

AVCO Everett Research Lab., Inc.

2385 Revere Beach Parkway

Everett, MA 02149

J. A. Polutchko

Dynatrend Incorporated

1911 No. Ft. Meyer Drive,

Suite 907

Rosslyn, VA 22209

B. Wasserman

Dynatrend Incorporated

21 Cabot Road

Woburn, MA 01801
No. of

Copies

Paul Zieglebaum

Advanced Fossil Power Systems

Electric Power Research Institute

P. 0. Box 10412

3412 Hillview Avenue

Palo Alto, CA 94303

D. DeCoursin

FluiDyne Engineering Corp. 590001 son Memorial Highway

Minneapolis, MN 55422

Dr. R. Rosenberg

RM-9132

General Electric Co. Space Sciences Co.

Space Division

P. 0. Box 8555

Philadelphia, PA 19101

L. Terrey

General Electric Co. Space Sciences Co.

Space Division

P. 0. Box 8555

Philadelphia, PA 19101

Dr. D. Montgomery

NW14-3211

MIT/FBNML

170 Albany Street

Cambridge, MA 02139

Prof. J. F. Louis

Rm 31-254

Massachusetts Institute of Technology

Department of Aeronautics \& Astronautics

77 Massachusetts Avenue

Cambridge, MA 02139 
No. of

Copies

H. Kent Bowen

Massachusetts Institute of Technology

Department of Aeronautics \& Astronautics

77 Massachusetts Avenue

Cambridge, MA 02139

Dr. D. Murphree

Mississippi State University

Aerophysics and Aerospace Engineering

P. 0. Drawer A/AP

Mississippi State, MS 29762

Dr. D. Bl ackketter

Department of Mechanical Engineering

Montana State University

Bozeman, MT 59715

Dr. B. Rhodes

Montana College of Mineral Science and Technology

West Park Street

Butte, MT 59701

Dr. J. J. Rasmussen

Montana Energy and MHD R\&D Institute

Box 3890

Butte, MT 59701

J. Plunkett

Montana Energy and MHD R\&D Institute

Box 3890

Butte, MT 59701

Mr. G. Seikel, Manager

MHD Project Office

Mai1 Stop 500-202

NASA/Lewis Research Center

2100 Brookpark Road

Cleveland, $\mathrm{OH} 44135$
No. of

Copies

Dr. Bercaw, Assistant Manager

MHD Project Office

Mail Stop 500-202

NASA/Lewis Research Center

2100 Brookpark Road

Cleveland, $\mathrm{OH} \quad 44135$

D. Bienstock

Pittsburgh Energy Technology Center

4800 Forbes Avenue

Pittsburgh, PA 15213

R. Gibbons

Ralph M. Parsons Co.

100 West Walnut Street

Pasadena, CA 91124

Dr. R. Y. Pei

Rand Corporation

2100 M Street NW

Washington, DC 20037

Mr. M. Jones

Energy Conversion Division

Reynolds Metals Co.

P. 0. Box 1200

Sheffield, AL 35660

Mr. C. A. Hauenstein

LA39

Rockwe 11 International

Rocketdyne Division

Energy Systems Group

8900 DeSoto Avenue

Canoga Park, CA 91304

Dr. F. G. Blottner $/ 1261$

Sandia Laboratories

P. 0. Box 500

Albuquerque, NM 87115

Dr. E. H. Eustis

Stanford University

Palo Alto, CA 94305 
No. of

Copies

C. Maxwe 11

STD Corporation

P. 0. Box "C"

Arcadia, CA 91006

H. Graham

TRW

One Space Park

Redondo Beach, CA 90278

J. Hardgrove

TRW

One Space Park

Redondo Beach, CA 90278

2 Samuel Schneider

U.S. Department of Commerce

National Bureau of Standards

Washington, DC 20234

Dr. B. Dicks, Director

University of Tennessee Space Institute

Tullahoma, TN 37388

Dr. S. Wu

Energy Conversion Division

University of Tennessee Space Institute

Tullahoma, TN 37388

Dr. J. Chapman, Program Manager

University of Tennessee Space Institute

Tullahoma, TN 37388

Mr. R. H. Smith, Section Manager

Planning and Information Services

University of Tennessee Space Institute

Tullahoma, TN 37388

27 DOE Technical Information Center
No. of

Copies

Mr. J. Sadler

Westinghouse Electric

Corporation

Advanced Energy Systems Division

P. 0. Box 10864

Pittsburgh, PA 15236

Mr. F. Retallick

Westinghouse Electric

Corporation

Advanced Energy Systems Division

P. 0. Box 10864

Pittsburgh, PA 15236

Mr. J. M. Feret

Westinghouse Electric

Corporation

Advanced Energy Systems Division

P. 0. Box 10864

Pittsburgh, PA 15236

Dr. B. Rossing

Westinghouse Electric

Corporation

Research \& Development Center

1310 Beulah Road

Pittsburgh, PA 15235

G. Rudins

Department of Energy

Division of MHD

ET-FE-MHD

Mail Stop 336

Washington, DC 20545

M. Sluyter

Department of Energy

Division of MHD

ET-FE-MHD

Mail Stop 336

Washington, DC 20545

J. Epstein

Department of Energy

Division of MHD

ET-FE-MHD

Mail Stop 336

Washington, DC 20545 
No. of

Copies

\section{S. Sacks}

Department of Energy

Division of MHD

ET-FE-MHD

Mail Stop 336

Washington, DC 20545

\section{ONSITE}

DOE Richland Operations Office

H. E. Ransom

50 Pacific Northwest Laboratory

J. L. Bates

L. R. Bunne 11

T. D. Chikalla

P. E. Hart

J. M. Lytle (2)

D. D. Marchant (30)

C. R. Hann

L. K. Mudge

D. E. Olesen

L. C. Schmid

G. L. Tingey

R. P. Turcotte

P. C. Walkup

Technical Files (5)

Publishing Coordination EI(2) 